\title{
Scavenging amphipods of the Tonga Trench: an analysis of community assemblage and population structure
}

\author{
James Peter Ashley Wilson
}

\author{
A thesis \\ submitted to Victoria University of Wellington \\ in partial fulfilment of the requirement \\ for the degree of \\ Master of Science in Marine Biology
}

Victoria University of Wellington

Te Whare Wānanga o te Ūpoko o te Ika a Māui 





\section{Abstract}

The hadal zone is the common name for the deepest section of the ocean $(6,000-11,000$ $m$ depth). It encompasses $45 \%$ of the ocean's depth range, and is mostly represented by oceanic trenches. Trench habitats lack sufficient sampling and the communities within are not well understood. Often, samples are derived from a single depth and thus the population dynamics of trench communities have not been analysed comprehensively.

Scavenging amphipods are abundant and diverse taxa in the trench environment, and have been found in every trench sampled to date. They rapidly intercept and consume carrion falls at the deepest trench depths, and act as key prey items to predators in the shallower depths of the hadal zone. There appears to be a relationship of increasing abundance and decreasing diversity of scavenging amphipods with depth. However in the Tonga Trench, sampling of hadal amphipods has been limited, and these patterns remain unclear.

The QUELLE (Quest for the Limit of Life) project in 2013 was led by The Japan Agency for Marine-Earth Science and Technology (JAMSTEC). As part of this project, the YOK 13-10 voyage examined scavenging amphipods in the Tonga Trench. The voyage used baited traps to sample depths of 6,250 $\mathrm{m}$ and $\sim 10,800 \mathrm{~m}$ from October 6 - October 21 in 2013. The main objectives of the present study were to: identify scavenging amphipod assemblages within the Tonga Trench and compare them to other trenches of the South Pacific; analyse the population structure of Hirondellea dubia between depths in the Tonga Trench; and identify a suitable total length proxy for $\mathrm{H}$. dubia.

Six species of amphipods were identified from depths of $\sim 6,250 \mathrm{~m}$ and $\sim 10,800 \mathrm{~m}$ in the Tonga Trench. At $\sim 6,250 \mathrm{~m}$ Alicella gigantea, Eurythenes gryllus, H. dubia, Bathycallisoma schellenbergi, an alicellid species, and a gammarid species were recovered. In contrast, $H$. dubia was the only species recovered from $\sim 10,800 \mathrm{~m}$. The abundance of amphipods was higher at the $\sim 10,800 \mathrm{~m}$ site while the diversity was much lower. 
The assemblage of scavenging amphipods in the Tonga Trench was similar to those from past sampling efforts in the same trench. There were also similarities to the assemblages in the adjacent Kermadec Trench, and together these observations support the classification of these two trenches as a single biogeographic province. The assemblages in the Peru-Chile Trench in the South East Pacific were more dissimilar sharing only a few species. The present study provides new Tonga Trench records of the vertical ranges of $A$. gigantea, E. gryllus, and $H$. dubia. It also extends the maximum known depth of $H$. dubia to $10,807 \mathrm{~m}$. This thesis expanded our current knowledge of A. gigantea, by reporting the first instance of this large amphipod in the Tonga Trench, and the second known instance of the species at hadal depths.

An analysis of Hirondellea dubia population structure revealed ontogenetic vertical structuring in the Tonga Trench. Juveniles dominated the composition in the shallow end of the $H$. dubia vertical range, while very few juveniles were found at the deepest site. Juveniles were substantially smaller at $\sim 6,250 \mathrm{~m}$ compared to $\sim 10,800 \mathrm{~m}$, and this may suggest that juveniles migrate down the trench slope with increasing age. The most likely mechanism for distributing juveniles to the shallower depths is the ascending migration of brooding females. However, this is still not certain as no brooding females were captured. The shallower depth provides a higher quality of food source and the reduced hydrostatic pressure allows for a faster metabolic rate. Thus, this distribution is likely driven by the distribution of food sources throughout the trench in combination with hydrostatic pressure.

The dimensions of several established proxies for total length were evaluated for $H$. dubia. Pereonite 2-7 had the strongest correlation to total length, however it was highly distorted by dorsal curvature. Both the pereonite 2-7 and the pleosome were considered inaccurate due to sexual dimorphism making them inappropriate as proxies. Pereonite 1 was proportionately larger in juvenile lifestages. However, overall pereonite 1 was considered the strongest candidate for a proxy, this is because it was the least influenced by dorsal curvature and was a conspicuous segment that was easy to measure. 


\section{Acknowledgements}

Firstly I would like to express my sincere gratitude to my supervisors, Ken Ryan and Kareen Schnabel. Without your continuous support, patience, and guidance this project would not have been possible. Ken, I doubt many other professors have students in as many different fields of biology, and I believe your ability to provide critical and insightful feedback across these subjects is a strong testament to your abilities as a supervisor. Kareen, your expertise and advice were invaluable to me, particularly in the early stages of this project when you were teaching me completely new set of skills. Melina also deserves an honourable mention for taking notes at all our meetings.

A special thanks must be extended to Ashley Rowden. Without you I could not have worked on this project, I truly value the opportunity you gave me. For everything you've done Ashley, I am in debt to you. In addition the experience of attending the workshop in Okinawa was an incredible adventure for me, and acknowledgements here should extend to the NIWA crew who took me in, during, and after the workshop. In particular Daniel Leduc who has provided opportunities for collaboration outside of this project.

Thanks to Hiroshi Kitazato, the voyage leader of YK13-10, and the whole voyage team for their help during sample collection. Thanks also to the scientists and technicians at the NIWA Invertebrate Collection. This work was supported by VUW grant 80837, and NIWA's 'Vulnerable Deep-Sea Communities' project. For the opportunity to sample the deep-sea, I thank Anne-Nina Loerz, Alan Jamieson, and Peter McMillan for that amazing voyage across the Tasman.

Thanks to my dear friends and flatmates Alex, Alex, and Alex. Especially Alex, you are my favorite of all the Alex's. To my friends in general, thanks for your support and friendship.

Last but not the least, I would like to thank my parents and to my brothers for supporting me throughout writing this thesis and my life in general. To Barbara in particular, I would not have gotten very far without your continued support. 


\section{Table of Contents}

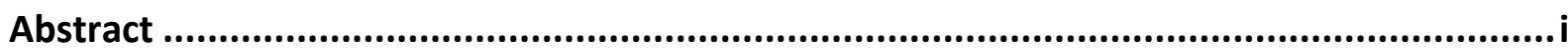

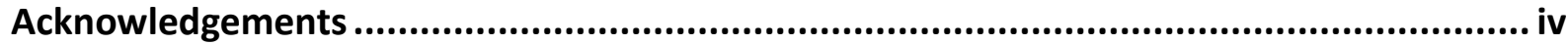

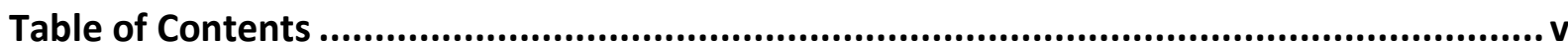

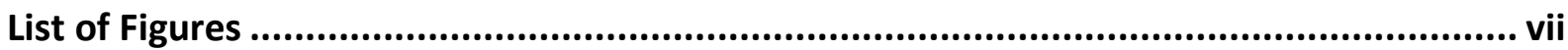

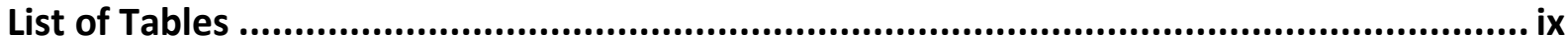

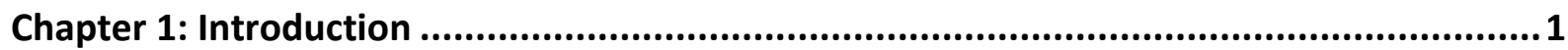

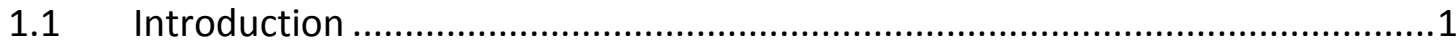

1.1.1 Hadal zone..........................................................................

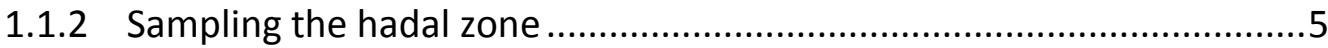

1.1.3 Scavenging amphipods............................................................... 7

1.1.4 The Tonga Trench .................................................................. 10

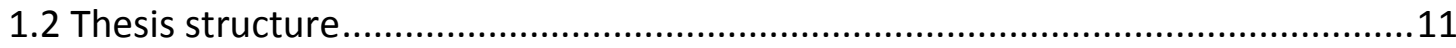

Chapter 2: Scavenging amphipod assemblage In the Tonga Trench................................. 12

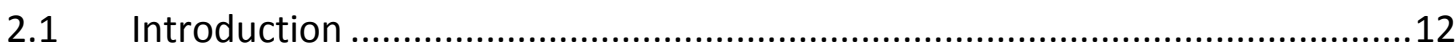

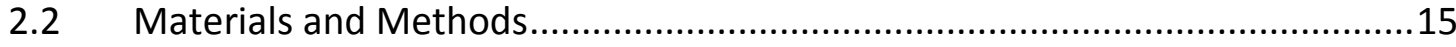

2.2.1 Study Site and Voyage .............................................................. 15

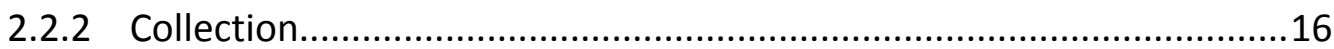

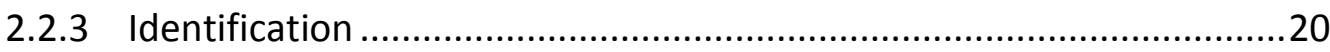

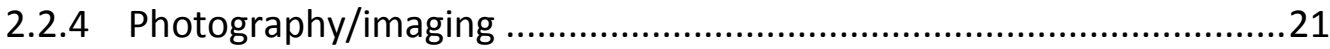

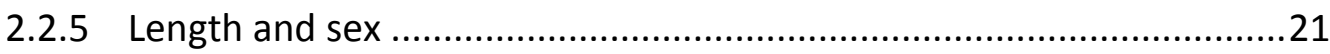

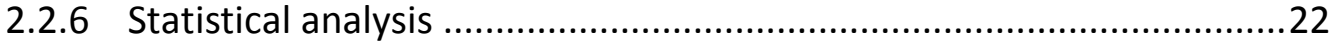

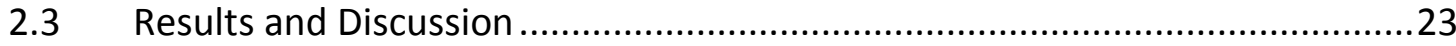

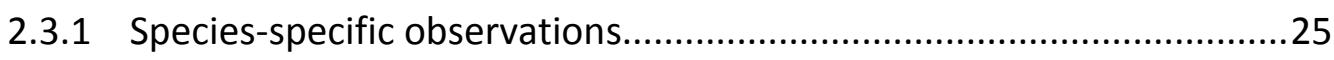

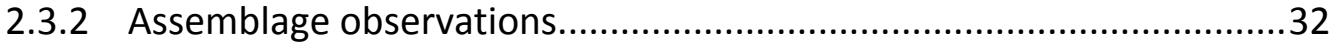

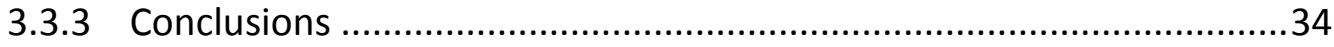


Chapter 3: Population structure of Hirondellea dubia from the Tonga Trench, with an analysis of proxies for total length................................................................................ 35

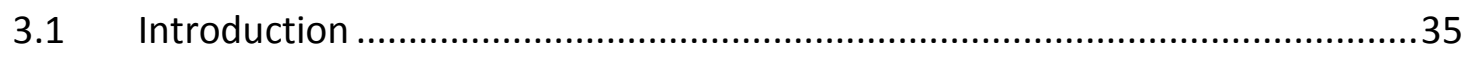

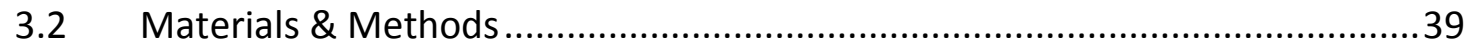

3.2.1 Study site, sample collection and identification .......................................39

3.2.1 Determining sex....................................................................................

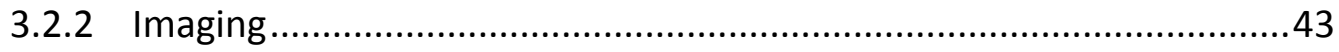

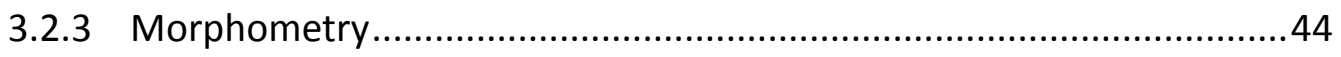

3.2.4 Statistical analyses ......................................................................... 47

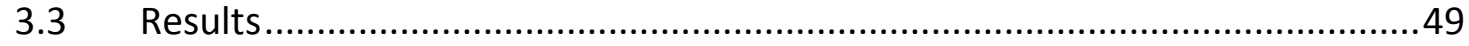

3.3.1 Sex and lifestage composition .......................................................... 49

3.3.2 Size structure analysis .......................................................................50

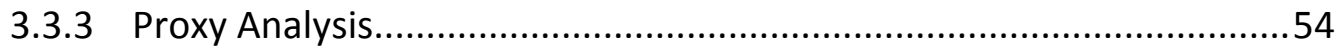

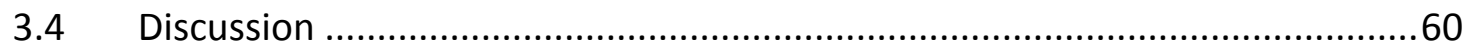

3.4.1 Population structure ………………………...................................6

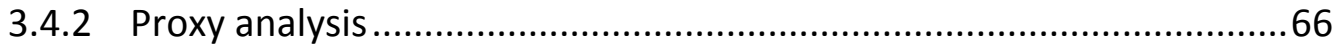

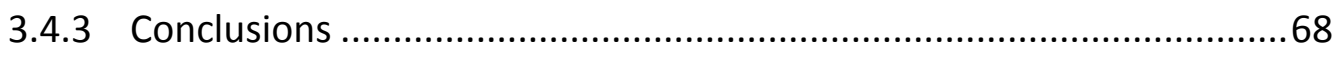

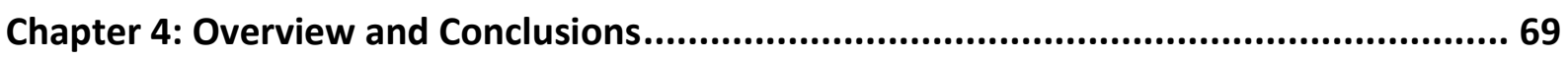

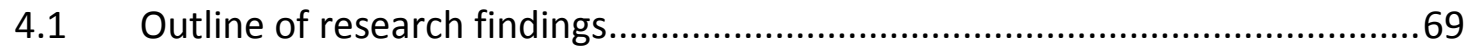

4.1.1 Identify scavenging amphipod species in the hadal environment of the Tonga Trench

4.1.2 Compare the scavenging amphipod assemblage structure of the Tonga Trench with others of the South Pacific Ocean .

4.1.3 Examine the population structure of Hirondellea dubia in the Tonga

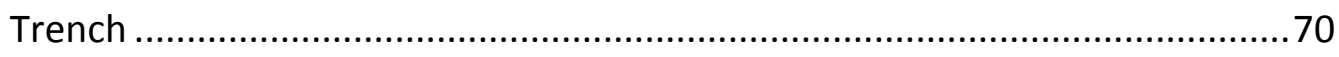

4.1.4 Identify a total length proxy for Hirondellea dubia ..............................70

4.2 Synthesis of findings ...................................................................................

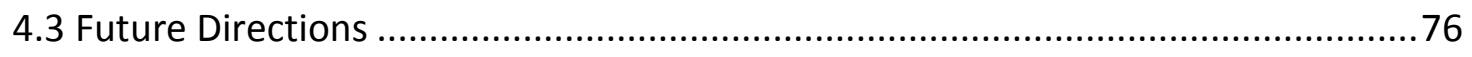

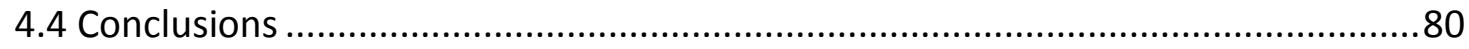

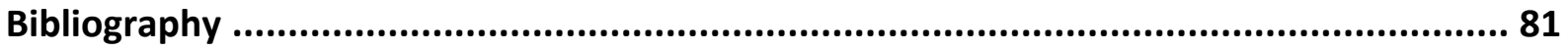




\section{List of Figures}

\section{Chapter 2}

2.1: Tonga Trench Study site in the Southwest Pacific Ocean . . . . . . . . . . 15

2.2: Baited Traps used to catch amphipods from the Tonga Trench. . . . . . . . . 17

2.3: The sediment sampling-camera lander being deployed $\ldots \ldots \ldots \ldots \ldots 18$

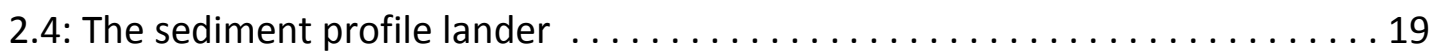

2.5: The Shinkai 6500 submersible being deployed in the Tonga Trench . . . . . 20

2.6: Male Alicella gigantea individual recovered from $6253 \mathrm{~m}$ depth. . . . . . . 26

2.7: Bathycallisoma schellenbergi recovered from $6,253 \mathrm{~m} \ldots \ldots \ldots \ldots \ldots .27$

2.8: Hirondellea dubia recovered from $10,807 \mathrm{~m} \ldots \ldots \ldots \ldots \ldots \ldots$

2.9: Eurythenes gryllus recovered from $6,253 \mathrm{~m} \ldots \ldots \ldots \ldots \ldots \ldots \ldots$

2.10: Alicellid species recovered from $6,256 \mathrm{~m} \ldots \ldots \ldots \ldots \ldots \ldots \ldots \ldots \ldots$

2.11: Examples of the unidentified gammarid species recovered from $6,256 \mathrm{~m}$. . .32

\section{Chapter 3}

3.1: External morphology used to distinguish male $H$. dubia. . . . . . . . 41

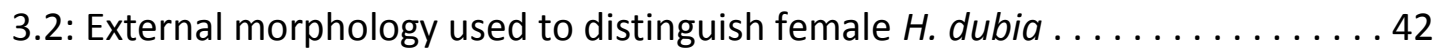

3.3: Example of $H$. dubia image alongside a calibrating scale $\ldots \ldots \ldots \ldots \ldots 44$

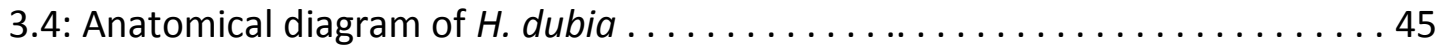


3.5: Examples of curvature recorded in $\mathrm{H}$. dubia

3.6: Frequency in percentage of $H$. dubia sexes and Lifestages across two depths ...

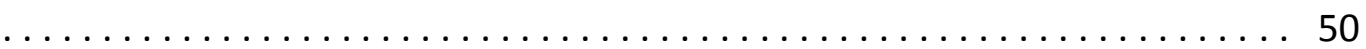

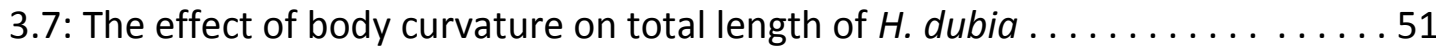

3.8: Average lengths of $\mathrm{H}$. dubia at trap heights at $10.800 \mathrm{~m} \ldots \ldots \ldots \ldots \ldots 52$

3.9: Profile plot of $H$. dubia size structure across depths and lifestages. . . . . . . 54

3.10: Profile plot of $\mathrm{H}$. dubia size structure across depths and lifestages using potential proxies. . . . . . . . . . . . . . . . . . . . . 57

3.11: Ratios of segments:total length accross lifestages and sexes. . . . . . 59 


\section{List of Tables}

Chapter 2

2.1: Sample details for scavenging amphipods $\ldots \ldots \ldots \ldots \ldots \ldots \ldots \ldots \ldots \ldots \ldots \ldots \ldots$

2.2: Composition and abundance of bait-attending amphipods recovered . . . . . 24

2.3: Details of collected $A$. gigantea individuals $\ldots \ldots \ldots \ldots \ldots \ldots \ldots \ldots$

\section{Chapter 3}

3.1: Criteria for assigning lifestage to $\mathrm{H}$. dubia individuals

3.2: Quantity of morphometricly analysed $H$. dubia from depths and lifestages/sexes

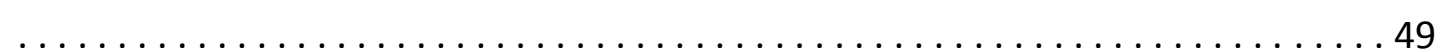

3.3: Length $(\mathrm{mm})$ data for each lifestage of $H$. dubia at depths of $6,250 \mathrm{~m}$ and

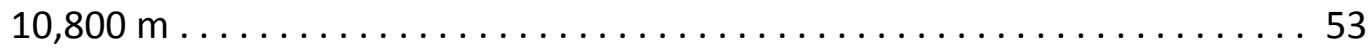

3.4: Correlations between $H$. dubia segments and total length in $\mathrm{mm} \ldots \ldots \ldots 5$ 



\section{Chapter 1: Introduction}

\subsection{Introduction}

The deep sea (> $200 \mathrm{~m}$ depth; Gage and Tyler, 1991) is the largest and least explored habitat on the planet (Ramirez-Llodra et al., 2010), and it contains a high diversity of species and extreme environmental conditions (Hessler and Sanders, 1967; RamirezLlodra et al., 2010). Deep-sea communities provide a number of ecological services such as: driving nutrient regeneration and biogeochemical cycles that support primary and secondary production throughout the oceans (Danovaro et al., 2008; Thurber et al., 2013); transporting atmospheric carbon to deep sea water masses through the biological pump (Christina \& Passow, 2007; Danovaro et al., 2008; Thurber et al., 2013); and supporting the microbial oxidation of pollutants like methane (Mora et al., 2012). These services occur on a global scale, but they are not extensively studied (Thurber et al., 2013). They may be vulnerable to future changes in ocean biogeochemistry (Mora et al., 2012), and more research is therefore needed to understand the communities of the deep sea. The deep sea is separated into distinct zones based on depth. The greatest of these depths, the hadal zone (>6,000 m; Wolff, 1960), represents an understudied and unique habitat in the deep sea (Jamieson et al., 2010).

\subsubsection{Hadal zone}

The hadal zone $(6,000-11,000 \mathrm{~m})$ encompasses just under half of the oceans depth range (Jamieson et al., 2010). After the first discovery of marine life beyond 6,000 $\mathrm{m}$ depth (Nybelin, 1951), the hadal zone was named after the realm of Hades, the underworld in Greek mythology (Bruun, 1956). Initial sampling lacked the replication and range of depths necessary to record spatial or temporal population and community dynamics (Wolff, 1970). More recently the hadal zone has been shown to host a high degree of endemism and diversity (Jamieson, 2015), and spatial population dynamics are now being 
examined (Blankenship et al, 2006; Eustace et al., 2013). Technical challenges involved with sampling at these depths have made the hadal zone the most understudied habitat on Earth (Jamieson, 2015). The change in community structure from the abyssal $(3,000-$ $6,000 \mathrm{~m}$; Tyler, 1995) to hadal zone at $6,000 \mathrm{~m}$ is distinct, because the hadal zone is mainly comprised of steeply sloped trenches, and the unique topography of these trenches cause variation in environmental variables beyond simply increasing hydrostatic pressure (Jamieson et al., 2010; Thurber et al., 2013).

Deep ocean trenches are formed by converging plate boundaries. Typically the denser oceanic plate will be forced under the thinner continental plate and into the mantle (Stern, 2002). This process is called subduction and can produce deep valleys (trenches) in the sea floor. Trenches are isolated from each other by shallower habitat and are distributed worldwide, though the majority are in the Pacific Ocean proximal to continental shelves (Jamieson et al., 2010). The topography of trenches are defined by steep slopes creating a deep V-shaped valley in the sea floor. The incline of trench slopes usually fluctuates from 5 to $15^{\circ}$, however the slopes may reach angles of $<2^{\circ}$ and $>45^{\circ}$ (Beliaev \& Brueggeman, 1989). The trench axis itself is usually level, sedimentary, and 2$5 \mathrm{~km}$ in width (Jamieson et al., 2010). Due to the destructive nature of converging plate boundaries, trench sites are often subject to earthquakes and volcanic activity (Beliaev \& Brueggeman, 1989; Stern, 2002). Seismic activity in tandem with steeply inclined slopes facilitates large rates of sedimentation into the trench axis (Beliaev \& Brueggeman, 1989; Ichino et al., 2015). The changes in environmental variables driven by the topography and immense depth of a trench help to define the communities that live in them.

Our understanding of environmental variables in the hadal zone has vastly improved since initial sampling (Menzies, 1965; Tyler, 1995; Jamieson, 2015). Water masses in trenches are not stagnant as once suggested (Johnson, 1998), and instead deep-water currents keep bottom waters circulated. In the Pacific Ocean, thermohaline circulation drives two deep water masses, the Lower Circum-Polar Water (LCPW) and the North Pacific Deep Water (NPDW) (Siedler et al., 2004). The LCPW penetrates the Pacific from the south and 
continues north and clockwise, and the Southwest Pacific trenches are therefore typically colder than North Pacific trenches (Siedler et al., 2004; Jamieson, 2015).

Below 4,000 m depth, temperatures slowly increase with rising hydrostatic pressure, a process caused by adiabatic heating (Bryden, 1973). The temperatures are low compared to surface waters, and the range within trenches is small, typically $1.0-2.5^{\circ} \mathrm{C}$ (Danovaro et al., 2004). However small differences in temperature influence distributions and spatial population structure of shallow water fauna, and may also modify the distribution of hadal life (Thurston et al., 2002; Danovaro et al., 2004). Temperature varies substantially between trenches, and in the Western Pacific, the bottom water increases by $\sim 0.5{ }^{\circ} \mathrm{C}$ between the southern and northern trenches (Jamieson et al., 2010). The salinity remains at 34-35 PSU (Beliaev and Brueggerman, 1989), so although changes in salinity have ecological consequences in shallow waters, the same doesn't seem to be true in the hadal zone (Tyler, 1995). Dissolved oxygen does vary between trenches and over temporal scales, however generally the levels detected at this depth are not considered limiting to hadal fauna (Beliaev \& Brueggeman, 1989; Tyler, 1995). The circulation of deep water masses ensures that both salinity and dissolved oxygen remain relatively stable and comparable to abyssal levels (Vinogradova, 1959; Beliaev \& Brueggeman, 1989; Tyler, 1995; Kitahashi et al. 2013).

Hydrostatic pressure increases linearly with depth, and increases by 1 atmosphere (atm) every $10 \mathrm{~m}$ of depth (Wolff, 1960; Jamieson et al., 2010). The hadal zone includes pressures from 600-1,100 atm, the highest experienced by any known life on earth (Jamieson, 2015). Immense hydrostatic pressure can inhibit biological functions in shallow species (Somero, 1992). Most hadal fauna have a limited range of pressure tolerance with $66 \%$ of species being confined within 1-2 km vertical range (Beliaev \& Brueggeman, 1989). However the tolerance of pressure in hadal fauna is larger than in that of shallow water species, because at great depths a large change in depth represents a proportionately smaller shift in pressure (Wolff, 1960; Jamieson et al., 2010). The barriers and adaptations brought about by hydrostatic pressure are many and include inhibition of enzymatic 
functions (Wolff, 1960; Somero, 1992), storage of metabolic energy in the form of lipid reserves (Beliaev \& Brueggeman, 1989; Somero, 1992), adaptation to subunit assembly and stability of proteins (Somero, 1992), and the Carbonate Compensation Depth (CCD), which represents a barrier to organisms that use calcium carbonate in their structural tissue (Jamieson et al., 2010). Hydrostatic pressure alone does not justify the distinction of the hadal and abyssal zones, however in combination with other environmental variables, it contributes to the unique setting found in trenches (Wolff, 1960; Somero, 1992; Siedler et al., 2004; Jamieson et al., 2010).

Food supply is one of the most defining variables of hadal faunal diversity and distribution (Blankenship and Levin, 2006; Jamieson et al., 2010; Eustace et al., 2013; Ichino et al., 2015). Almost all of the food resource in the deep sea is directly or indirectly derived from surface waters (Tyler, 1995), the only known exceptions being chemosynthetic production at hydrothermal vents and methane seeps, both of which been observed in trenches (Barnes et al., 1992; Fujikura et al., 1999; Ohara et al 2012). Surface-derived organic matter reaches hadal depth in several forms (Jamieson et al., 2010): particulate organic matter (POM) which is largely dead planktonic material (Stockton and DeLaca, 1982; Saint-Marie, 1992); larger carrion falls (Saint-Marie, 1992; Britton and Morton, 1994); or terrestrial plant matter (Wolff, 1960; Kobayashi et al., 2012). This organic matter must travel large distances during the descent, and intercepting zooplankton and microbial species consume, degrade and fragment the food source. In this way, the quality and quantity of organic matter typically reduces with depth (Sokolova, 1994; Christina \& Passow, 2007). In the case of larger carrion falls, the drop in food quality is significantly less overall, because the large surface-area-to-volume ratio of a carcass slows degradation by pelagic heterotrophic organisms (Sokolova, 1994; Lebrato and Jones, 2009; Jamieson et al., 2010). The steep V-shaped slopes of the trench cause POM to accumulate along trench axes, resulting in a unique trend of increasing POM quantity with depth (Jamieson et al., 2010; Ichino et al., 2015). In addition, seismic activity that is common near trenches facilitates this accumulation of organic matter through deep water landslides (Itoh et al., 2011; Eustace et al., 2013; Glud et al., 2013). Productivity in surface waters and nearby 
landmasses have direct impacts on the food supply in trenches (Ichino et al., 2015), and there is therefore considerable variation between trenches in the input of organic matter.

The unique environmental variables and isolation of each trench have all likely contributed to the endemism and exclusion of certain taxa from the hadal zone (Jamieson et al., 2010). Environmental variables are not consistent across all trenches and differences in latitude, trench topography, seismic activity, and surface productivity make generalising trench habitats difficult (Ichino et al., 2015). Thus each study of hadal fauna must consider the independent characteristics of the relevant trench.

\subsubsection{Sampling the hadal zone}

Hadal sampling has been sporadic and uncoordinated over the last 30 years (Jamieson et al., 2010). Limitations in current technology and the immense depths of trenches make experimentation on hadal fauna difficult (Tyler, 2003; Jamieson, 2015), thus research has been conducted in an explorative and observational capacity (Tyler, 2003; Jamieson, 2015). Tethered sampling techniques have been utilized in the past (Kullenberg, 1956; Wolff, 1960), however these are not practical at hadal depths. Surface vessels must withstand the weight of the connecting wire and the attached equipment, and few research vessels currently have the capability to sample deeper than 6,000 m (Jamieson, 2015). The method of attaching instruments to free falling landers has become popular in hadal studies (Hessler et al., 1978; Blankenship et al., 2006; Jamieson et al., 2009b; Eustace et al., 2013). The method involves deploying an instrument that sinks to the seafloor autonomously, and once sampling is complete, an acoustic signal or preset timer jettisons ballast weights, thus allowing the now buoyant system to rise to the surface where it is collected by a research vessel (Murashima et al., 2009; Jamieson, 2015). This technique does include the risk of the instrument failing to release its ballast weights, and therefore losing valuable traps and equipment. However, the method allows smaller vessels to conduct hadal research, and for a wide variety of instruments to be deployed on these free fall systems (Jamieson et al., 2009b; Glud et al., 2013). 
Baited traps and cameras are commonly used in benthic hadal studies (Perrone et al., 2002; Jamieson et al., 2009b; Gallo et al., 2015). These techniques have been well utilised due to the accessibility and relative cheapness compared to other techniques (Jamieson, 2015), and baited traps in particular can be attached and deployed by systems that have entirely independent purposes. Research on samples collected by baited traps include phylogenetics (France and Kocher, 1996; Ritchie et al., 2015), physiological and taxonomic studies (Tamburri and Barry, 1999; Kilgallen, 2015; Kilgallen and Lowry, 2015), diet analyses (Blankenship and Levin, 2007), and size - structure analyses (Thurston et al., 2002; Blankenship et al., 2006). The instruments specifically target bait-attending fauna, and therefore are biased towards mobile carrion-dependant scavengers. Variations in trap design, height off seafloor, orientation of trap, and length of deployment likely preclude capture of some hadal scavengers (Hessler et al., 1978; Ingram and Hessler,1983; Legeżyńska et al., 2000; Blankenship et al., 2006). Use of baited cameras has become more prevalent as the technology becomes more accessible, the advantages of baited cameras include recording behaviour at bait and the observation of fauna that attended bait but were not captured (Jamieson et al., 2009b; Gallo et al., 2015). Recent technological advances have allowed for more extensive research in this zone, however there are still many limitations for research to overcome (Gallo et al., 2015).

Representatives of most marine taxa are present in the hadal zone, however hadal fauna are adapted to the extreme environment and are thus dissimilar to shallow water relatives (Jamieson et al., 2010). Invertebrates dominate these depths (Jamieson, 2015), and some of most prolific and well-studied groups are molluscs (Wolff, 1960), echinoderms (Wolff, 1960; Beliaev \& Brueggeman, 1989), annelids (Beliaev \& Brueggeman, 1989; Paterson et al., 2009), and crustaceans (Jamieson et al., 2009a). A large percentage of the known hadal fauna are benthic (Wolff, 1960; Beliaev \& Brueggeman, 1989), and this is most likely due to the methods employed to sample hadal depths (Hessler and Sanders, 1967). Mobile scavengers in particular have been sampled in great numbers using baited traps and cameras (Jamieson et al., 2010). Amphipoda are often the most prolific scavenging fauna captured in baited traps and appear to be 
important members of the hadal communities (Hessler et al., 1978; Blankenship et al., 2006; Eustace et al., 2013).

\subsubsection{Scavenging amphipods}

Scavenging amphipods are a conspicuous and widely distributed component in hadal communities (Wolff, 1960; Fujii et al., 2013). They act as key prey items for predators in the shallower depths of the hadal zone (Eustace et al., 2013), and dominate the scavenging community at carrion falls in the greater depths of a trench (Jamieson et al., 2009a; Jamieson et al., 2009b). Amphipods therefore play an important role as a disperser of organic matter in hadal depths, particularly at depths past 8,000 $\mathrm{m}$ where they are often the only scavenging fauna detected (Hessler et al., 1978; Eustace et al., 2013). Amphipods are often the first fauna to attend bait (Hessler et al., 1978), and they are thought to facilitate the attraction of other amphipods and fauna to the carrion. This facilitation may be a result of the amphipods disturbing and fragmenting the carcass thereby enhancing the spread of food particles, and perhaps releasing feeding byproducts such as ammonia that may attract new amphipods (Perry, 1960; Hessler et al., 1978). It is interaction such as these that make amphipods an important group to study in the hadal zone.

Hadal scavenging amphipods have been recorded in every trench sampled to date, and represent diverse and abundant taxa at these depths (Wolff, 1960; Jamieson et al., 2010). There appears to be a relationship of increasing abundance and decreasing diversity of scavenging amphipods with depth (Hessler et al., 1978). This increasing abundance is in contrast with regular deep sea patterns, and is likely related to the accumulation of organic matter down the slopes of trenches (Itoh et al., 2011; Ichino et al., 2015). All of the scavenging amphipods collected from hadal depths have belonged to the suborder Gammaridea (Brusca and Brusca, 1990) with a large portion of those belonging to the superfamily Lysianassoidea (Dana, 1849).

There are two distinct forms of lyssianassoids at hadal depths (Jamieson et al., 2010). The larger benthopelagic amphipods have cutting mouthparts and highly expansive guts, and 
their adaptation to store energy as lipids allow them to fast between irregular carrion falls (Beliaev \& Brueggeman, 1989; Somero, 1992; Jamieson et al., 2010). The alternative form of lyssianassoids are smaller benthic species that possess grinding mandibles and nonexpanding guts that must more or less constantly consume and metabolise food (Dahl, 1979; Blankenship and Levin, 2007; Jamieson et al., 2010).

Hadal amphipods are highly adapted to endure extreme hydrostatic pressures and limitations in food supply. The ability of amphipods to detect and intercept bait is particularly impressive (Jamieson et al., 2010); they use chemosensory appendages to detect the odour plumes released by carrion falls (Tamburri and Barry, 1999). Although many hadal amphipods consume carrion, they are not exclusively reliant on necrophagy (De Broyer et al., 2004). There is evidence that these scavengers supplement necrophagy with detrivory, carnivory, and even cannibalism (Blankenship and Levin, 2007; Jamieson, 2010), and some amphipods may even be capable of digesting wood debris derived from terrestrial plants (Kobayashi et al., 2012).

Scavenging amphipod species are vertically stratified throughout the trench environment (Blankenship et al., 2006) due to the limited depth range of each species (Beliaev \& Brueggeman, 1989), and interspecific competition for food in the deeper hadal depths (Blankenship et al., 2006; Blankenship and Levin, 2007). As previously stated, the diversity of species typically decreases with depth in a trench, and often the deepest section of a trench is dominated by a single amphipod species (Blankenship et al., 2006; Eustace et al., 2013). However amphipod community structure varies between trenches, and often the known range of one species can vary drastically between these hadal habitats (Fujii et al., 2013). Differences in community composition within and between trenches indicate that these communities may have been isolated over geological timescales, and thus have developed a unique composition and structure (France, 1993; Jamieson et al., 2011). More sampling is required to gain a better understanding of these variations between depths and trenches. 
The population structures of many hadal amphipods are not well understood. Past trench sampling efforts have often targeted a single depth thus neglecting patterns that may occur across a species' full depth range (Hessler et al., 1978; Perrone et al., 2002; Thurston et al., 2002; Eustace et al., 2013). Blankenship et al. (2006) reported ontogenetic structuring of Hirondellea dubia (Dahl, 1959) between depths of 7,349 m and $10,787 \mathrm{~m}$ in the Tonga trench. Hirondellea dubia juveniles were captured in the shallower depths but were absent at the greater depths (Blankenship et al., 2006). The stratification of juveniles to shallow depths was attributed to an increase in metabolic rate under lower hydrostatic pressure (Blankenship et al., 2006), and the higher quality of POM at shallow depths (Hessler et al., 1978). Ontogenetic structuring was previously unknown in the hadal environment, but since then (2006) it has also been reported in the Izu-Bonin Trench (Eustace et al., 2013), for Hirondellea gigas (Birstein and Vinogradov, 1955). Understanding of amphipod population structure has been limited by logistical difficulties in collecting samples from these extreme depths and improvements to methodology will allow a more detailed understanding of life at these depths in the future.

Analysis of amphipod populations has often used length-based size structure to define age groups (Thurston et al., 2002; Blankenship et al., 2006), but variations in methodology have hindered comparisons between studies. An accurate total length measurement is needed to separate size classes, however this is difficult in amphipods due to their dorsal curvature (Stebbing, 1919; Chapelle, 1995). Total length measurements are taken along the dorsal aspect from the head to the tip of the telson (Hessler et al., 1978), but this measurement is influenced by the telescoping of dorsal segments, which can cause $>10 \%$ variation in length (Stebbing, 1919; Chapelle, 1995; refs). Dorsal curvature can be avoided by measuring a segment of the amphipod as a proxy in place of measuring total length (Chapelle, 1995). A large single segment is ideal as a proxy because it is conspicuous and easy to measure while also avoiding any variability in length cause by dorsal curvature (Stebbing, 1919; Chapelle, 1995). A proxy should not be a segment that displays sexual dimorphism, as while sex-based variation is uncommon in hadal lyssianassoids, small variations could confound size structure analysis (Chapelle, 1995; Kilgallen, 2015). A 
variety of proxies have been used in amphipods in the past (Von Westernhagen, 1976; Hessler et al., 1978; Chapelle, 1995; Thurston et al., 2002), however a consensus for a single proxy to be used in hadal amphipods would be useful to make future study crosscomparable.

\subsubsection{The Tonga Trench}

The Tonga Trench is located in the Southwest Pacific Ocean, it lies directly north east of the Kermadec trench and New Zealand's EEZ. The Tonga Trench's greatest depth is 10,882 m deep, a site known as the Horizon Deep (Wright et al., 2000). This depth is exceeded only by the Challenger Deep site in the Mariana Trench, making it the second deepest trench in the world. The Tonga Trench runs from 15오 to 25오, and the surface waters above trench are typically oligotrophic, with primary productivity is aproximatly $<100 \mathrm{mg}$ $\mathrm{C} / \mathrm{M}^{2} /$ day (Herring, 2002). Although the Tonga Trench has been sampled with trawls (Beliaev \& Brueggeman, 1989) and baited traps (Blankenship et al., 2006), the habitat requires further investigation to unravel the structure of scavenging amphipod assemblage and population structures.

The Japan Agency for Marine-Earth Science and Technology (JAMSTEC) led the QUELLE (Quest for the Limit of Life) project in 2013. The YK 13-10 voyage was part of this project that sampled depths of $\sim 6,250 \mathrm{~m}$ and $\sim 10,800 \mathrm{~m}$ from October 6 - October 21 in 2013 in the Tonga Trench. Baited traps were deployed during this voyage providing the opportunity to examine scavenging amphipods at these depths. The present study has utilised the samples collected during this voyage, with the following objectives:

(1) Identify scavenging amphipod species in the hadal environment of the Tonga Trench.

(2) Compare the scavenging amphipod assemblage structure of the Tonga Trench with studies in this trench and others of the South Pacific Ocean.

(3) Examine the population structure of Hirondellea dubia in the Tonga Trench.

(4) Identify a suitable total length proxy for Hirondellea dubia. 


\subsection{Thesis structure}

Chapter 1 has already provided an overview of the hadal zone and the scavenging amphipod fauna within it.

Chapter 2 details the methods involved in the collection and identification of hadal scavenging amphipods from the Tonga Trench. The species composition of the amphipod assemblage is described and compared between a site on the outer trench slope $(\sim 6,250$ $\mathrm{m}$ depth) and a site at the trench axis ( 10,800 $\mathrm{m}$ depth), as well as with assemblages in trenches elsewhere.

Chapter 3 describes the population structure of the scavenging amphipod Hirondellea dubia at the two depths sampled. Here H. dubia are classified into life-history stages and morphometric analyses conducted and described. These data is then used to compare lifestage composition and size structure of $\mathrm{H}$. dubia between the two sampling depths. This chapter also contains an analysis of proxies for the total length of the amphipod.

Finally, Chapter 4 provides an overview of the preceding chapters and an outline for future research directions. Literature cited in the course of the present study has been documented in the bibliography at the end of this chapter.

Chapters 2 and 3 of the thesis have been written in a format ready for submission to a scientific journal for publication. As a result there is some repetition of introductory material in these chapters. 


\section{Chapter 2: Scavenging amphipod assemblage In the Tonga Trench}

\subsection{Introduction}

The hadal zone $(6,000-11,000 \mathrm{~m})$, encompasses $45 \%$ of the oceans depth range (Wolff, 1960; Jamieson et al., 2010), and oceanic trenches are the dominant environment within these depths. The benthic habitat in the hadal zone takes up only 1-2 \% of the total seafloor area, however this habitat is host to highly endemic and abundant biological communities (Wolff, 1960; Somero, 1992; Fujii et al., 2010; Jamieson et al., 2010; Ichino et al., 2015). These hadal communities are less understood than shallow water benthic communities, and while they are generally high in biomass and abundance, the diversity of species is low (Beliaev \& Brueggeman, 1989). Benthic community diversity decreases with depth leading to increasing dominance of a few abundant species (Wolff, 1960; Beliaev \& Brueggeman, 1989).

Representatives of most marine taxa are present in the hadal environment (Wolff, 1960; Jamieson et al., 2010), however these hadal species are dissimilar to shallow water equivalents due to adaptation to the extreme environmental conditions that define the trench habitat. The adaptation is so specific that a small change in environmental variables changes diversity of taxa substantially (Hessler et al., 1978; Ichino et al., 2015). Changes in depth modify environmental variables such as hydrostatic pressure, distribution of organic matter, and temperature (Jamieson et al., 2010; Itoh et al., 2011; Ichino et al., 2015). However, our understanding of hadal community composition has been limited by logistical difficulties in collecting samples from these extreme depths

resulting in very few samples often only from a single depth (Hessler et al., 1978; Perrone et al., 2002; Thurston et al., 2002; Eustace et al., 2013). 
Amphipods are the dominant scavengers in the trench environment (Wolff, 1960). They rapidly intercept and consume carrion falls at the deepest trench depths and have been found in all the trenches sampled to date (Wolff, 1960; Jamieson, 2015). Although trench amphipods consume carrion, they are not exclusively reliant on these large one-off events. Detrivory, carnivory and even cannibalism have been recorded with varying prevalence at different depths and lifestages (Blankenship and Levin, 2007; Jamieson et al., 2010). The partitioning of these feeding strategies is likely a mechanism for such species to co-exist in a habitat limited in organic matter (Blankenship et al., 2006; Blankenship and Levin, 2007).

The structure of scavenging amphipod assemblages has not often been examined across trenches (Jamieson et al 2011, Fujii et al., 2013), rather studies of amphipods more often focus on a single species or depth within a trench (Beliaev \& Brueggeman, 1989; Thurston, 2002). In the Tonga Trench, species have been found to be vertically stratified (Blankenship et al., 2006), the distributions of these species were thought to be driven by interspecific interactions and partitioning of feeding strategies (Blankenship and Levin, 2007). However a more detailed understanding of the assemblage at these depths is needed to determine these trends with confidence. There is therefore impetus to complete more sampling across multiple depths in trenches, and to revisit previously sampled trenches to sample depths outside those recorded from previous studies.

The extreme depth of the hadal zone has made recovering amphipods difficult and sporadic over the last 30 years, however there has been a resurgence of hadal studies partially due to advancement in technological capabilities (Jamieson, 2015). Baited traps and cameras have begun to reveal more of the diversity and abundance of scavenging amphipods in the trench environment (Jamieson et al., 2010). The use of baited traps is a reliable way to recover the scavengers, because amphipods are mobile and can escape methods such as trawling that were used more frequently in the past (Wolff, 1960; Beliaev \& Brueggeman, 1989). Consistent methodology also provides datasets that are 
comparable for future analyses of amphipod assemblage composition between depths and among trenches.

Scavenging amphipods have been found in every trench sampled to date, and many species are cosmopolitan in trenches worldwide, however these trenches are isolated from one another by large distances of abyssal plains and are characterized by a different set of environmental conditions (Jamieson et al., 2010; Thurber et al., 2013). Differences in amphipod assemblage structure between and within trenches suggest that amphipod assemblages may have been isolated over geological timescales and each has evolved different ecological adaptations and different key species dominate (Jamieson et al. 2011). However, sampling effort remains small with most studies still describing species new to science, and the use of molecular techniques to understand connectivity among trenches is still in its infancy. The variables that determine biogeographic distribution and depth limits for hadal amphipods require more sampling and analysis.

The Japan Agency for Marine-Earth Science and Technology (JAMSTEC) lead the QUELLE (Quest for the Limit of Life) project in 2013, and during part of this project the Research Vessel YOKOSUKA sampled depths of $\sim 6,250 \mathrm{~m}$ and $\sim 10,800 \mathrm{~m}$ in from October $6-21$ in 2013 (voyage YK 13-10). The purpose of the voyage was in part to describe the biological communities of the Tonga Trench in the south western Pacific Ocean and compare theses hadal assemblages to others found in the western Pacific, ie the Mariana, Japan, and Kermadec trenches. The voyage used baited traps deployed by free fall landers in combination with traps and direct sampling made by a piloted submersible. The voyage also collected data on geology and the biogeochemistry of the sediment, however the present study focuses on the scavengers caught by baited traps and the submersible.

The objectives of the present research are to: (1) identify scavenging amphipod species in the hadal environment of the Tonga Trench; (2) describe and compare the scavenging amphipod assemblage structure of the Tonga Trench with assemblages detected in the past and in other trenches of the South Pacific Ocean. 


\subsection{Materials and Methods}

\subsubsection{Study Site and Voyage}

Figure 2.1: Tonga Trench Study site in the Southwest Pacific Ocean. (A) The red square identifies the study site where samples were collected. (B and C) Red spots signified the two sampling sites, $\sim 10,800 \mathrm{~m}$ in the trench axis, and $\sim 6,250 \mathrm{~m}$ on the trench outer slope. Figure from Leduc et al., 2015.

The Tonga Trench is located in the Southwest Pacific Ocean and is 10,882 meters deep at the axis of the trench, a site known as the Horizon Deep (Wright et al., 2000). This depth is exceeded only by the Challenger Deep site in the Mariana Trench. The Tonga Trench runs from $\sim 15^{\circ} \mathrm{S}$ to $\sim 25^{\circ} \mathrm{S}$ (Figure $2.1 \mathrm{~A}$ ). Samples of scavenging amphipods were collected from 2 depths within the trench: $\sim 10,800 \mathrm{~m}$ at Horizon Deep, and at a $\sim 6,250 \mathrm{~m}$ site on the edge of the trench. During the voyage, 6 lander deployments and 3 dives from a piloted submersible (Shinkai 6500) successfully collected a variety of samples (Table 2.1). 


\subsubsection{Collection}

Table 2.1: Sample details for scavenging amphipods, Site 1 corresponds to trench edge site, site 2 corresponds to Horizon Deep site. Time at sea floor indicate the hours and minutes that each sample had to collected scavengers from the sea floor.

\begin{tabular}{|c|c|c|c|c|c|c|}
\hline $\begin{array}{c}\text { Site/ } \\
\text { Dive } \\
\text { No. }\end{array}$ & Depth $(\mathbf{m})$ & latitude & longitude & Date & Gear & $\begin{array}{l}\text { Time at sea floor } \\
\text { hours:minutes }\end{array}$ \\
\hline 1370 & 6,255 & $23: 36.7500: \mathrm{S}$ & $174: 17.3444: \mathrm{W}$ & $15 / 10 / 2013$ & $\begin{array}{c}\text { Trap deployed by } \\
\text { submersible and } \\
\text { suction sampler }\end{array}$ & $3: 00$ \\
\hline $1-1$ & 6,256 & $23: 36.6771: \mathrm{S}$ & $174: 16.8787: \mathrm{W}$ & $09 / 10 / 2013$ & $\begin{array}{c}\text { sediment profile } \\
\text { lander }\end{array}$ & $2: 46$ \\
\hline $1-2$ & 6,253 & $23: 36.6344: \mathrm{S}$ & $174: 16.8133: \mathrm{W}$ & $10 / 10 / 2013$ & $\begin{array}{c}\text { sediment profile } \\
\text { lander }\end{array}$ & $11: 16$ \\
\hline $2-1$ & 10,817 & $23: 16.4294: \mathrm{S}$ & $174: 44.9826: \mathrm{W}$ & $11 / 10 / 2013$ & $\begin{array}{c}\text { camera-corer } \\
\text { lander }\end{array}$ & $7: 02$ \\
\hline $2-2$ & 10,807 & $23: 16.5298: \mathrm{S}$ & $174: 44.8380: \mathrm{W}$ & $12 / 10 / 2013$ & $\begin{array}{c}\text { sediment profile } \\
\text { lander }\end{array}$ \\
\hline $2-3$ & 10,807 & $23: 16.5085: \mathrm{S}$ & $174: 45.1347: \mathrm{W}$ & $13 / 10 / 2013$ & $\begin{array}{c}\text { camera-corer } \\
\text { lander }\end{array}$ & $8: 06$ \\
\hline $2-4$ & 10,805 & $23: 16.54365: \mathrm{S}$ & $174: 45.2294: \mathrm{W}$ & $14 / 10 / 2013$ & $\begin{array}{c}\text { sediment profile } \\
\text { lander }\end{array}$ & $9: 43$ \\
\hline
\end{tabular}

The majority of samples were collected by deployment of baited traps (Figure 2.2). The traps were $25 \mathrm{~cm} \times 25 \mathrm{~cm} \times 36 \mathrm{~cm}$ with two $6 \mathrm{~cm}$ diameter openings. The walls of the trap were covered with a $3 \mathrm{~mm}$ mesh, and bait was placed in fine mesh bags attached to the inside wall of the trap. The bait consisted of pieces of raw fish (previously frozen). The amount of time each trap spent on the seafloor varied (Table 2.1). 


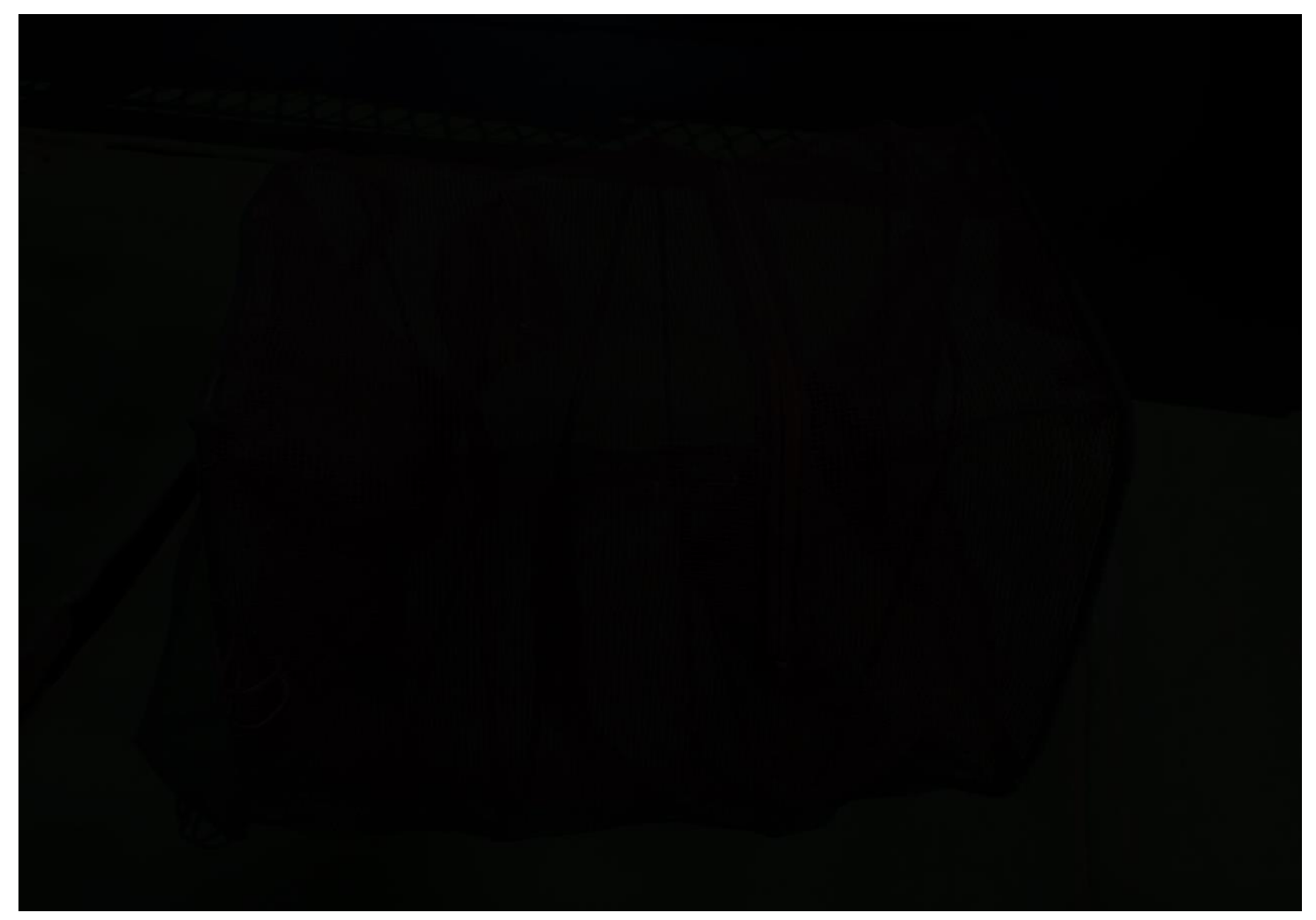

Figure 2.2: Baited Traps used to catch amphipods from the Tonga Trench. These traps were attached to Landers at multiple heights.

The baited traps were deployed to the sea floor by attachment to two autonomous freefall landers, and on one dive by the submersible. The landers used were a sediment sampling-camera lander and a sediment profile lander.

The sediment sampling-camera lander (Figure 2.3) was used to collect sediments, make sea floor observations, collect scavenging amphipods, and to take measurements of pressure, temperature and conductivity (salinity) using a CTD during the lander decent. One of the baited traps were attached to the lander at the base ( $0 \mathrm{~m}$ above seabed), and two were attached on the frame at a height of $1.5 \mathrm{~m}$ above the seabed. 


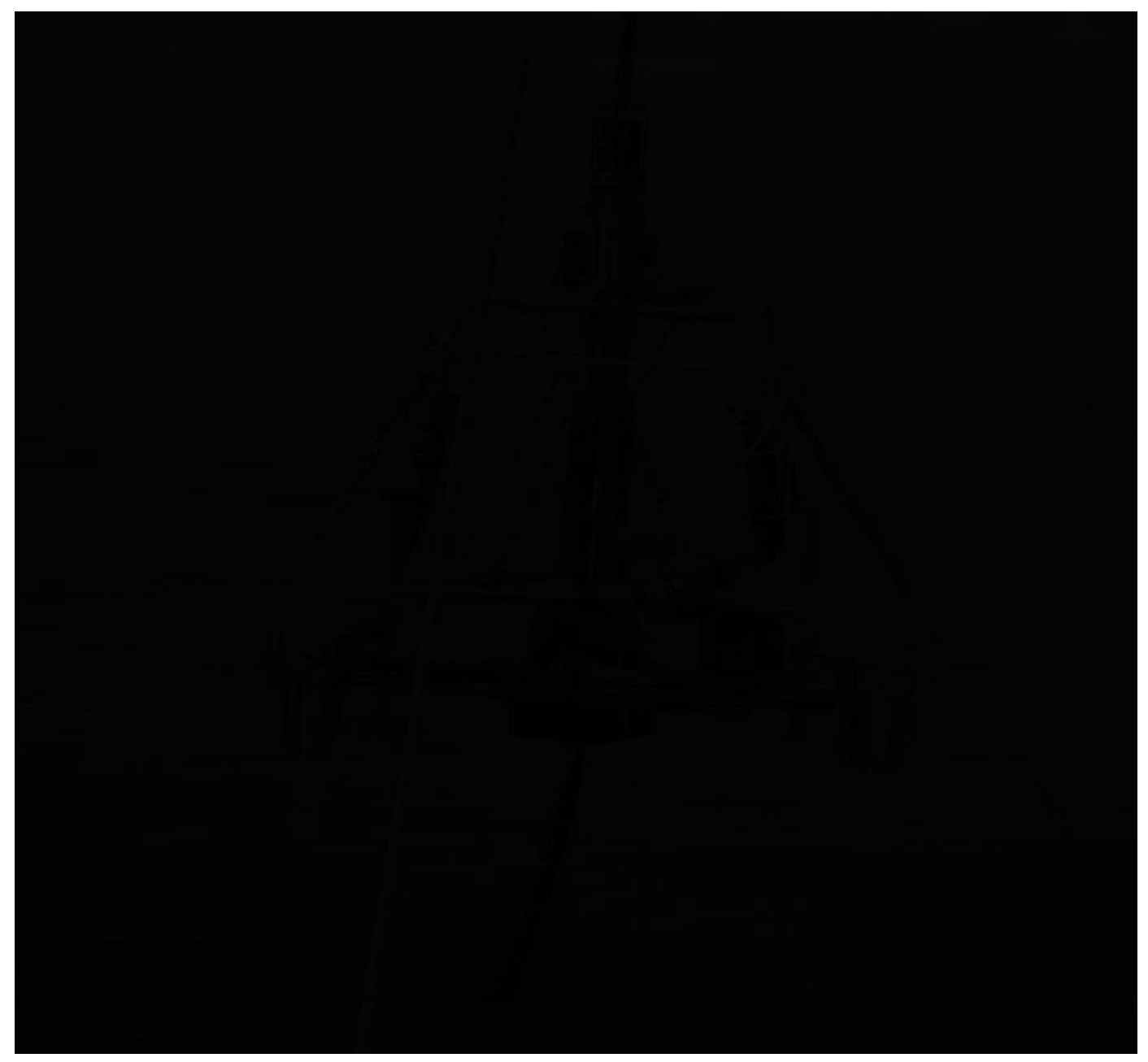

Figure 2.3: The sediment sampling-camera lander being deployed. Three baited traps can be seen, with 2 at the base of the lander and one at the top. Transparent tubes at the lander base collect sediment upon settlement on seafloor.

The sediment profile lander (Figure 2.4) also collected amphipods by baited trap, and in addition the lander was used to obtain $\mathrm{O}_{2}$, (oxygen) resistivity, and temperature microprofiles recorded by a central measuring unit made up of various microsensors. Two baited traps were placed on the frame of the sediment profile lander at $1.8 \mathrm{~m}$ above the seabed, however no traps were placed at the base of the lander to avoid any damage that amphipods attracted to the bait might do to the delicate profile electrodes as they entered the sediment. 

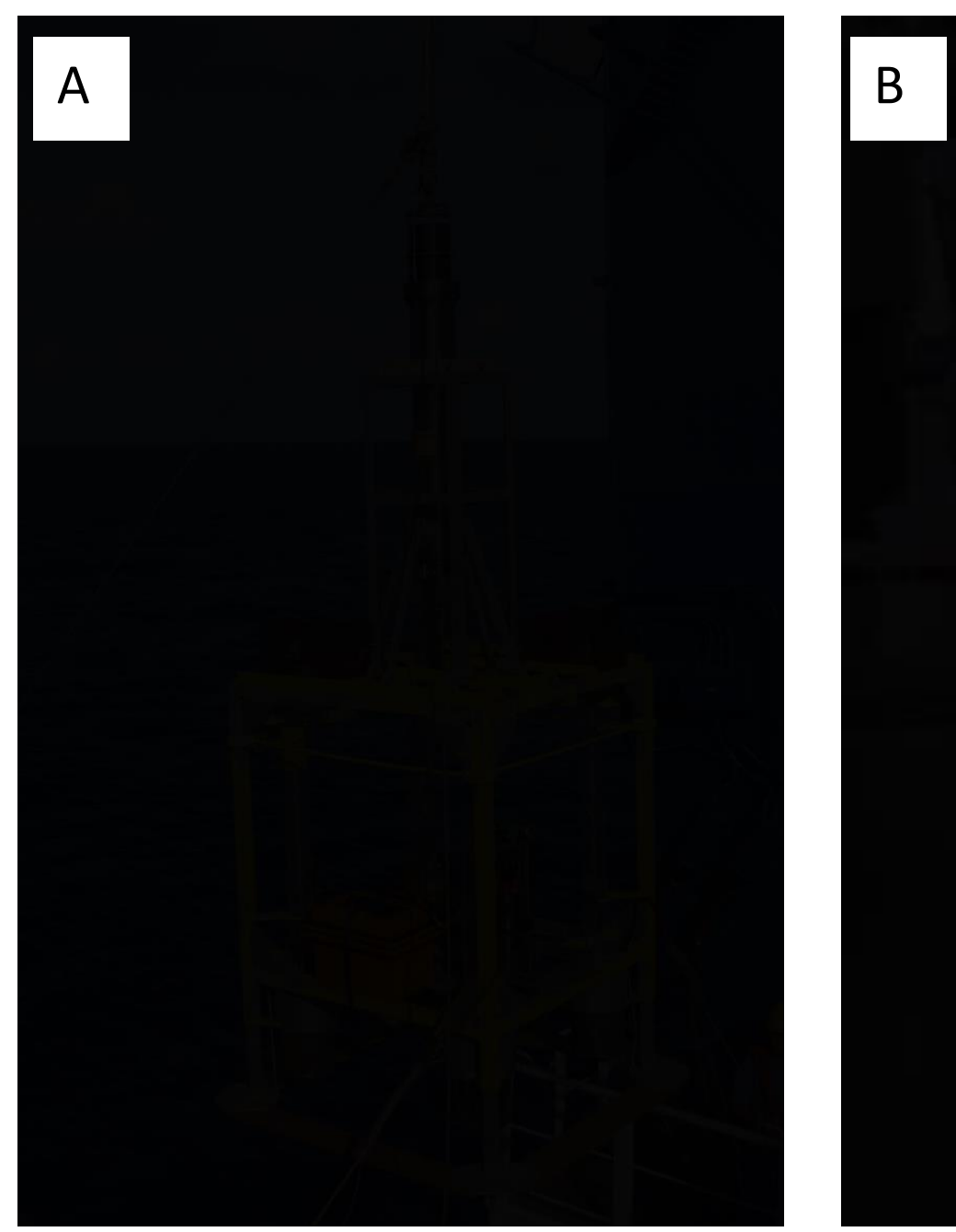

Figure 2.4: The sediment profile lander. (A) lander being deployed. Two baited traps can be seen on top of the yellow frame of the lander. (B) Central measuring unit made up of various microsensors to detect environmental variables in the sediment.

The Shinkai 6500 submersible (Figure 2.5) collected samples from a dive (Dive No. 1370) to the edge the Tonga Trench. Two of the standard baited traps and one larger trap (overall dimension $45 \times 21 \times 55 \mathrm{~cm} ; 11 \mathrm{~mm}$ mesh; 5 and $8 \mathrm{~cm}$ openings) were deployed on the seafloor at the beginning of the dive and recovered before the submersible ascended to the surface. In addition a single amphipod individual was collected using the submersible's suction sampler. 
Figure 2.5: The Shinkai 6500 submersible being deployed in the Tonga Trench.

Once the traps were brought onboard, all amphipods were recovered and fixed and preserved in $100 \%$ ethanol. Amphipods were split into samples based on the traps and deployments that collected them. A small number of specimens were removed from the most abundant samples for separate analysis by Japanese scientists. In the laboratory ashore, samples were further divided by species (see below). Some tissue samples of the various amphipods were dissected at the laboratory for future molecular analysis. The abundance for each species was obtained by counting all the individuals in a sample. The ethanol was then drained and the sample was blotted dry and weighed on a balance to the nearest $0.01 \mathrm{~g}$.

\subsubsection{Identification}

Amphipods were identified to the lowest possible taxonomic level following Ingram and hessler (1987), Barnard and Barnard, (1969), Kilgallen, (2015), and Kilgallen and Lowry, (2015). The identification of the largest individual of Alicella gigantea was compared with 
the type specimen descriptions from the Atlantic (Chevreux, 1899), North Pacific (De Broyer and Thurston, 1987), and as re-described by Jamieson et al. (2013) from the neighbouring Kermadec Trench.

Amphipods were primarily identified under a stereoscopic microscope (LEICA MZ 8, Germany), in cases when small parts needed to be dissected and examined, a compound microscope (Carl Zeiss, Germany) was used. Many of the amphipods had suffered severe damage or degradation during collection. Nevertheless, identification of these individuals was still attempted. Such individuals were always marked as damaged and so that they could be removed from later analysis if the identification was considered unreliable.

\subsubsection{Photography/imaging}

All individuals other than Hirondellea dubia (Dahl 1959) species were photographed, sexed, and measured using the following methods. For detail about the methodology used for H. dubia see Chapter 3.

Larger species were photographed with a Sony NEX-7 camera positioned $23 \mathrm{~cm}$ above the individual. Smaller species were photographed under a stereoscopic microscope using either a U3CMOS series C-mount USB3.0 CMOS camera with C-mount 0.50X camera adapter, or an ODCM0310C series C-Mount USB2.0 CMOS camera with C-mount 0.50X adjustable camera adapter (ProSciTech, Australia). Photographs were taken against a scale were possible, or otherwise a separate image of the scale was taken at a focus and zoom matching the image of the specimen.

\subsubsection{Length and sex}

All measurements and sexing was conducted using the stereoscopic microscope or the compound microscope. Measurements were made along the dorsal aspect, from the head to the tip of the telson. Image analysis was conducted with software ImageJ (ImageJ v. 1.49; NIH, USA; Abramoff et al 2002). The degree of dorsal curvature varied within and between species. No adjustment was made for this curvature, which will have introduced 
a degree of inaccuracy to these measurements. However these lengths were not used in any length-based population analysis so this was considered acceptable.

The sex of an individual was established by the presence of penile papillae (male), oostegites (female), or the absence of both of these (Juvenile) (Hessler et al., 1978). When individuals were damaged or missing segments, all possible sexing/measuring were made, while noting that the individual was damaged.

\subsubsection{Statistical analysis}

Statistical analyses were conducted using the IBM ${ }^{\circledR}$ SPSS $^{\circledR}$ statistics software (version 22.0, 2015), and all the results were assessed at the 95\% confidence level. Following the sexing of all individuals, sex ratios were calculated and a $\chi^{2}$ test was used to detect any significant deviation from a 1:1 male to female ratio. 


\subsection{Results and Discussion}

The baited traps successfully captured a variety of scavenging fauna at 2 hadal depths. A total of 552 amphipods were captured at the $\sim 6,250 \mathrm{~m}$ depth and 3,174 were collected at the $10,800 \mathrm{~m}$ depth (Table 2.2 ). The baited traps nearly exclusively caught amphipods, the only non-amphipod organisms collected were two mysids at the trench edge site and these most likely entered the traps in shallower water.

The 2 depths sampled varied substantially in amphipod assemblage structure. A total of 6 amphipod species were sampled across the two depths (Table 2.2). All six of these species were found in the $6,250 \mathrm{~m}$ site while only one (Hirondellea dubia) was found at the 10,800 m depth. Alicella gigantea Chevreux, 1899, Eurythenes gryllus (Lichtenstein, 1822), Hirondellea dubia Dahl, 1959, Bathycallisoma schellenbergi (Britein and Vinogradova, 1958) were positively identified, and the remaining species were an alicellid species, and an unidentified gammarid species. H. dubia was the sole species found at $\sim 10,800 \mathrm{~m}$, and typically in high abundance. The assemblage structure at 6,250 m was more complex, where the alicellid species was the most abundant making up $47 \%$ of the individuals, $E$. gryllus was also prevalent comprising $20 \%$ of the assemblage, while B. schellenbergi, $H$. dubia, the unidentified gammarid sp., and $A$. gigantea were the least prevalent making up $15,13,4$, and $1 \%$ respectively of the total assemblage. (Table 2.2 ). 
Table 2.2: Composition and abundance of bait-attending amphipods recovered from 6 stations sampled across 2 depths in the Tonga Trench.

\begin{tabular}{|c|c|c|c|c|}
\hline Site:dive No. & Depth (metres) & Species present & Count & Weight (grams) \\
\hline $1370 / 1-5$ & 6254 & Eurythenes gryllus & 3 & 4.9 \\
\hline \multirow{6}{*}{$1-1$} & \multirow{6}{*}{6256} & Alicella gigantea & 1 & 142.64 \\
\hline & & Eurythenes gryllus & 14 & 10.86 \\
\hline & & Alicellid sp. & 90 & \multirow{4}{*}{$12.09^{a}$} \\
\hline & & $\begin{array}{c}\text { Scopelocheirus } \\
\text { (Bathycallisoma) schellenbergi }\end{array}$ & 20 & \\
\hline & & Hirondellea dubia & 7 & \\
\hline & & Gamarid sp. & 10 & \\
\hline \multirow{6}{*}{$1-2$} & \multirow{6}{*}{6253} & Alicella gigantea & 1 & 11.08 \\
\hline & & Eurythenes gryllus & 93 & 82.6 \\
\hline & & Alicellid sp. & 170 & \multirow{4}{*}{$20.7^{a}$} \\
\hline & & $\begin{array}{c}\text { Scopelocheirus } \\
\text { (Bathycallisoma) schellenbergi }\end{array}$ & 63 & \\
\hline & & Hirondellea dubia & 66 & \\
\hline & & Gamarid sp. & 14 & \\
\hline $2-1$ & 10800 & Hirondellea dubia & 592 & 32.15 \\
\hline $2-2$ & 10807 & Hirondellea dubia & 68 & 3.37 \\
\hline $2-3$ & 10807 & Hirondellea dubia & 1763 & 91.71 \\
\hline $2-4$ & 10804 & Hirondellea dubia & 751 & 42.46 \\
\hline
\end{tabular}

${ }^{a}$ Weights were determined prior to separation of these 4 species

$\tilde{\perp}$ 


\subsubsection{Species-specific observations}

Alicella gigantea (Figure 2.6) is recorded here for the first time from the Tonga Trench. Despite appearing to be a cosmopolitan species at abyssal depths (Barnard and Ingram, 1986; Hasegawa et al., 1986; De Broyer and Thurston, 1987), this large scavenger has only been recorded from the South Pacific once before in the neighbouring Kermadec Trench (Jamieson et al., 2013). The two individuals, a juvenile and a male (Figure 2.6 shows the large male), were recovered during independent deployments of the sediment samplingcamera lander to $6,250 \mathrm{~m}$. This depth is within the known range of $A$. gigantea (Barnard and Ingram, 1986), although this is only the second record of the species at hadal depths. A. gigantea is the largest known amphipod with a maximum recorded length of $340 \mathrm{~mm}$ (Harrison et al., 1983). The specimens recovered in the present study were 91.7 and 254.7 $\mathrm{mm}$ in length and within the known range of size and similar to the range of sizes recorded by Jamieson et al., (2013) in the in neighbouring Kermadec Trench (102-290 $\mathrm{mm})$.

Although A. gigantea has a worldwide distribution, it has not been caught by traps at these depths in the Tonga Trench in the past (Blankenship et al., 2006; Jamieson et al., 2011). Furthermore many of the locations where A. gigantea have been captured have been sites of repeated sampling (Barnard and Ingram, 1986; Hasegawa et al., 1986; De broyer and Thurston, 1987). It is possible that the time taken for A. gigantea to attend bait may have limited the chances for the species to be recovered previously in the Tonga Trench. In the Kermadec Trench, A. gigantea only attended bait after $\sim 5$ hours (Jamieson et al., 2013), and the maximum abundance was only achieved after 16 hours on the seafloor, however in the present study the large male was recovered in a trap that was deployed for only 2:46 hours somewhat contradicting this pattern. It is also possible that the species occurs in extremely low abundance with a scattered distribution. It is likely a combination of both that has resulted in the absence of $A$. gigantea from past sampling efforts and small sample size in the present study. 
Table 2.3: Details of collected A. gigantea individuals.

\begin{tabular}{l|l|lllll}
\hline $\begin{array}{l}\text { Dive } \\
\text { number }\end{array}$ & $\begin{array}{l}\text { Depth } \\
\text { (metres) }\end{array}$ & $\begin{array}{l}\text { NIWA } \\
\text { Catalog } \\
\text { Number }\end{array}$ & Date & Sex & Length (mm) & Weight (g) \\
\hline $1-1$ & 6253 & 89965 & $09 / 10 / 2013$ & Male & 254.7 & 142.6 \\
$1-2$ & 6256 & 92773 & $10 / 10 / 2013$ & Juvenile & 91.74 & 11.1
\end{tabular}

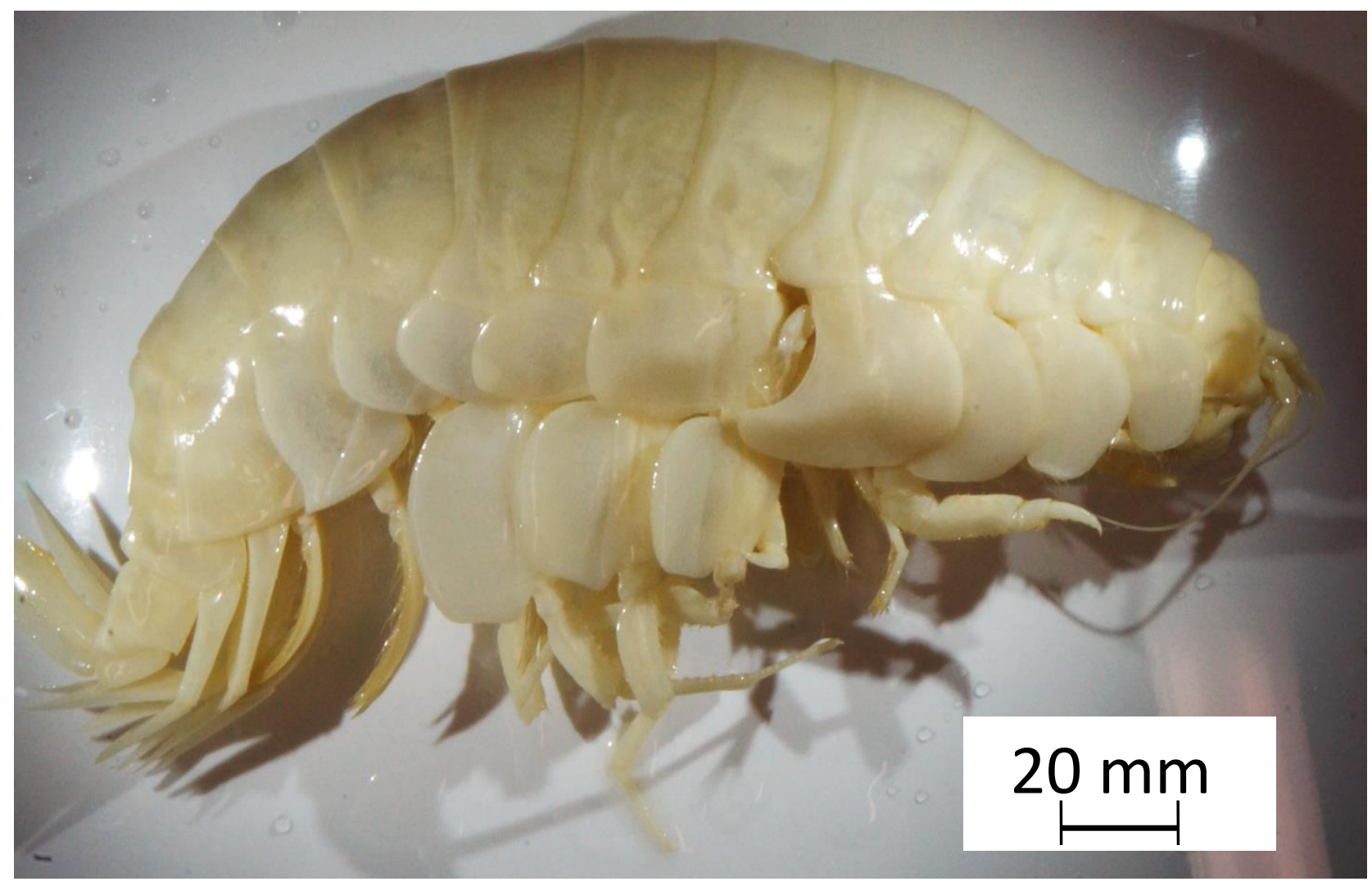

Figure 2.6: Male Alicella gigantea individual recovered from 6,253 m depth (Dive number 1-1, NIWA Catalog Number 89965).

Bathycallisoma schellenbergi (Figure 2.7) were captured in both samples at the $\sim 6,250 \mathrm{~m}$ depth, and none of the samples at the 10,800 m depth. Recovered individuals were all within the known size range of $B$. schellenbergi previously sampled in the Tonga Trench (Blankenship et al., 2006). A $15.6 \mathrm{~mm}$ female was the largest individual captured while 6.5 $\mathrm{mm}$ was the smallest juvenile captured. No sexually mature males or females were captured and the ratio between males and females did not differ significantly from 1:1 ( $\chi 2$ $(1,72)=0.5, p=0.48)$. 
All the $B$. schellenbergi caught at $6,250 \mathrm{~m}$ were relatively young instars, and this is consistent with the lifestage assemblage recorded by Blankenship et al. (2006) at this depth. This pattern reinforces the observation of vertical ontogenetic structuring in $B$. schellenbergi (Blankenship et al., 2006).

Scopelocheirus schellenbergi has often been referred to as a true hadal species being captured only in hadal depths. However a recent taxonomic revision has combined Scopelocheirus schellenbergi and Bathycallisoma pacifica into the latter genus. The combined records extend the depth range into the lower abyss and this species cannot be considered an exclusively hadal species (Kilgallen and Lowry, 2015). However recent genetic work indicated that there may be need for distinctions within $B$. schellenbergi into several species (Ritchie et al., 2015). Further analysis into this species is required to resolve the systematic status of this species and its taxonomy.
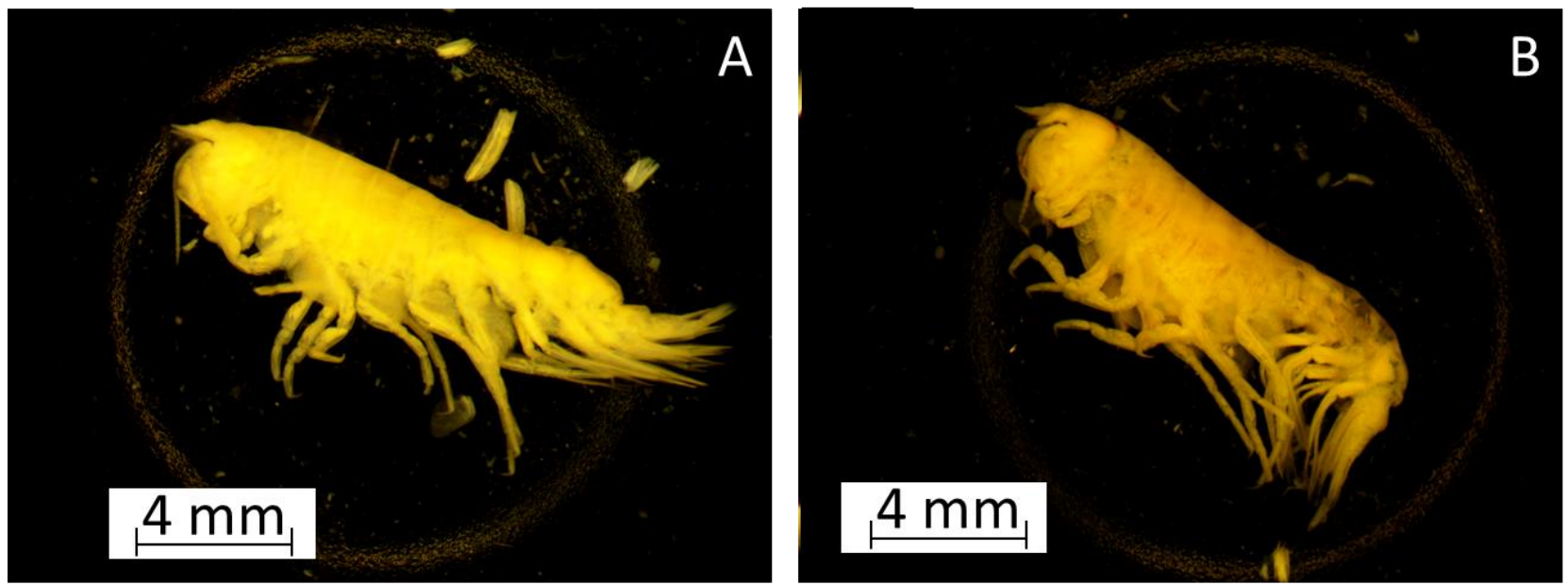

Figure 2.7: Bathycallisoma schellenbergi recovered from 6,253 m (Dive number 1-2, NIWA Catalog Number 92765). (A) Female. (B) Male

Hirondellea dubia (Figure 2.8) was recovered from a slightly deeper depth than the previous record $(10,787 \mathrm{~m}$ in Blankenship et al., 2006). These new data also provide a new Tongan Trench shallow record of 6,253 for $H$. dubia. However $H$. dubia have been recorded at abyssal depths in the Tonga Trench $(6,000 \mathrm{~m}$ in Jamieson et al., 2011), and a recent genetic study revealed that $H$. dubia can be found as shallow as 5,469 $\mathrm{m}$ (Ritchie et al., 2015). Hirondellea dubia were found at relatively low abundance at the $\sim 6,250 \mathrm{~m}$ site when compared to the high abundance detected at the $\sim 10,800 \mathrm{~m}$ site. Such high 
abundance in hadal depths is typical of Hirondellea species across many trenches (France et al., 1993; Perrone et al., 2002; Horton and Thurston, 2013).

When Blankenship et al., (2006) sampled a similar depth of $10,782-10,787 \mathrm{~m}$, the abundance of $\mathrm{H}$. dubia varied between 0 and $\sim 800$ individuals, and samples from the present study showed a similar degree of variability between 68 and 1763 individuals. However on average more amphipods at $10,800 \mathrm{~m}$ were recovered in the present study than by Blankenship et al., (2006). Due to the high variability in abundance, it is difficult to determine whether the low number recorded in Blankenship et al., (2006) is representative of the $H$. dubia numbers at this depth. However our sampling techniques varied with regards to trap heights off the sea floor and size and shape of the traps deployed, therefore abundance data may not be comparable. The size structure, sex ratios, and population dynamics of this species are investigated further in Chapter 3 of this thesis.
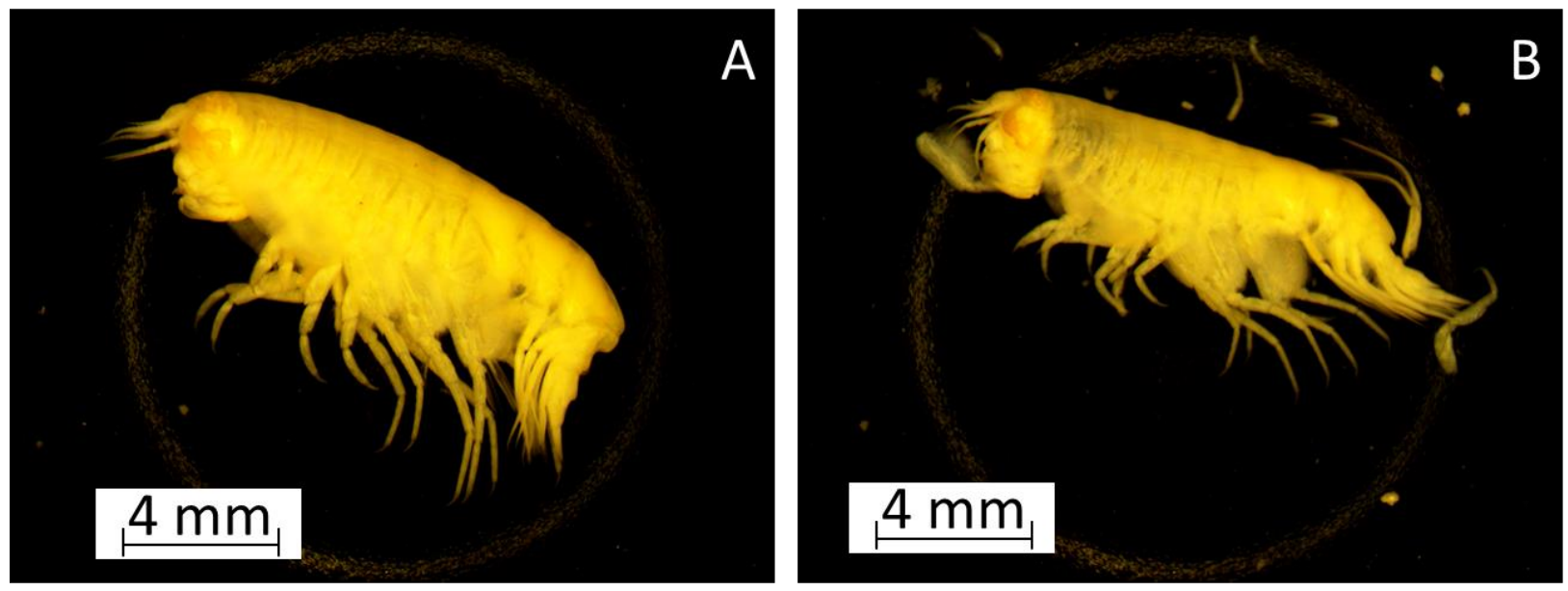

Figure 2.8: Hirondellea dubia recovered from 10,807 m (Dive number 2-3, NIWA Catalog Number 92767). (A) Female. (B) Male

Eurethenes gryllus (Figure 2.9) was captured at the 6,250 $\mathrm{m}$ depth by the large trap deployed by the Shinkai 6500 , and by the traps attached to the sediment samplingcamera lander. No specimens were captured at the $\sim 10,800 \mathrm{~m}$ depth, which is consistent with the findings of Blankenship et al., (2006). The 6,256 $\mathrm{m}$ depth is within the known range of E. gryllus, however it does provide a new depth limit for the Tonga Trench albeit only by a few metres (Blankenship et al., (2006) reported the species at 6,252 m). 
The sizes of recovered E. gryllus ranged from a juvenile at $25.4 \mathrm{~mm}$ to a small female 62.2 $\mathrm{mm}$ in length, and all of the individuals recovered would be considered medium to smallsized based on the analysis of size structure by Ingram and Hessler (1987). Furthermore, all the E. gryllus were immature instars. The traps in the present study were not deployed to heights greater than $1.8 \mathrm{~m}$ off the seafloor, however the size and immaturity of individuals caught is consistent with past findings of E. gryllus, where there is an increase in body size with increasing height off the sea floor. In this species, the adults become more pelagic indicating some degree of ontogenetic structuring (Ingram and Hessler, 1983; Christiansen et al., 1990; Jamieson et al., 2011). However, because the traps were only deployed to one depth off the sea floor $(1.8 \mathrm{~m}$ on the sediment sampling-camera lander), future study would need to compare traps across multiple heights off the sea floor to fully examine this vertical stratification.

The ratio of sexes in recovered $E$. gryllus did not significantly differ from 1:1 for $(\chi 2(1,94)=$ $0.17, p=0.680)$. This result is not surprising for an immature population of amphipods, as Thurston et al. (2002) stated that deviation from a 1:1 ratio is likely connected to reproductive behaviour, which we would not expect from an immature population of amphipods. This ratio is consistent with those detected in past studies at this depth in the Tonga Trench (Blankenship et al., 2006), and Kermadec Trench (Jamieson et al., 2011).

Eurethenes gryllus was the only species to be captured by the larger trap deployed by the Shinkai 6500, and this was most likely due to the large mesh size (11 mm), providing a means of escape for smaller scavenging amphipods. In addition, the trap was only deployed for less than 3 hours on the seafloor due to limitations of the Shinkai 6500, and the amount of time deployed may not have been long enough to attract the larger bait attending scavengers as previously suggested also for $A$. gigantea (Jamieson et al., 2011).

Eurethenes gryllus is a cold water stenotherm that is distributed to shallower waters in higher latitudes and at greater depths in lower latitudes (Thurston et al., 2002). The Tonga and Kermadec trenches are highly connected and the difference in temperature between the trenches is negligible (Beliaev and Brueggeman, 1989), however the distribution of $E$. 
gryllus is restricted to $\sim 6,000 \mathrm{~m}$ in the Kermadec Trench (Jamieson et al., 2011). The difference $(\sim 250 \mathrm{~m})$ in the vertical distribution of E. gryllus between the trenches somewhat contradicts the theory of stenothermic driven distribution. The Peru-Chile Trench is approximately $0.75{ }^{\circ} \mathrm{C}$ warmer than the Kermadec Trench at comprable depths, however E. gryllus was found there at 8,074 $\mathrm{m}$ in the Peru-Chile Trench, almost $\sim 2,000 \mathrm{~m}$ greater than in the Kermedec Trench (Fujii et al., 2013). The distribution of E. gryllus could be driven by environmental conditions as well as temperature.
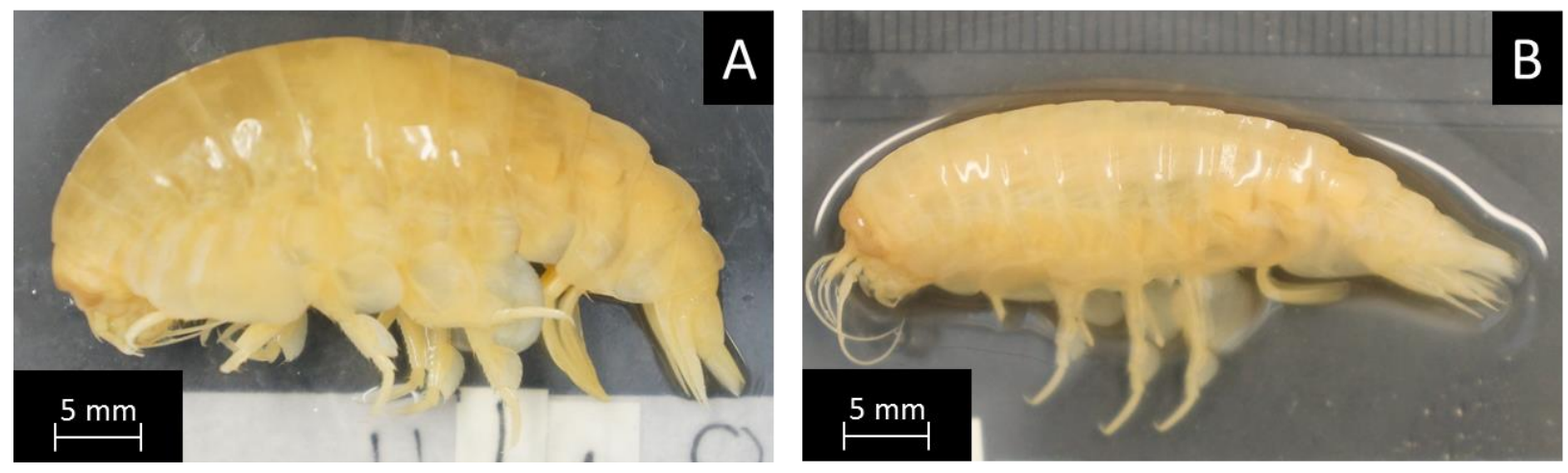

Figure 2.9: Eurythenes gryllus recovered from 6,253 m (Dive number 1-2, NIWA Catalog Number 92772). (A) Female. (B) Male

The unkown Alicellid species (Figure 2.10) was the most abundant species captured at the $\sim 6,250$ site, but was not found at the deeper site. The species ranged in size from a $7.5 \mathrm{~mm}$ juvenile, to a $23.5 \mathrm{~mm}$ male, and the ratio of males to females did not significantly differ from $1: 1(\chi 2(1,113)=0.717, p=0.397)$. Although it could not be identified beyond the family level during the course of the present study, this species most closely resembled a species of Paracella. Several species of this genus were recorded in the neighbouring Kermadec Trench (Jamieson et al., 2011), and the size range of specimens found in the present study falls within the known size range of Paracella species (2-23 mm, Shulenberger and Hessler, 1974; Barnard and Shulenberger, 1976; Thurston, 1979). If this species is indeed a Paracella, then the collection at $\sim 6,250$ would slightly extend the known depth record by $\sim 250 \mathrm{~m}$ in the Kermadec Trench (Jamieson et al., 2011). This difference in depth may discredit the hypothesis that the unknown Alicellid is a Paracella species, however other benthopelagic scavengers such as E. gryllus are shown here to exist 250 m deeper in the Tonga Trench (Jamieson et al., 2011; Present study). 

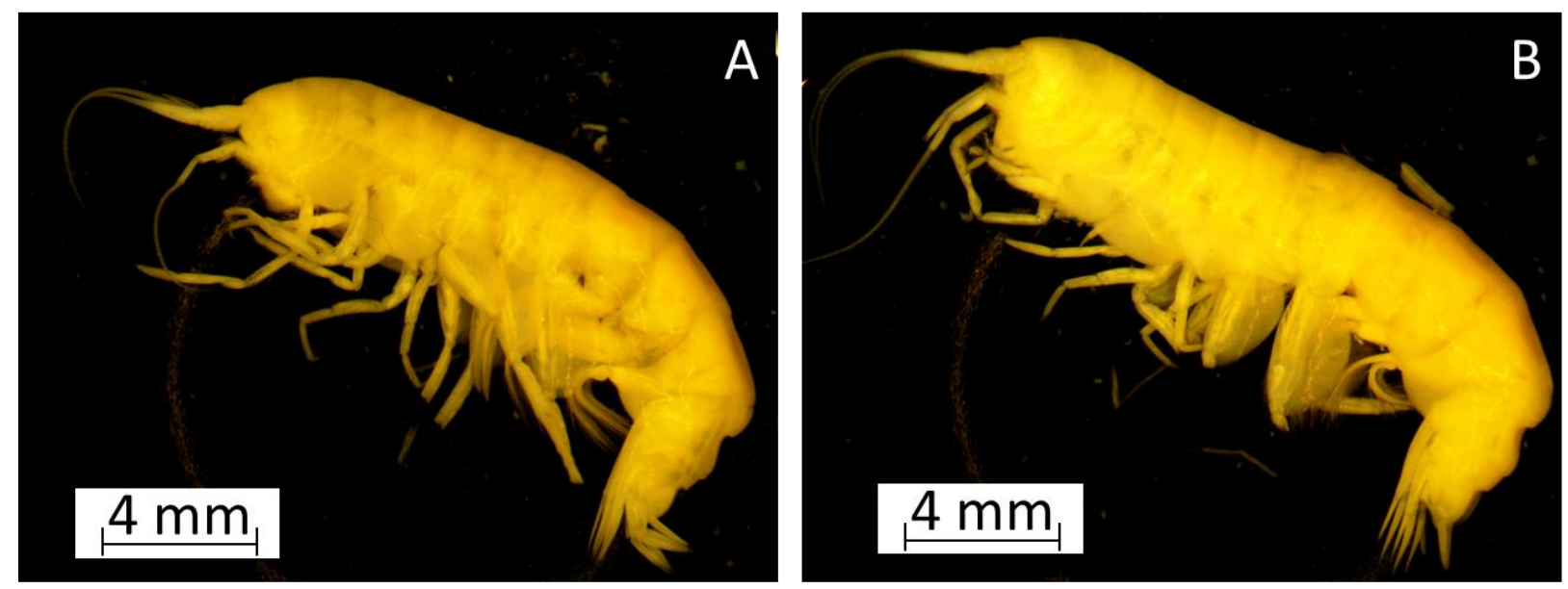

Figure 2.10: Alicellid species recovered from 6,256 m (Dive number 1-1, NIWA Catalog Number 92774). (A) Female. (B) Male

The unidentified gammarid species (Figure 2.11) was recovered in both deployments to the $6250 \mathrm{~m}$ depth. The species displayed very little range in size from $8.6 \mathrm{~mm}$ to $9.5 \mathrm{~mm}$. Attempts to sex the species was impaired by the small body size, the extreme dorsal curvature and a rigid and brittle exterior. With further investigation the species might be classified as Uristes chastaini, which is known from depths of 7,349-9,274 $\mathrm{m}$ in the Kermadec Trench (Blankenship-Williams and Levin, 2009). Although the sampling depth in the present study was $\sim 1,000 \mathrm{~m}$ shallower, this gammarid shares some morphological characteristics with $U$. chastaini. In addition, Blankenship et al. (2006) noted that $U$. chastaini was only found in samples that also recovered $H$. dubia and $B$. schellenbergi, which is consistent with the findings of the present study, although any significance of this pattern remains unclear. However, contrary to the findings of the present study, at each depth $U$. chastaini were recovered in the Kermadec Trench several individuals were ovigerous females (Blankenship et al., 2006). 

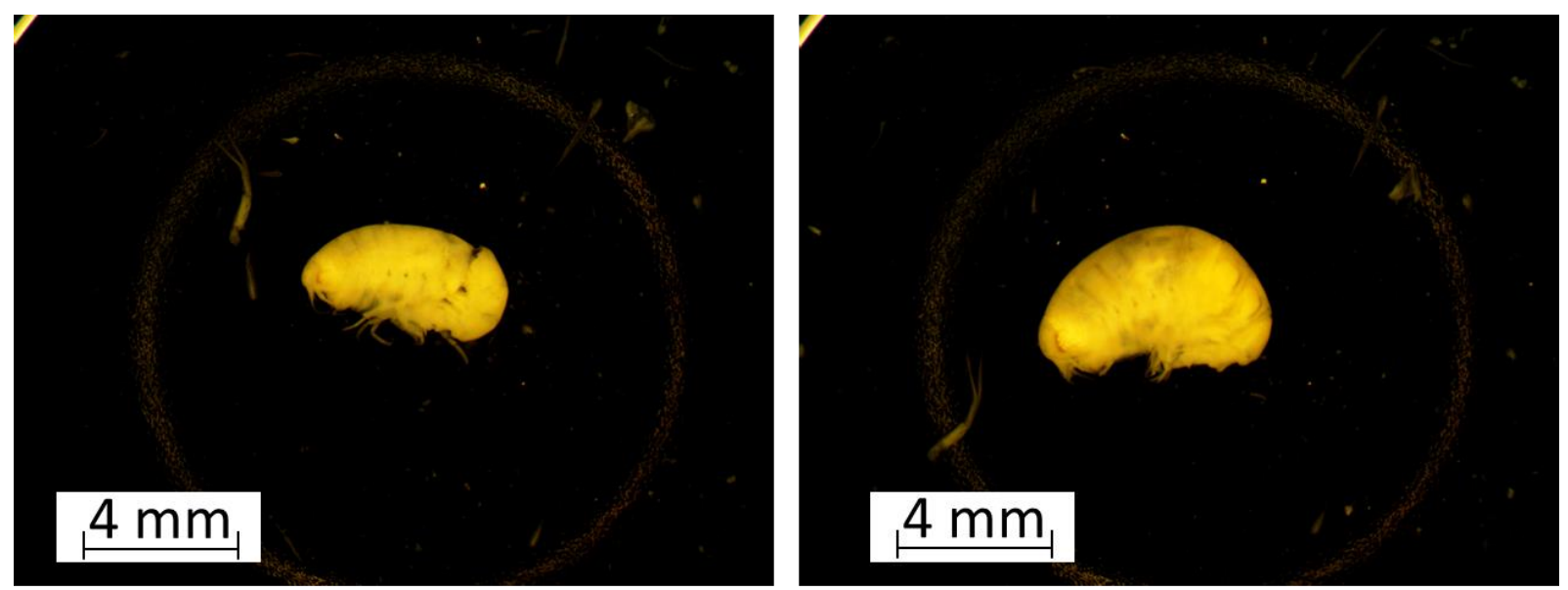

Figure 2.11: Examples of the unidentified gammarid species recovered from 6,256 m (Dive number 1-1, NIWA Catalog Number 92774).

\subsubsection{Assemblage observations}

There is a clear relationship of decreasing diversity and increasing abundance with depth in the Tonga Trench, as has been previously observed in the hadal environment (Wolff, 1960; Beliaev and Brueggeman, 1989). Amphipods completely dominated the bait attending scavenging fauna at both depths sampled during the present study, and were particularly abundant in the deeper depth of the trench, a finding consistent with many hadal studies (Wolff, 1960; Perrone et al., 2002; Thurston et al., 2002; Eustace et al., 2013). However these relationships may not be representative of the true hadal assemblage composition as the methodology used may have excluded scavengers that were not trapped and recovered during the deployment (Hessler et al., 1978; Ingram and Hessler 1983; Blankenship et al., 2006).

The diversity of scavenging amphipod species found in the present study was comparable to that of past studies in the Tonga Trench. For example, Blankenship et al. (2006) detected 5 amphipod species at $\sim 6250 \mathrm{~m}$, a number close to the 6 species reported here at this depth. The assemblages of species detected in the present study are also comparable to sampling efforts conducted in the Kermadec Trench, sharing species such B. schellenbergi, H. dubia, and an alicellid, possibly a member of the Paracella genus (Blankenship et al., 2006; Jamieson et al., 2009a; Fujii et al., 2013). The similarity in 
composition between the Tonga and Kermadec Trenches supports the characterization of these adjacent trenches as a single biological province with a similar hadal community (Vinogradova, 1979; Blankenship et al., 2006). This proposition is further supported by genetic analysis of $\mathrm{H}$. dubia, which showed that individuals between these two trenches were more similar than those found in the New Hebrides or Mariana Trenches (Ritchie et al., 2015). However, there are variations between the Tonga and Kermadec trenches, such as the oligotrophic waters over the Tonga Trench and the shifts in vertical ranges of scavengers like E. gryllus (Longhurst et al., 1995).

The Tonga Trench contains several cosmopolitan trench species such as $E$. gryllus and $B$. schellenbergi, while the genus Hirondellea is also widespread, generally dominating the deepest ranges of trenches around the world (Horton and Thurston, 2013; Fujii et al., 2013; Eustace et al., 2013; Kilgallen, 2015; Ritchie et al., 2015). The present study contributes to the expansion of the vertical and geographical range of Hirondellea dubia. A recent genetic study on the superfamily Lysianassoidea revealed $\mathrm{H}$. dubia occurred at depths as shallow as 5,369 m (Ritchie et al., 2015), making $H$. dubia's known vertical range approximately $5.5 \mathrm{~km}$, which is substantially larger than most hadal amphipods (Hessler et al., 1978; Ingram and Hessler 1983; Beliaev and Brueggeman, 1989).The same genetic analysis noted $\mathrm{H}$. dubia in the New Hebrides and Mariana Trenches albeit in low numbers (Ritchie et al., 2015). Although no H. dubia have yet been detected in the Izu Bonin or Japan Trenches, $H$. dubia is distributed across a number of the trenches in the western Pacific Ocean.

The scavenging amphipod assemblage of the Peru-Chile Trench in the eastern Pacific Ocean is similar to the Tonga Trench in that it contains several cosmopolitan shallow trench species such as E. gryllus and members of the Paracella genus, and also a high abundance of the Hirondellea genus in the greater depths of the trench (Fujii et al., 2013). However, in the Peru-Chile Trench E. gryllus persists throughout the trench and the Hirondellea genus is represented by three species $H$. sonne, $H$. thurstoni, and $H$. wagneri (Fujii et al., 2013; Kilgallen, 2015). Hydrostatic pressure and organic matter distribution 
are considered key drivers in defining the composition of hadal scavenger communities (Wolff, 1960; Beliaev and Brueggeman, 1989). In the Peru-Chile Trench, temperature and organic matter quantity are higher than in the Tonga Trench (Longhurst et al., 1995; Daneri et al., 2000; Blankenship and Levin 2007; Fujii et al., 2013), and these factors may have driven the differences in the scavenging amphipod assemblage composition and structure between the trenches (Fujii et al., 2013).

\subsubsection{Conclusions}

The composition of the amphipod assemblage found in the present study was similar to past sampling efforts in the Tonga Trench. There were also similarities to the adjacent Kermadec Trench (Blankenship et al., 2006; Jamieson et al., 2011) and more limited similarities to the Peru-Chile Trench (Fujii et al., 2013). The present study extends the known range of $H$. dubia to $10,807 \mathrm{~m}$ depth, and provides new records of $A$. gigantea, $E$. gryllus, and $H$. dubia vertical ranges in the Tongan Trench. In addition this is the first recorded instance of $A$. gigantea in the Tonga Trench, and the second study to record $A$. gigantea in the south Pacific, as well as the second to record the species at hadal depths. 


\section{Chapter 3: Population structure of}

\section{Hirondellea dubia from the Tonga Trench, and analysis of proxies for total length}

\subsection{Introduction}

Scavenging amphipods are a defining element of hadal communities (Wolff, 1960; Hessler et al., 1978; Ingram and Hessler, 1983), where they act as key prey items to predators in the shallower depths of the hadal zone (Jamieson et al., 2009a), and dominate the scavenging community at carrion falls, particularly in the greater depths of a trench. Amphipods have been recovered by almost every instance of sampling by baited traps at hadal depths (Hessler et al., 1978; Blankenship et al., 2006; Eustace et al., 2013), and they are frequently recorded by baited cameras and trawl sampling efforts (Wolff, 1960; Jamieson et al., 2009b; Gallo et al., 2015). The scavenging amphipods rapidly detect, intercept, and consume carrion, and they attend bait in exceptionally high abundance. The success of amphipods at the deeper hadal depths has been attributed to their adaptations to hydrostatic pressure and limited supply of organic matter in the trench environment (Jamieson et al., 2010).

Jamieson (2015) described the criteria that amphipods must meet to be prolific in this environment. These are primarily the ability to effectively extract resources from carrion falls and to survive large periods of starvation, however scavengers must also be capable of supplementing their diet between carrion fall events. In the past hadal amphipods were thought to rely on necrophagy for sustenance (De Broyer et al, 2004), however it is likely that they also undertake detritivory, carnivory, and even cannibalism (Blankenship and Levin, 2007; Jamieson et al., 2010). The ability to supplement their diet also allows 
species to partition food sources in order to co-exist at similar depths in the organic matter limited trenches (Blankenship et al., 2007).

Hadal amphipods have adapted to a particular range of hydrostatic pressures and $85 \%$ of all known hadal fauna have a depth range that is less than $3 \mathrm{~km}$ (Beliaev \& Brueggeman, 1989; Blankenship et al., 2006). Oceanic trenches commonly exceed $3 \mathrm{~km}$ of depth range (for example the hadal zone in the Tonga Trench has a vertical range of $\sim 5 \mathrm{~km}$ ), and therefore trench amphipod assemblages are likely to be vertically stratified (Beliaev \& Brueggeman, 1989, Blankenship et al., 2006). In the past, amphipods have often been sampled from a single depth, and so population structure has not been comprehensively analyzed in many trenches (Hessler et al., 1978; Thurston et al., 2002; Perrone et al., 2002), however efforts to sample across depths have increased (Blankenship et al., 2006; Eustace et al., 2013; Jamieson, 2015). Vertical stratification of several amphipod species were recorded in the Tonga and Kermedec Trench (Blankenship et al., 2006), stratification was also detected between lifestages of Hirondellea dubia (Dahl, 1959) and Bathycallisoma schellenbergi (formerly Scopelocheirus schellenbergi) (Britein and Vinogradova, 1958). This vertical ontogenetic stratification was previously unknown in the hadal environment.

The genus Hirondellea is found throughout the world's ocean trenches (Hessler et al 1978; Blankenship et. al., 2006; Eustace et. al., 2013; Horton and Thurston, 2013; Kilgallen, 2015). The genus often dominates assemblages in the deepest sections of trenches, occurring at baited traps, and has been visualized by cameras in extremely high abundance (Hessler et al., 1978; Blankenship et al., 2006). Hirondellea dubia inhabits depths from 7,349-10,787 $\mathrm{m}$ in the Tonga Trench and is the most adundant species caught in traps deeper than 7,500 $\mathrm{m}$ (Blankenship et al., 2006). Individuals caught in the upper portion of the depth range were almost exclusively early instars, and this may have been driven by a combination of hydrostatic pressure and distribution of food sources (Blankenship et al., 2006; Eustace et al., 2013). More analyses of population and 
assemblage structure between depths are needed to gain a better understanding of these relationships and the variables that drive them.

Analysis of amphipod size structure between depths has suffered in the past due to inconsistencies in methodology (Chapelle, 1995; Thurston et al., 2002). Variations in lifehistory trait measurement, trap design, trap position above the seafloor, and amphipod length measurements are found across many hadal scavenger studies (Hessler et al., 1978; Ingram and Hessler,1983; Legeżyńska et al., 2000). Acquiring an accurate total length measurement from amphipods is challenging due to dorsal curvature, because dorsal segments may telescope into each other. Dorsal curvature can account for more than $10 \%$ of the variation in length between amphipods (Charniaux-Cotton, 1957; Chapelle, 1995). This variation can be bypassed by measuring a portion of the amphipod as a proxy in place of measuring along the entire dorsal aspect (Chapelle, 1995), and a conspicuous proxy also allows for more individuals to be measured if a portion of the specimens are damaged, hence, giving a larger samples size per effort. A variety of proxies have been used in amphipods in the past (Hessler et al., 1978; Thurston et al., 2002), however none have been comprehensively examined for $\mathrm{H}$. dubia, and a consensus for a single proxy to be used in hadal amphipods would be helpful in making future research in this area comparable.

In October of 2013 the YOK 13-10 voyage was part of a series of trench investigations under the QUELLE (Quest for the Limit of Life) round-the-world expedition conducted by the Japan Agency for Marine-Earth Science and Technology (JAMSTEC). The YOK13-10 voyage aimed to analyse benthic life within the Tonga Trench among other goals, and thus baited traps were deployed to the axis of the trench (Horizon Deep) and to the edge of the Trench. The species composition of the amphipods in these samples were described in Chapter 2 of this thesis. In this chapter I analyse the size structure of $\mathrm{H}$. dubia at these two depths. Vertical ontogenetic structuring of $\mathrm{H}$. dubia in the Tonga Trench has been examined between depths of 7,349 $\mathrm{m}$ and 10,782 $\mathrm{m}$ (Blankenship et al., 2006), and the present study expands this analysis to the edges of the known range of $\mathrm{H}$. dubia to depths 
of $\sim 6,250 \mathrm{~m}$ and $\sim 10,800 \mathrm{~m}$. The secondary objective of this chapter is the analysis and identification of a suitable proxy for total length of $H$. dubia. 


\subsection{Materials \& Methods}

\subsubsection{Study site, sample collection and identification}

For details of the study site and methods concerning the collection and identification of $H$. dubia see Chapter 2 (section 2.2).

Hirondellea dubia individuals from all samples were sexed, imaged, and then analysed morphometrically. When the numbers of individuals in a sample exceeded 450 , a random subset of 450 individuals were processed as outlined below. In samples that contained fewer than 450 individuals, all the individuals were processed.

\subsubsection{Determining sex}

Individuals were placed in a dish of $80 \%$ ethanol and examined under a stereoscopic microscope (LEICA MZ 8, Germany). Small dissected parts were examined at higher magnification under a compound microscope (Carl Zeiss, Germany). Sex and life stage were identified using criteria from Hessler et al. (1978), which targeted the scavenging amphipod Hirondellea gigas, however similar criteria are used to sex many gammaridean amphipods (Blankenship et al 2006; Eustace et. al., 2013). Each H. dubia was manipulated using tweezers under the microscope in order to examine genitalia. Hirondellea dubia were separated into 7 distinct life stages based on as the criteria shown in Table 3.1 (Hessler et al., 1978, Blankenship et al., 2006; Eustace et al., 2013). The number associated with each lifestage represents the stage of development, and is not representative of age and cannot be compared across sexes (i.e. male 3 is the fully mature male, while female 3 is still immature). 


\begin{tabular}{|c|c|c|}
\hline $\begin{array}{l}\text { Sex/life } \\
\text { stage }\end{array}$ & $\begin{array}{l}\text { Lifestage } \\
\text { code }\end{array}$ & Description \\
\hline Juvenile & J & No visible papillae or oöstegites \\
\hline Male ${ }^{\top} 2$ & $\mathrm{M} 2$ & $\begin{array}{l}\text { Penile papillae present, calceoli absent from } \\
\text { antenna }\end{array}$ \\
\hline Male ${ }^{\lambda} \mathbf{3}$ & M3 & $\begin{array}{l}\text { Penile papillae present, calceoli present, slightly } \\
\text { elongated second antenna }\end{array}$ \\
\hline Female $\bigcirc \mathbf{2}$ & $\mathrm{F} 2$ & $\begin{array}{l}\text { Short oöstegites trace can be found on } \\
\text { pereiopods } 3-5\end{array}$ \\
\hline Female $q \mathbf{3}$ & F3 & Small oöstegites protrude from pereiopods 3-5 \\
\hline Female $\odot \mathbf{3 a}$ & $\mathrm{F} 3 \mathrm{a}$ & Oöstegites protrude out over the abdomen \\
\hline Female $q 4$ & F4 & Large oöstegites possessing setae \\
\hline
\end{tabular}

Males were identified when penile papillae were found on the ventral surface between the $7^{\text {th }}$ pereonite and the $1^{\text {st }}$ pleonite (Figure 3.1). Males were then further divided into $\mathrm{M} 2$ and $\mathrm{M} 3$ by detecting calceoli on the antennae (Figure 3.1). 
A

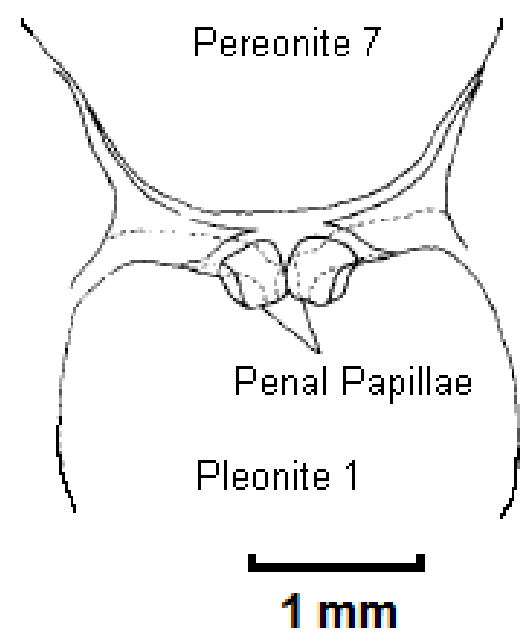

B

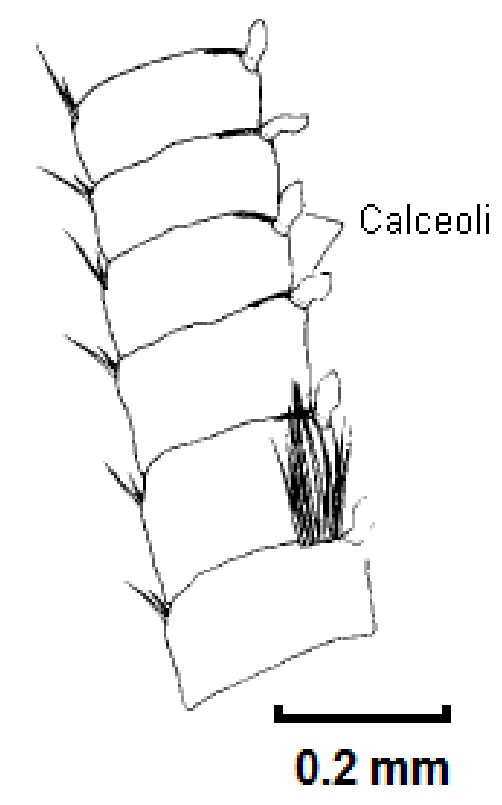

Figure 3.1: External morphology used to distinguish male $\boldsymbol{H}$. dubia adapted from Hessler et al. 1978. (A) Ventral aspect of male, penal papillae are found between the pereonite 7 and pleonite 1 somites. (B) Second antenna of M3 amphipod, calceoli observed at joints of antenna segments.

Oöstegites on pereopods 3-5 were used to classify an amphipod as female. Females were further split into F2, F3, F3a, and F4 based on the size and structure of the oöstegites (Table 3.1, Figure 3.2). In smaller individuals, pereiopods were amputated and examined at higher magnification under a compound microscope to identify the size of the oöstegites. 

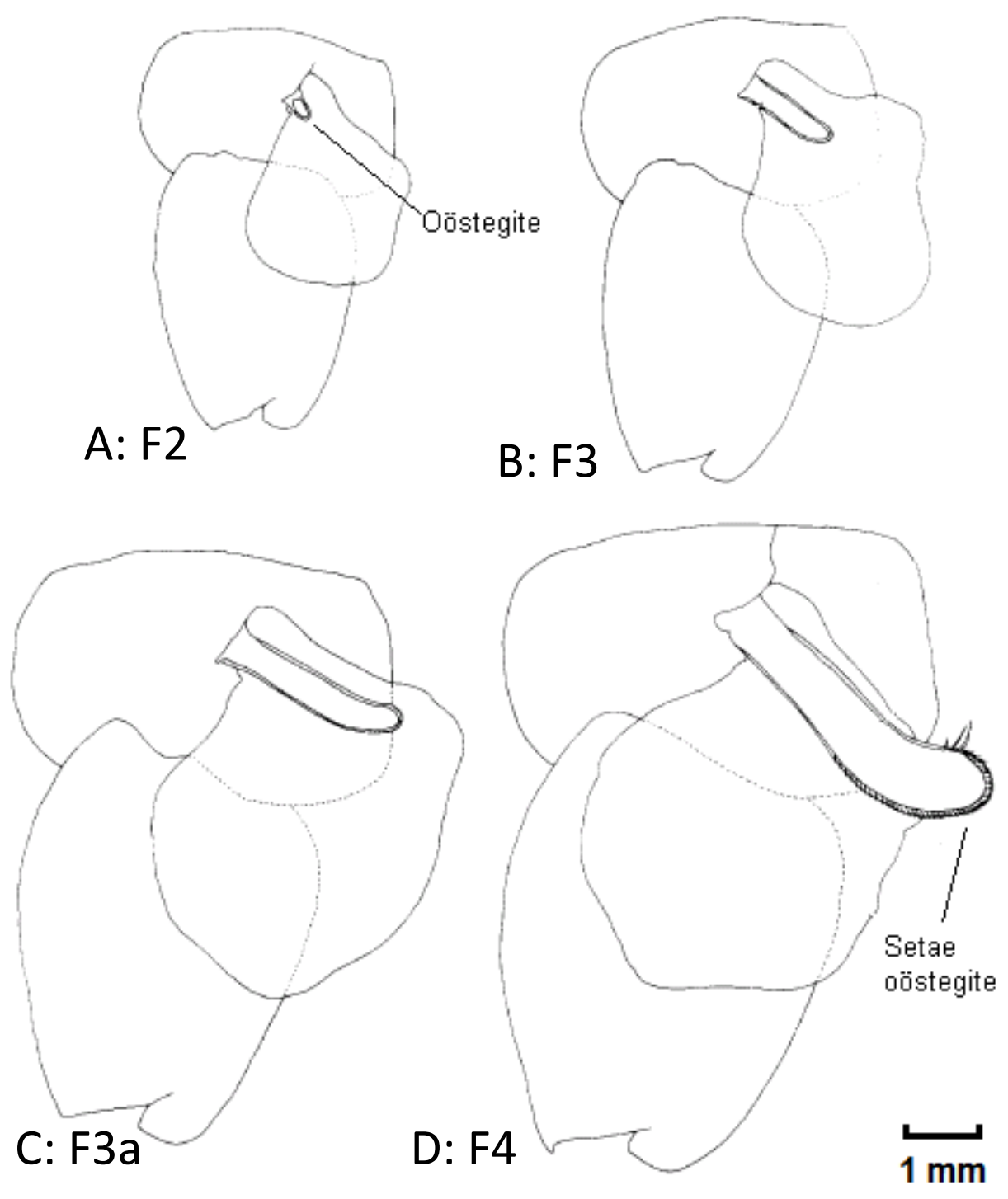

Figure 3.2: External morphology used to distinguish female $\boldsymbol{H}$. dubia adapted from Hessler et al. 1978. (A, B, C, D) Refer to Table 3.1 for detailed description of these female lifestages.

Juveniles were classified when an individual was too small to be sexed or when genitalia were indistinguishable. The lifestages of M1 and F1 were included under the classification of juveniles, and therefore calculating growth rates between the first and second stage of each sex was not possible.

When individuals were damaged in areas that were important for sexual identification, an attempt was made to search for other evidence that indicated the sex of the individual. For example, the presence of calceoli on the antenna would be sufficient to classify the 
amphipod as M3 even if the penile papillae were damaged. Such individuals were always marked as damaged so that they could be removed later from data analysis if this damage caused significant inaccuracy. If male or female parts were detected then individuals were classified as that sex immediately and no further investigation was made into examining parts associated with the opposite sex. Consequently, inter-sex individuals may have been overlooked.

\subsubsection{Imaging}

Images were captured using either a U3CMOS series C-mount USB3.0 CMOS camera (ProSciTech, Australia) with C-mount 0.50X camera adapter or a ODCM0310C series CMount USB2.0 CMOS camera (ProSciTech, Australia) with C-mount 0.50X adjustable camera adapter.

A photograph of a $\mathrm{cm}$ scale was taken at the same standard magnification used for all photographs (x8 zoom), to calibrate morphometric measurements (Figure 3.3). All Individuals were laid on their side in a black dish filled with ethanol (80\%) to make distinctions between segments easier during measurements (Figure 3.3). The limbs were extended before each image was taken. Several images at differing planes of focus were taken of each individual to obtain quality images of dorsal plate distinctions and the details of the limbs. 
A

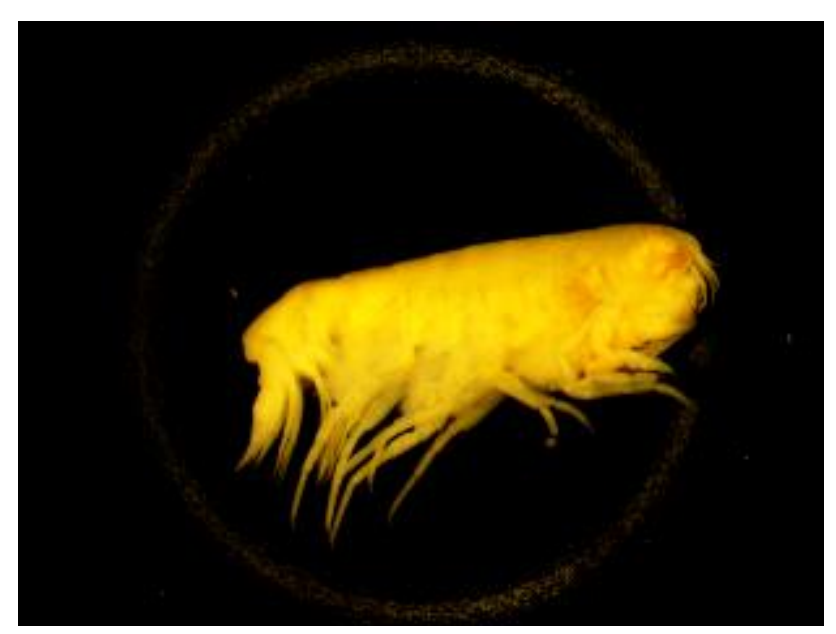

B

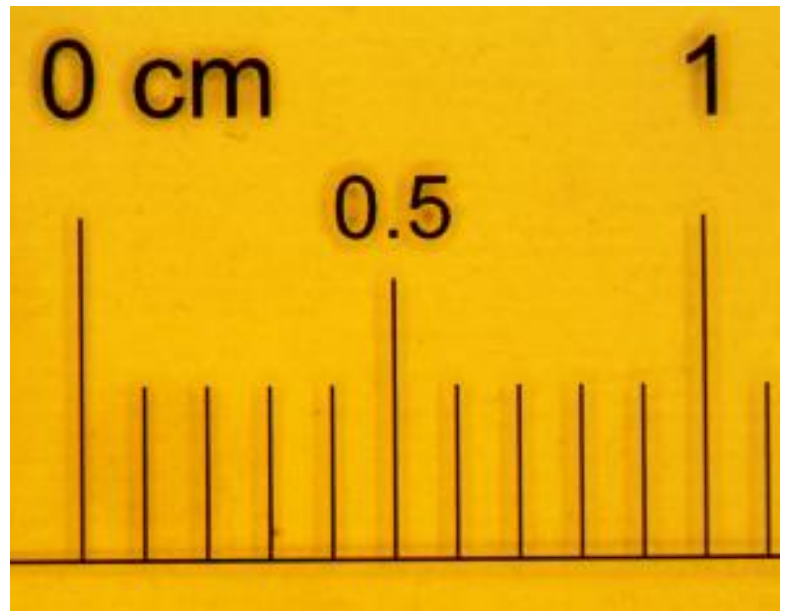

Figure 3.3: Example of $\boldsymbol{H}$. dubia image alongside a calibrating scale. (A) Male amphipod collected from $\sim 10,800 \mathrm{~m}$. (B) Image of scale under $32 x$ zoom.

\subsubsection{Morphometry}

All morphometric analyses were conducted using the image analysis software Image 1.49 (Abramoff et al., 2002). H. dubia individuals were measured for total length. Measurements were made along the dorsal aspect, separately recording lengths for; the head, pereonite 1 , pereonite 2 to 7 , the pleosome, the urosome, and these were then combined to create a total length value (Figure 3.4). Each measurement was conducted using the segmented straight line tool in ImageJ. Typically this composed of a single measurement from the start of the segment to the end, however for larger segments the line was broken up into a series of connected lines. Telson length was also recorded when possible, however because the telson generally contributes only marginally to total length its exclusion from total length was presumed to be negligible (Sainte Marie, 1992; Chapelle, 1995). 


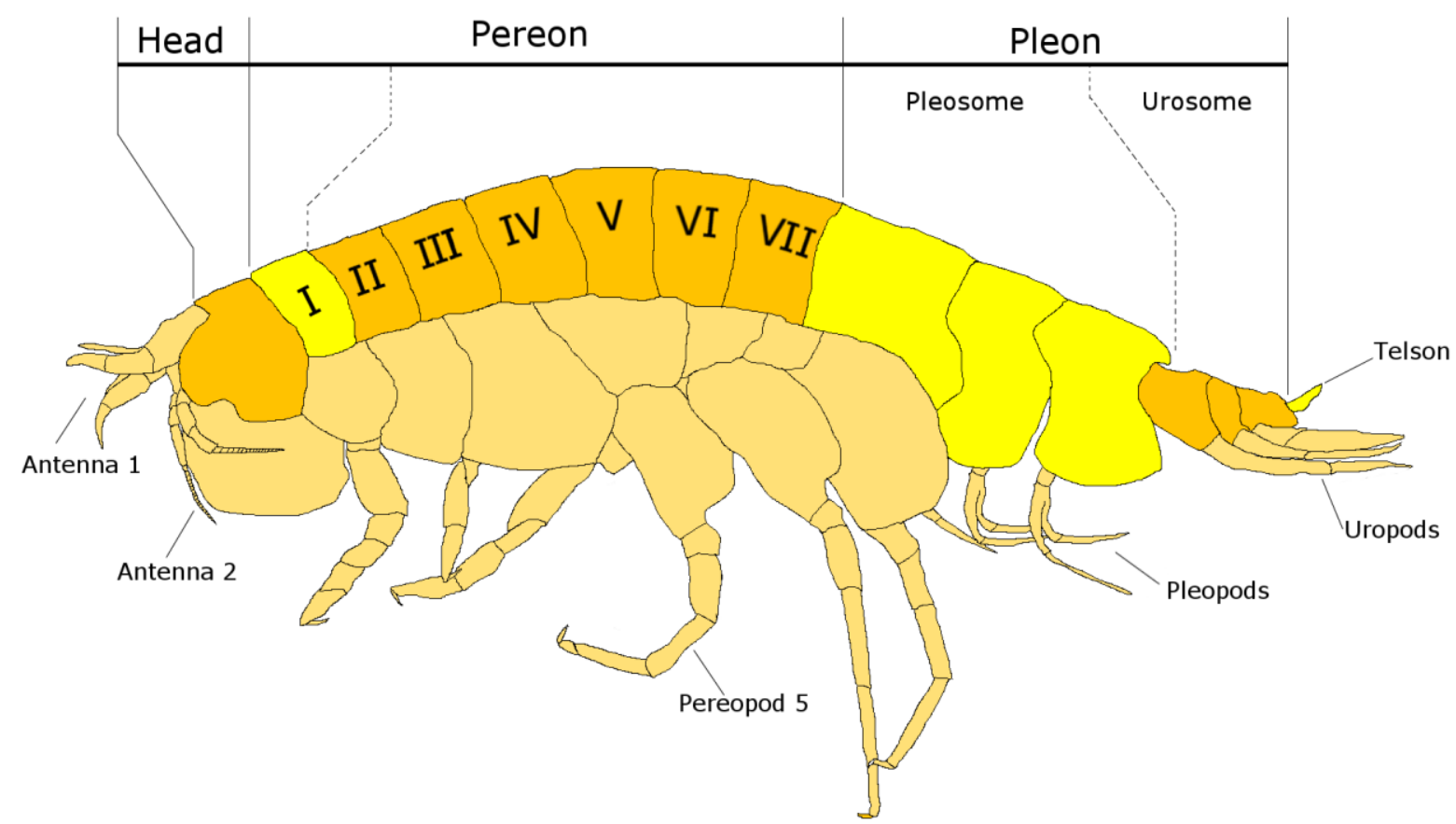

Figure 3.4: Anatomical diagram of $\boldsymbol{H}$. dubia. Measured segments are highlighted by dark orange and bright yellow (alternating for contrast), pereonites 1-7 are notated with roman numerals.

The segments measured are displayed in Figure 3.4;

- Head: From base of antenna 1 to anterior part of pereonite 1

- Pereonite 1: From anterior to posterior margins of pereonite 1

- Pereonite 2-7: From pereonite 2 to 7 in increments of 2 pereonites. i.e., 2-3,4-5,67.

- Pleosome: The three pleonites of the pleosome were measured separately then combined

- Urosome: All pleonites in urosome in one straight line from the anterior margin of pleonite 4 to the base of the telson

- Telson: From base to tip 
These segments and the method by which they were measured were chosen to maximise the accuracy of the total length estimate while optimizing the effort to measure. This approach meant using as few measurements as possible while still maintaining a high level of precision. These segments were also chosen because they were easy to observe in the small $H$. dubia and would therefore make good proxies for future studies if any of the segments provided a close correlation to total length. When individuals were damaged or missing entire segments, all possible measurements were still made, however it was noted that the individual was damaged so that it could be excluded from the data analysis at a later time.

Curvature of the dorsal aspect varied amoung individuals, and this reticulation was not possible to correct or keep consistent in the preserved amphipods without causing damage. In order to control for any exaggeration or variation in total length measurements caused by dorsal curvature, four categories ranging from 1- 4 were recorded. These categories were assigned to amphipods based on an angle calculated using imagej 1.49 (Abramoff et al 2002) from the $5^{\text {th }}$ pereon between the head and the base of the telson( Figure 3.5). An angle of $200-160^{\circ}$ was categorised into curvature rating $1 ; 160-120^{\circ}, 120-90^{\circ}$, and $<90^{\circ}$ were rated 2,3 , and 4 respectively (Figure 3.5 ).

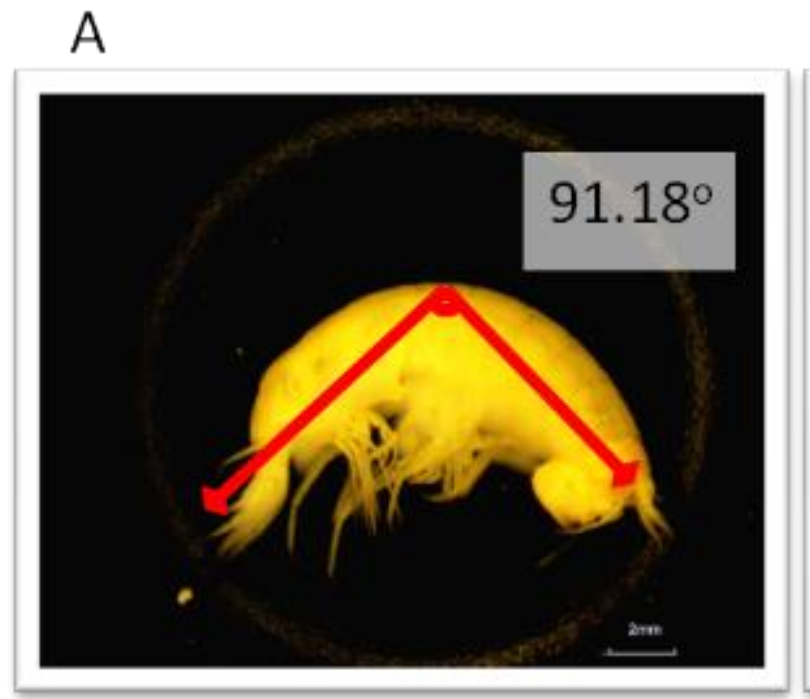

B

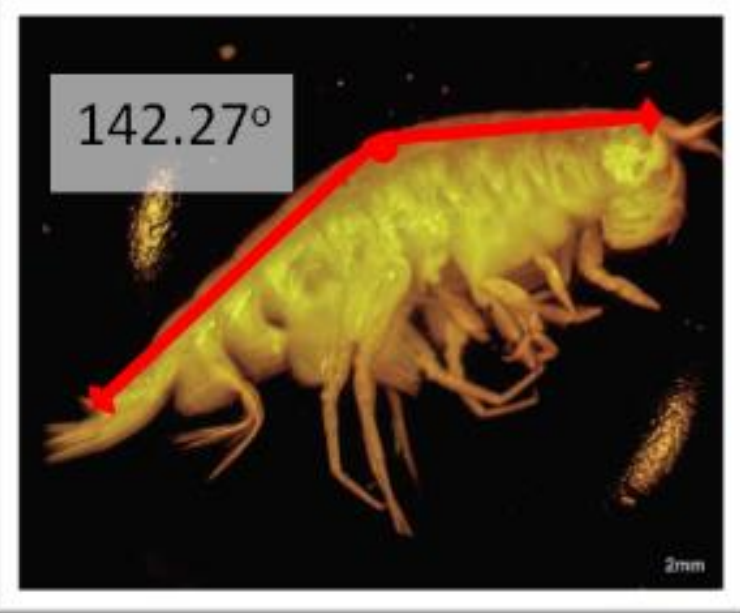

Figure 3.5: Examples of curvature recorded in $\mathbf{H}$. dubia. (A) $91.18^{\circ}$ corresponds to a curvature rating of 3. (B) $142.27^{\circ}$ corresponds to a curvature rating of 2 . 
Baited trap height off the seafloor varied between $0 \mathrm{~m}, 1.5 \mathrm{~m}$, and $1.8 \mathrm{~m}$ (see section 2.2.2). To investigate bias due to trap height off sea floor, the differences in amphipod size and abundance caught between traps of varying height were examined.

\subsubsection{Statistical analyses}

Statistical analyses were conducted using the IBM ${ }^{\circledR}$ SPSS $^{\circledR}$ statistics software (version 22.0, 2015), and all results were assessed at the 95\% confidence level unless otherwise specified. Between-groups factorial Analysis of Variance (ANOVA) and Analysis of Covariance (ANCOVA) were used to compare means in all cases when assumptions of normality and homogeneity were met. In some cases normality was only approaching significance, however after evaluating the normal Q-Q plots these cases were considered acceptable for parametric analysis.

A Pearson's chi square test of contingencies was used to evaluate sex composition. The test used the whole dataset of sexed individuals transformed into percentage data that was calculated per depth/site. Female and male lifestages were each pooled into two groups called females and males, respectively, and sexual composition was then compared between the samples from depths of $6,250 \mathrm{~m}$ and $10,800 \mathrm{~m}$.

One way between groups ANOVA were conducted to assess if curvature or trap height impacted the variability of total length, and a Tukey's HSD post hoc analysis was run to detect the nature of this relationship. If curvature or trap height had a significant effect on amphipod total length it was included as a covariate of the size structure analysis of $H$. dubia.

Factorial between-groups ANCOVA was used to analyse $H$. dubia size structure between the lifestages and between the sites at 6,250 $\mathrm{m}$ and 10,800 $\mathrm{m}$ depths. The ANCOVA was run with covariates of curvature and trap height if there was significant influence on total length. A simple effects analysis was then performed by running an ANOVA with split file groups based on lifestage. The ANOVA assessed how depth impacted the variability of total length in each lifestage. This test was interpreted at the $10 \%$ significance level to 
control for the inflation of family-wise error rates that occurs when conducting multiple comparisons on the same set of data.

A series of Pearson's partial correlation tests were run examining correlation between each of the segments and total length. The best proxy was the segment that was most descriptive of the size structure patterns detected by total length. In addition, ratios of each segment to total length were created to compare the proportion that each segment contributed to the total length. One way between groups ANOVA were run between sex and lifestage to detect variation in proxies due to sexual dimorphism. Post hoc analysis with Tukey HSD were run to detect the nature of these relationships. 


\subsection{Results}

Of the 3247 Hirondellea dubia collected, 1471 individuals were sexed, imaged, and then morphometrically analysed (Table 3.2). Of these 72 were collected from the $\sim 6,250 \mathrm{~m}$ depth, and 1399 from the $10,800 \mathrm{~m}$ depth. Specimens that displayed characters intermediate between F3 and F4 were designated F3a. No brooding females or inter-sex amphipods were captured. It was not possible to determine the sex of the juveniles.

Table 3.2: Quantity of morphometricly analysed $H$. dubia from depths and lifestages/sexes

\begin{tabular}{|c|c|c|c|c|}
\hline \multicolumn{2}{|c|}{ Sex } & $\sim 6,250 \mathrm{~m}$ & $\sim 10,800 \mathrm{~m}$ & Total \\
\hline \multirow{5}{*}{ Female } & F4 & 0 & 40 & 40 \\
\hline & $\mathrm{F} 3 \mathrm{a}$ & 2 & 140 & 142 \\
\hline & F3 & 0 & 288 & 288 \\
\hline & F2 & 4 & 420 & 424 \\
\hline & Total & 6 & 888 & 892 \\
\hline Juvenile & J & 65 & 18 & 83 \\
\hline \multirow{3}{*}{ Male } & M2 & 1 & 383 & 384 \\
\hline & M3 & 0 & 110 & 110 \\
\hline & Total & 1 & 493 & 494 \\
\hline Total & & 72 & 1399 & 1471 \\
\hline
\end{tabular}

\subsubsection{Sex and lifestage composition}

Juveniles made up $90 \%$ of the population at $\sim 6,250 \mathrm{~m}$ compared to $1 \%$ at the $\sim 10,800 \mathrm{~m}$ depth (Figure 3.6). Overall the sexual composition was significantly different between depths, $\left(\chi^{2} 2,200=1018.7, p<0.001\right)$, with $80 \%$ of the variability in composition being described by depth (Cramer's $V=0.82)$. At both depths females were more abundant than males. At the $\sim 6,250 \mathrm{~m}$ depth, females and males made up $8 \%$ and $2 \%$ respectively, while 
at $10,800 \mathrm{~m}$ depth these percentages were higher, at $63 \%$ and $36 \%$ respectively (Figure 3.6). Generally the younger lifestages (F2, J, and $M 2$ ) made up a larger proportion of individuals at both depths, with $97 \%$ at $\sim 6,250 \mathrm{~m}$ and $59 \%$ at $\sim 10,800 \mathrm{~m}$ (Figure 3.6). Furthermore, no fully mature lifestages (M3 \& F4) were recorded from 6,250 m depth.

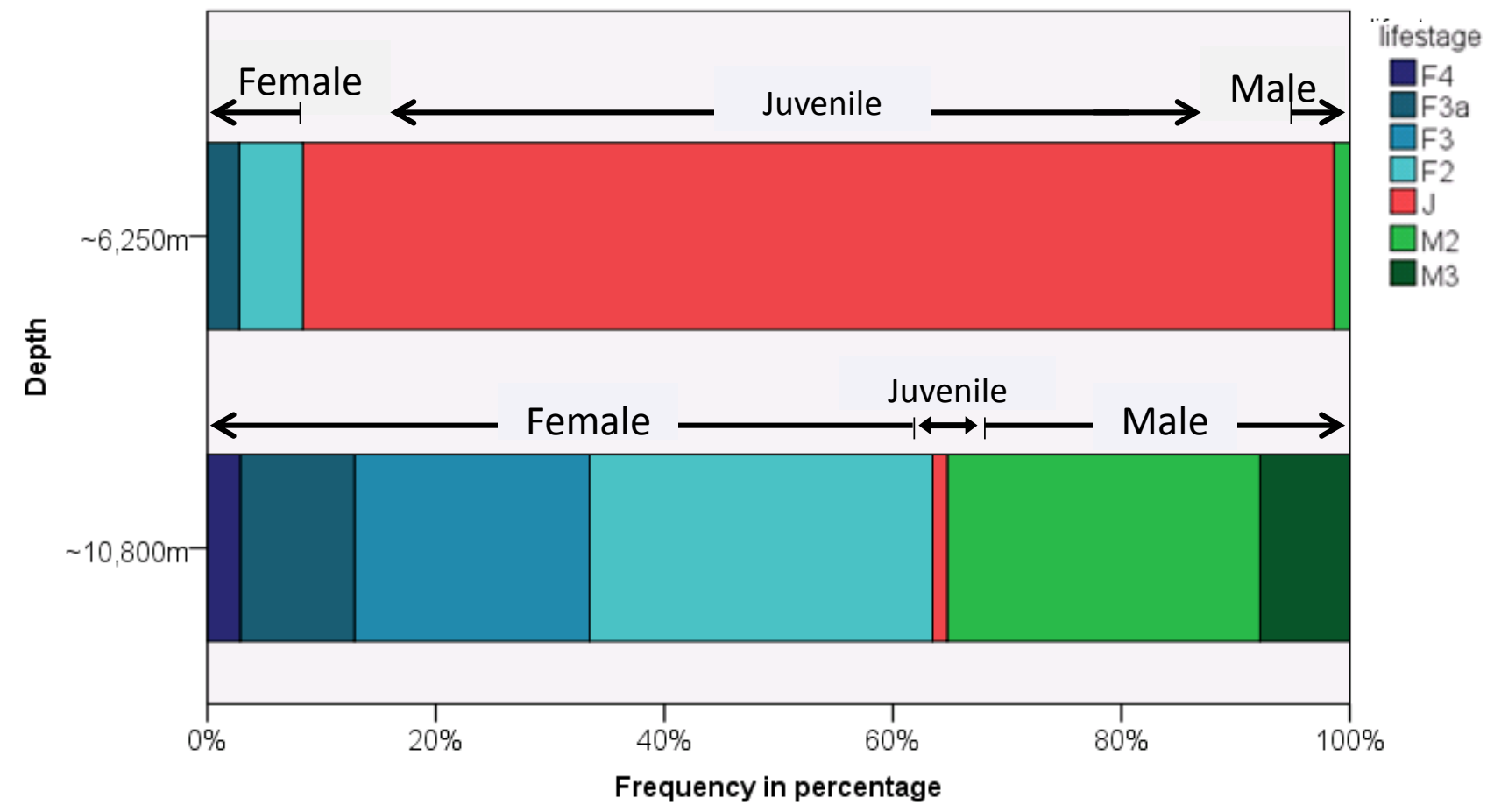

Figure 3.6: Frequency in percentage of $\boldsymbol{H}$. dubia sexes and Lifestages across two depths, $\sim 6,250 \mathrm{~m}(\mathrm{n}=72)$ and $\sim 10,800$ $m(n=1399)$.

\subsubsection{Size structure analysis}

\subsubsection{Curvature}

Amphipods with higher curvature ratings had significantly higher total lengths (Figure 3.7), $\left(F_{3,1173}=46.563, p<0.001\right)$. Individuals with curvature ratings of $1(\bar{X}=13.38, S D=2.27)$ and $2(\bar{X}=13.98, S D=2.54)$ had a significantly lower mean total length than those with curvature ratings $3(\bar{X}=15.57, S D=2.68)$ and $4(\bar{X}=16.14, S D=3.81)$. Based on this result, the effect of curvature was considered to be an important influence to include as a covariate in all analyses examining total length. 


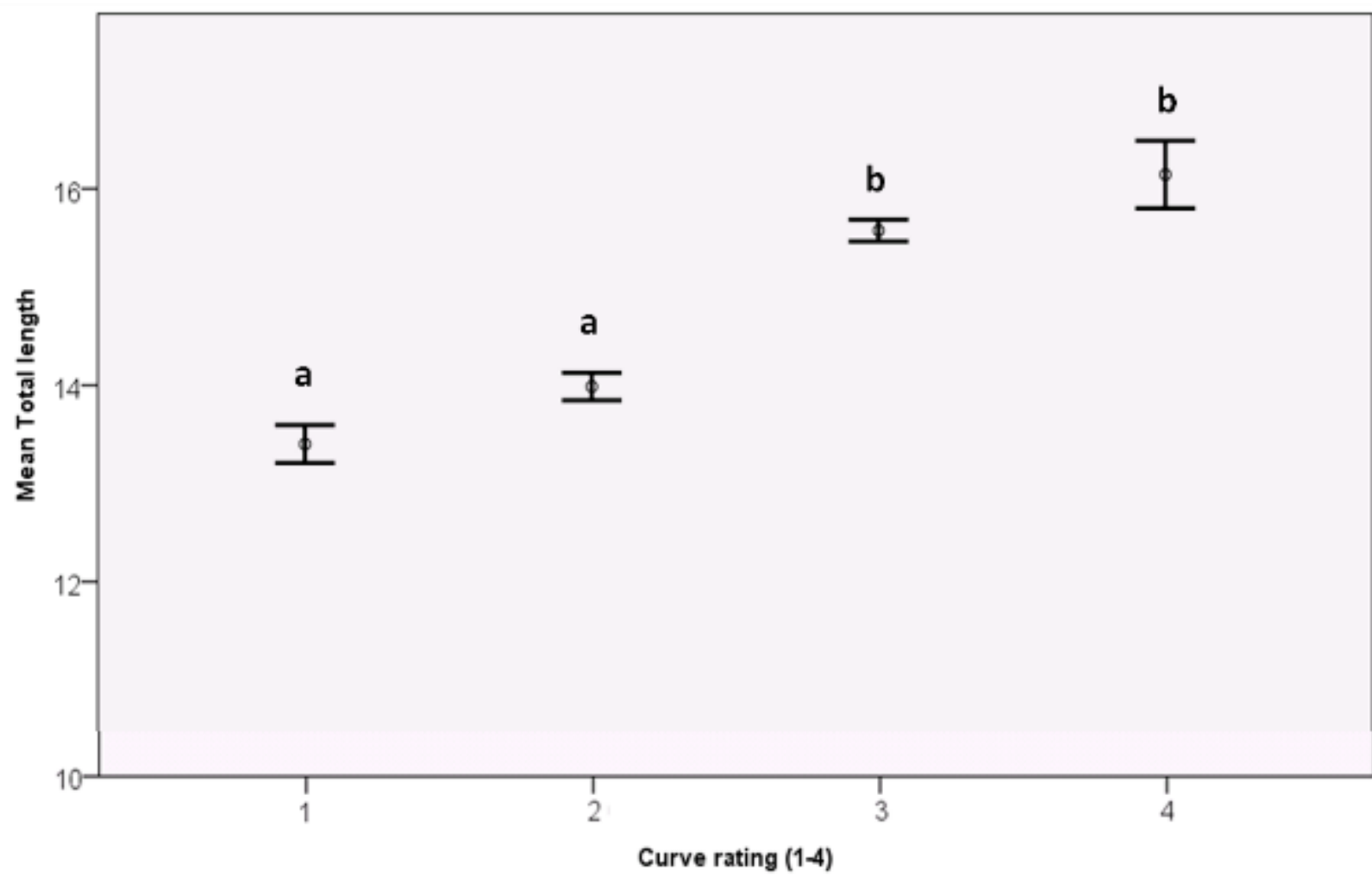

Figure 3.7: The effect of body curvature on total length of $\boldsymbol{H}$. dubia from all depths and lifestages .A Curvature rating of 1 corresponds to least curved, 4 to the greatest curvature. Error bars are standard error. Lowercase letters that are different indicate statistically significant differences at $p<0.05$.

\subsubsection{Trap height}

In order to explore bias due to trap height off the sea floor, the possible effect between samples collected at $\sim 10,800 \mathrm{~m}$ was examined (at $\sim 6,250 \mathrm{~m}$ only $1.8 \mathrm{~m}$ trap height was used). Traps set $0 \mathrm{~m}$ off the seafloor caught significantly larger amphipods $(\overline{\mathrm{X}}=15.8 \mathrm{~mm})$ than those set at $1.5(\bar{X}=14.14 \mathrm{~mm})$ and $1.8 \mathrm{~m}(\overline{\mathrm{X}}=15.11 \mathrm{~mm})\left(\mathrm{F}_{2,1130}=39.487, p<\right.$ 0.001) (Figure 3.8). The abundance of $H$. dubia also varied significantly between trap heights $\left(F_{2,10}=6.966, p<0.018\right)$. In traps at $0 \mathrm{~m}$ the mean abundance per trap was much greater than the higher $1.5 \mathrm{~m}$ and $1.8 \mathrm{~m}$ trap heights ( $\bar{X}=690$ vs 95 and 171, respectively). The mean abundances in the upper traps did not vary significantly from each other. The effect of trap height was considered to be an important influence to include as a covariate in all analyses examining total length. 

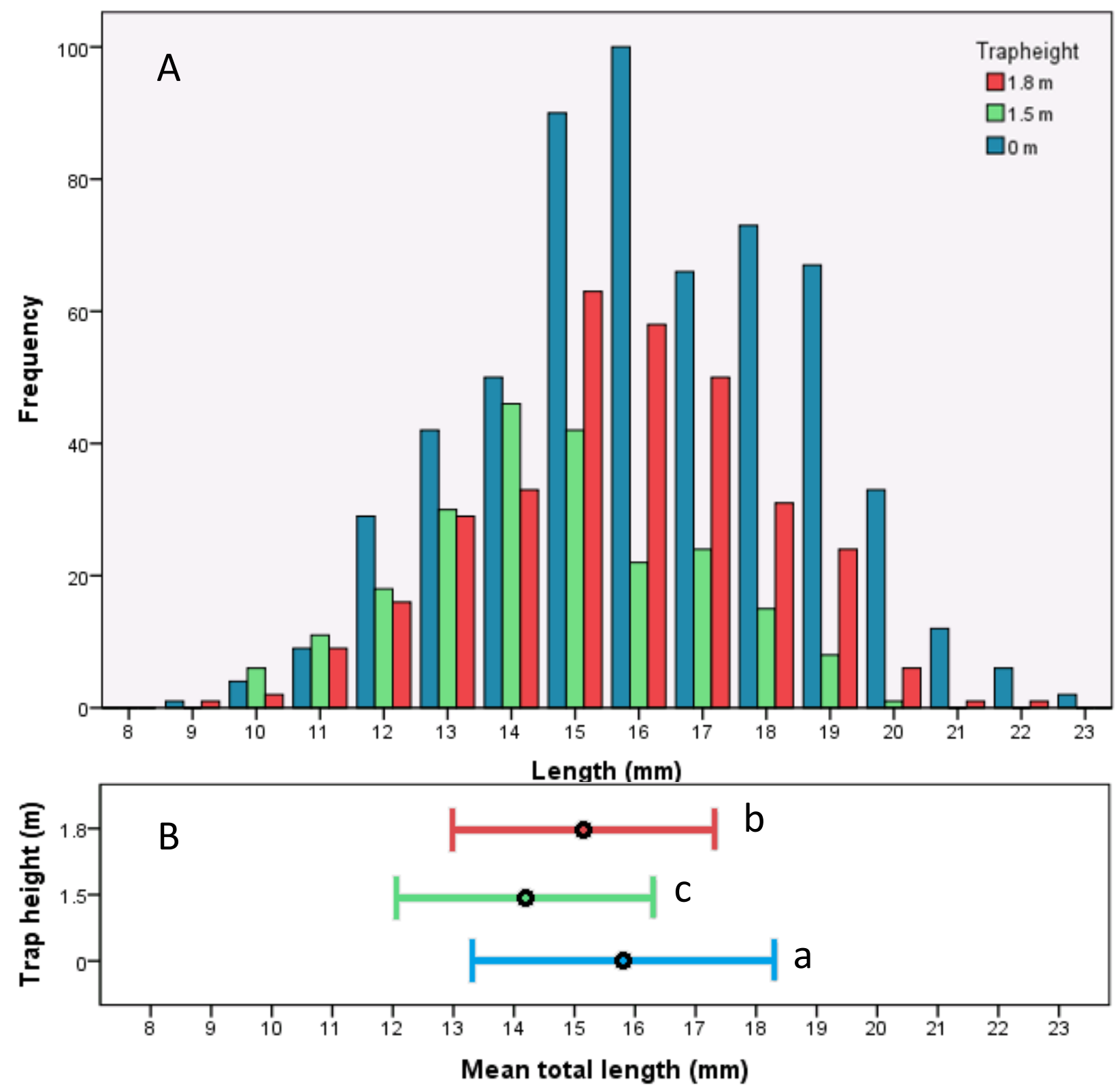

Figure 3.8: Average lengths of $\boldsymbol{H}$. dubia at trap heights at $\mathbf{1 0 , 8 0 0} \mathrm{m}$; A: Frequency bar graphs comparing trap heights 0 $\mathrm{m}$ (blue), $1.5 \mathrm{~m}$ (green), and $1.8 \mathrm{~m}$ (red). B: Error bars used are standard deviation, Lowercase letters that are different indicate statistically significant differences at $\mathrm{p}<0.05$.

\subsubsection{Size structure between depths and lifestages}

Hirondellea dubia ranged in size from $4.8 \mathrm{~mm}$ for the smallest juvenile, to $22.4 \mathrm{~mm}$ for adults, with males reaching $21.7 \mathrm{~mm}$ and females reaching $22.4 \mathrm{~mm}$ length (Table 3.3). 
Table 3.3: Length $(\mathrm{mm})$ data for each lifestage of $H$. dubia at depths of $6,250 \mathrm{~m}$ and $10,800 \mathrm{~m}$

\begin{tabular}{|c|c|c|c|c|c|c|c|c|}
\hline Depth & $\begin{array}{l}\text { Length } \\
\text { (mm) }\end{array}$ & F4 & F3a & F3 & F2 & J & M2 & M3 \\
\hline \multirow{3}{*}{$6,250 \mathrm{~m}$} & Min & \multirow{3}{*}{ na } & 14.6 & \multirow{3}{*}{ na } & 10.6 & 4.8 & \multirow{3}{*}{11.1} & \multirow{3}{*}{ na } \\
\hline & Mean & & 15.1 & & 11.3 & 6.2 & & \\
\hline & Max & & 15.7 & & 12.2 & 7.8 & & \\
\hline \multirow{3}{*}{$10,800 \mathrm{~m}$} & Min & 15 & 12.1 & 11.7 & 8.7 & 9.1 & 9.2 & 11.7 \\
\hline & Mean & 18.3 & 17.2 & 16.1 & 13.8 & 10.1 & 14.3 & 16.5 \\
\hline & Max & 22 & 22.4 & 22.4 & 19 & 11.1 & 21.7 & 19.9 \\
\hline
\end{tabular}

The total lengths of $H$. dubia at $\sim 10,800$ m depth $(\bar{X}=15.26)$ were significantly greater than at $6,250 \mathrm{~m}(\overline{\mathrm{X}}=6.98),\left(F_{1,1164}=16.2, p<0.001\right)$ (Figure 3.9). Total length also varied significantly among lifestages, $\left(F_{6,1164}=80.549, p<0.001\right)$, each lifestage was distinct in size from the lifestage that came before it, for example, F3 and M3 were significantly larger than $\mathrm{F} 2$ and $\mathrm{M} 2$ respectively. In addition, the mean total length of lifestages $\mathrm{M} 2$ and F2 were not significantly different from each other. Similarly, the male M3 was not distinct from female lifestages F3 and F3a (Figure 3.9; Table 3.3).

The change in average size between depths was significantly greater in juveniles $(\mathrm{J})$ and $\mathrm{M} 2$ than in the other lifestages. This significant interaction $\left(F_{3,1164}=2.968, p=0.03\right)$, was further examined by a simple effects analysis to determine the nature of this relationship. The combination of depth and lifestage significantly influenced the between-depth difference between some of the lifestages; J $\left(F_{1,1164}=70.155, \mathrm{p}<0.01\right)$, and M2 $\left(F_{1,1164}=\right.$ $6.776, p<0.01$ ) were significantly smaller in the $\sim 6,250 \mathrm{~m}$ compared to the $\sim 10,800 \mathrm{~m}$ depth, relative to differences between depths seen in lifestages F2 and F3a.

Female growth rates were analysed from F2-F4. Juveniles could not be sexed in the present study and were therefore excluded from sex-based growth rates. The rate of growth in females appears log-linear as there is a decrease in percentage growth with 
increasing developmental stage. Female growth decreased from a $16 \%$ increase between stage 2-3 to a $6 \%$ increase in total length between stages 3-5 (Figure 3.9); male growth rate was not projected given that only 2 stages in male growth could be distinguished in the present.

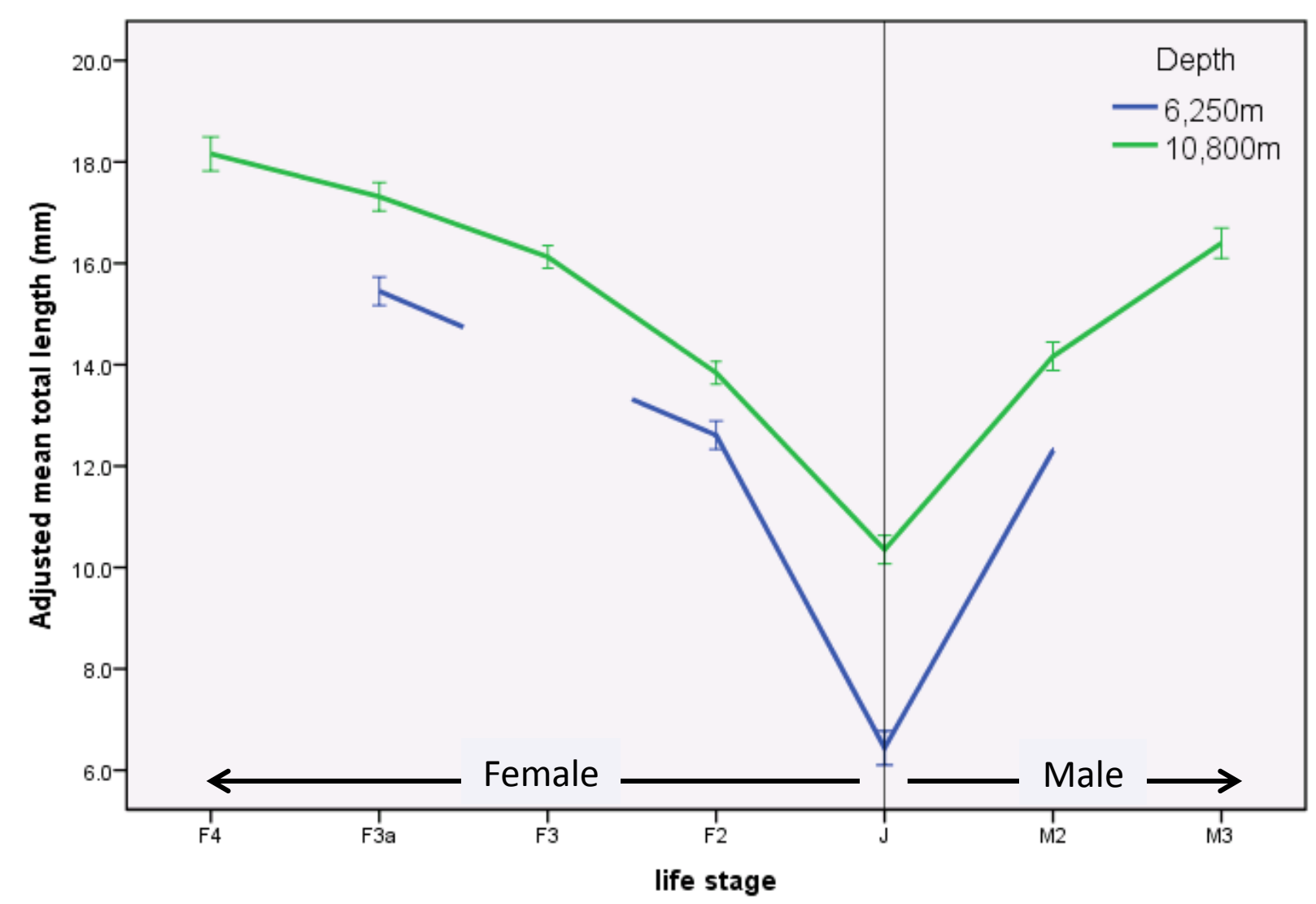

Figure 3.9: Profile plot of $\boldsymbol{H}$. dubia size structure across depths and lifestages. The adjusted mean total length on the $y$ axis is an estimated value based on the influence of covariates. Covariates appearing in the graph are evaluated at the following values: Curve rating $(1-4)=2.591$, trapheight $(\mathrm{m})=0.850$. Means of lifestages absent from the $\sim 6,250 \mathrm{~m}$ site were non-estimable and were not plotted. Error bars are standard error.

\subsubsection{Proxy Analysis}

\subsubsection{Total length correlation}

The diameter of the $4^{\text {th }}$ coxa has been used previously as a proxy for total length (Blankenship et al., 2006; Eusstace et al., 2013), however the $4^{\text {th }}$ coxa could not be 
measured as a proxy in the present study because it was often damaged and difficult to photograph with clarity.

The combined depth data indicated that the strength of the correlation between segment and total length increased with a segment's average length. Consequently the two longest segments, pereonite 2-7 and pleosome, were the most descriptive of total length (Table 3.4). These correlations did not vary with depths, however the segments did vary significantly in relative size between sexes (see section 3.3.3.2).

The three strongest correlating segments, pereonite 1, pereonite 2-7, and pleosome, were examined more closely to evaluate their efficiency as proxies by running the same factorial between groups ANCOVA used to analyse differences in lifestage size structure of $H$. dubia between depths (see section 3.2.4 and Figure 3.9).

Table 3.4: Correlations between $H$. dubia segments and total length in $\mathrm{mm}$

\begin{tabular}{|c|c|c|c|c|c|}
\hline & Head & Pereonite 1 & Pereonite 2-7 & Pleosome & Urosome \\
\hline $\begin{array}{c}\text { Person's } \\
\text { correlation }\end{array}$ & 0.819 & 0.851 & 0.953 & 0.902 & 0.819 \\
\hline $\boldsymbol{p}$ Value & $<0.001$ & $<0.001$ & $<0.001$ & $<0.001$ & $<0.001$ \\
\hline $\mathbf{N}$ & 1177 & 1177 & 1177 & 1177 & 1177 \\
\hline
\end{tabular}

All of the proxies showed results that varied to some degree from the original analysis on size structure (Compare Figure 3.10 A, B, and C, with Figure 3.9). Pereonite 1 most closely resembled the pattern in the original analysis with length significantly varying between depth $\left(F_{1,1164}=10.657, p=0.001\right)$ and lifestage $\left(F_{6,1164}=44.444, p<0.001\right)$, the only difference being the interactive effect of depth and lifestage, which was not significant $\left(F_{3}\right.$, $1164=1.959, p=0.118)$. A simple effects analysis on the pereonite 1 revealed the same pattern as the original analysis, with $\mathrm{J}$ and $\mathrm{M} 2$ showing the largest difference in size between depths and all life stages at the deep site significantly larger than at the shallow 
site (Figure 3.10A). Pereonite 2-7 varied from the original analysis substantially. Depth had no significant effect on pereonite 2-7 length $\left(F_{1,1164}=3.062, p=0.080\right)$ (Figure 3.10B). Pleosome length varied significantly with depth and lifestage, $\left(F_{1,1164}=21.58, p<0.001\right)$ and $\left(F_{6,1164}=53.9, p<0.001\right)$ respectively. The key difference between the pleosome and total length analysis was the patterns extracted from the simple effects analysis. Female lifestage F3a demonstrated the largest difference in size between depths ( $F 3 a, F=22.808$; $F 2, F=6.709$ ) (Figure 3.10C).

Curvature had a significant influence on total length (Figure 3.9) and all three of the proxies examined here: pereonite $1\left(\mathrm{~F}_{3,1173}=6.662, p<0.001\right)$; pereonite 2-7 $\left(\mathrm{F}_{3,1173}=\right.$ 85.541, $p<0.001)$; and pleosome $\left(F_{3,1173}=19.766, p<0.001\right)$. In all cases, increasing curvature generally correlated to increasing length, however the strength of this relationship varied between segments. $10 \%$ of the variability in total length could be attributed to curvature, (Eta-Squared, $\left.N^{2}=0.106\right)$, which is a medium-large effect (Cohen, 2013). In pereonite 1 , this variation was at its smallest, only $1 \%$ of the variability in total length could be attributed to curvature, (Eta-Squared, $N^{2}=0.017$ ), which is a small effect (Cohen, 2013). There was a large effect of calculated body length with Pereonite 2-7 where almost $20 \%$ of the variability was associated with curvature, (Eta-Squared, $N^{2}=$ 0.179) (Cohen, 2013). Finally the pleosome demonstrated a medium amount of variability caused by curvature, (Eta-Squared, $\left.N^{2}=0.048\right)$ (Cohen, 2013). 

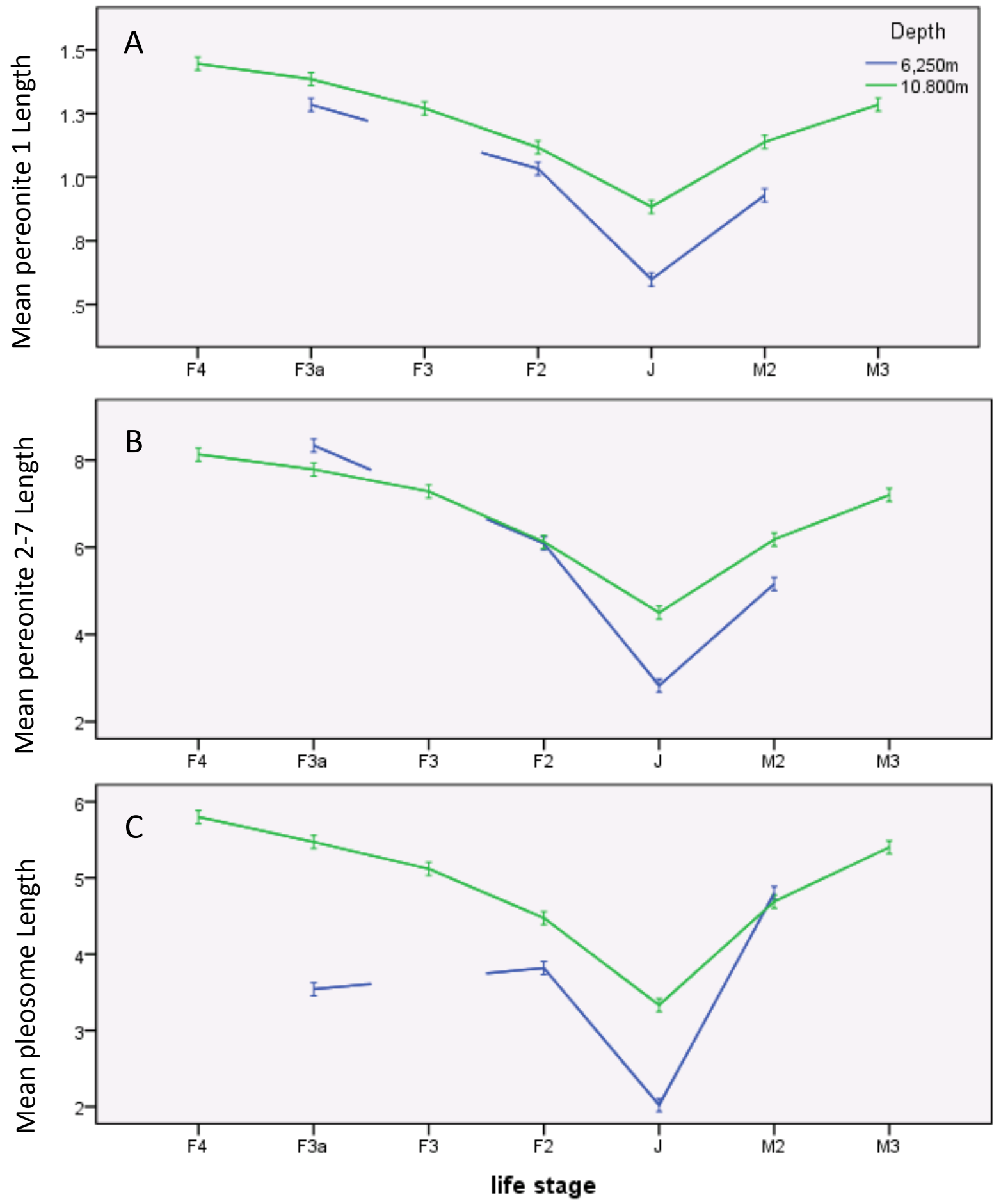

Figure 3.10: Profile plot of $\boldsymbol{H}$. dubia size structure across depths and lifestages using potential proxies, mean segment length on all y axes is an estimated value based on influence of covariates. Covariates appearing in the model are evaluated at the following values: Curve rating $(1-4)=2.591$, trapheight $(\mathrm{m})=0.850$. Means of lifestages absent from the $\sim 6,250 \mathrm{~m}$ site were non-estimable and were not plotted. Error bars are standard error. 


\subsubsection{Total-length ratio comparisons across lifestages}

The segments of pereonite 2-7 and pleosome contributed the most to amphipod total length (Figure 3.11); however the relative proportion that each segment contributed to total length varied between sexes and lifestages.

Head length made up a significantly greater proportion of total length in younger lifestages, $\left(F_{6,1170}=5.929, p<0.01\right)$ (Figure 3.11B). Juveniles $(J)$ had a significantly higher ratio of head to total length than that of lifestages F3, F3a, F4, and M3. The lifestage F4 had the lowest mean ratio, and was significantly smaller than the lifestages F2 and J.

Pereonite 1 length made up a significantly greater proportion of total length in juveniles (J) than in any other lifestage, $\left(F_{6,1170}=9.361, p<0.001\right.$; Figure 3.11C). The ratio of pereonite 1 to total lenght was statistically the same in all other lifestages (Figure 3.11C).

In Figure 3.11(D and E) lifestages were pooled by sex because the proportion that pereonite 2-7 and the pleosome contributed to total length did not differ significantly within lifestages of female or males. Pereonite 2-7 length made up a significantly greater proportion of total length in females than in juveniles $\left(F_{2,1174}=10.733, p<0.001\right.$; Figure 3.11). Pleosome length made up a significantly greater proportion of total length in males than in females $\left(F_{2,1174}=20.193, p<0.001\right.$; Figure 3.11).

Urosome length made up a significantly different proportion of total length between lifestages, $\left(F_{6,1170}=4.686, p<0.001\right)$. $F 3$ a had a significantly higher ratio of urosome to total length than that of the $J$ and $M 2$ lifestages, but no further significant difference was detected between any other lifestage. Figure 3.10 contains all the Tukey results for the head, pereonite 1, pereonite 2-7, and pleosome analysis, with significantly similar groupings are annotated with a shared lowercase letter. 

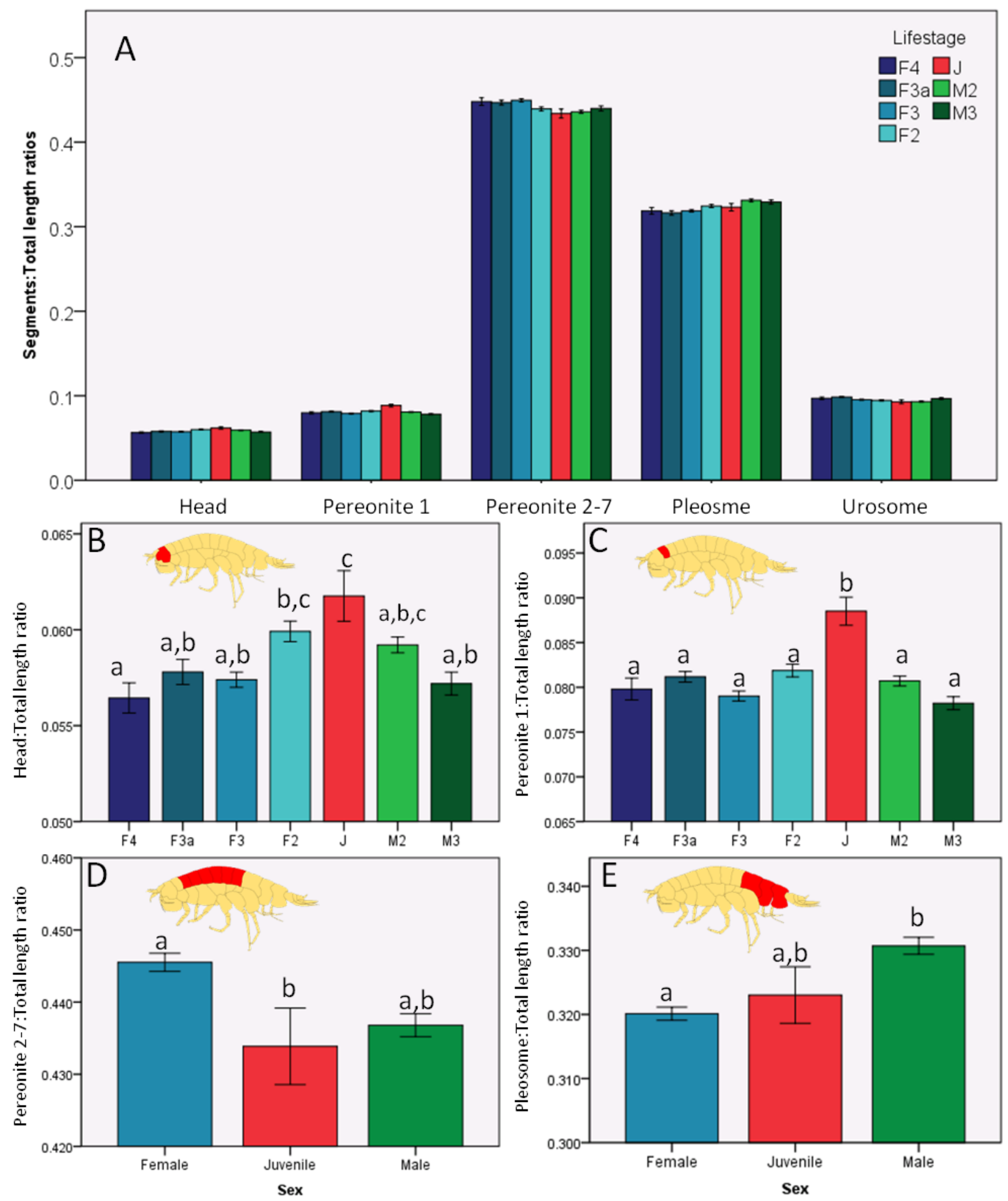

Figure 3.11: Ratios of segments:total length across lifestages and sexes. Shades of blue represent female lifestages, red represents juveniles, and shades of green represent male lifestages. In D and E, lifestages are combined into groups based on sex. In B, C, D, E: Insert highlights in red the segment being compared to total length. The results of a Tukey pairwise analysis are displayed with lowercase letters signifying significantly distinct groups, all erorr bars are standard erorr. 


\subsection{Discussion}

\subsubsection{Population structure}

The results of the present study support the current understanding that $H$. dubia exhibits ontogenetic vertical distribution. At the uppermost extent of $H$. dubia's vertical range in the Tonga Trench $(\sim 6250 \mathrm{~m})$, the proportion of juveniles was much greater than at $\sim 10,800 \mathrm{~m}$. In addition, no fully mature lifestages (M3, F4) were found at the $\sim 6,250 \mathrm{~m}$ depth, and the proportion of younger lifestages (F2, J, M2) was higher at both depths.

Hadal amphipods have typically been collected from only one site or depth within a trench, and ontogenetic structuring has likely been overlooked (Hessler et al., 1978; Perrone et al., 2002; Thurston et al., 2002). More recently, studies sampling across a range of depths have revealed ontogenetic structuring in Hirondellea gigas, a necrophagous amphipod that inhabits depths exceeding 6,500 $\mathrm{m}$ in the Mariana Trench in the north east Pacific Ocean (Eustace et al., 2013). Ontogenetic vertical structuring has also previously been examined in H. dubia in the Tonga Trench (Blankenship et.al., 2006). The present study adds two more depths to the analysis of $\mathrm{H}$. dubia population structure, and both of the new depths most likely represent the limits of $H$. dubia's vertical range in the Tonga Trench and are therefore valuable in uncovering distribution patterns and the drivers behind them (Blankenship et al., 2006; Jamieson et al., 2011).

A number of factors may be driving forces of ontogenetic structure in hadal depths: hydrostatic pressure, dissolved oxygen, salinity, temperature, and food availability are all environmental variables that can control distribution in marine fauna. Hydrostatic pressure has required significant adaptation for species to inhabit the deeper depths of the oceans especially in the hadal environment (Somero, 1992; Tamburri and Barry, 1999). For example, amphipod metabolic rate slows down with increasing pressure/depth (Blankenship et al., 2006, Jamieson et al., 2010, Eustace et al., 2015). Hirondellea spp. are the only amphipods found at depths exceeding $9 \mathrm{~km}$ and their known vertical range now exceeds $4.5 \mathrm{~km}$ of depth, and this range is among the top $15 \%$ largest of all hadal fauna, demonstrating the genus is well adapted to pressure (Beliaev \& Brueggeman, 1989; 
Blankenship et.al, 2006; Jamison et al., 2011). However, adaptation to hydrostatic pressure is common (Wolff, 1960; Somero, 1992; Jamieson et al., 2010), and pressure by itself has a greater impact on the distribution of shallow water organisms than on deep sea species (Beliaev \& Brueggeman, 1989). This is because the relative change in pressure is much larger at the surface where a small distance can increase pressure by many orders of magnitude (Jamieson et al., 2010). H. dubia's tolerance to a range of hydrostatic pressures in tandem with the presence of juveniles at both depths is a strong indicator that pressure alone does not drive ontogenetic structuring; instead a combination of pressure and other trench variables may be more likely (Blankenship et.al., 2006; Eustace et al., 2013).

Circulating deep ocean water masses, such as the Lower Circumpolar Deep Water (LCDW) current, prevent the waters in hadal depths from becoming stagnant (Warren, 1981; Johnson, 1998; Siedler et al., 2004; Seibel and Drazen, 2007; Jamieson et al., 2010); the LCDW current thereby ensures that dissolved oxygen is not a limiting factor to Tongan Trench scavenging amphipods like $H$. dubia. Temperature usually decreases with increasing depth (Wolff, 1960), however this relationship changes at depths greater than $4 \mathrm{~km}$ because temperature slowly rises with depth due to increasing pressure (adiabatic heating, Jamieson et al., 2010). A $\sim 1^{\circ} \mathrm{C}$ increase in temperature from depths of $\sim 6,250$ to $\sim 10,800$ has been observed in the Tonga Trench (Jamison et al., 2011; Fujii et al., 2013). Although changes in temperature impair the vertical distribution and migrations of deep sea biota (Danovaro et al., 2004), such an increase is small and is unlikely to be the lone driver of ontogenetic distribution patterns for H. dubia (Danovaro et al., 2004; Gibson et al., 2005).

Below $4000 \mathrm{~m}$, salinity near the seafloor generally remains constant at between 34-35 PSU (Tyler, 1995), which is very similar to that of the abyssal plain depth. Consistent salinity levels make it unlikely that salinity strongly influences vertical distribution of amphipods at hadal depths (Beliaev \& Brueggeman, 1989; Tyler, 1995). 
All of the described environmental variables are relatively stable in the hadal environment. In addition, ontogenetic vertical structuring appears to be a pattern exclusive to scavenging benthopelagic amphipods (Blankenship et al., 2006; Jamieson et al., 2010). The lack of this structuring in non-benthopelagic scavengers suggests that food distribution may have a larger influence in driving this pattern of population structure (Eustace et al., 2013). The distribution of food sources varies throughout the trench environment (Wolff, 1960; Tyler, 1995; Thurston et al., 2002). Although exceptions such as in situ chemosynthesis are possible in trenches (Fujikura et al., 1999; Rathburn et al., 2009; Ohara et al., 2012), most food is derived from waters above the hadal environment in the form of particulate organic matter (POM) or larger carrion falls (Stockton and DeLaca, 1982; Fabiano et al., 2001; Honjo et al., 2008; Romankevich, 2009). The latter loses relatively little nutrient value during descent through the water column, because the large surface area to volume ratio of a carcass prevents pelagic heterotrophic bacteria and zooplankton from exploiting all the high quality organic matter (Christina and Passow, 2007; Buesseler and Boyd, 2009). In contrast, POM usually decreases in nutrient value and quantity with depth due to longer exposure to heterotrophic organisms (Sokolova, 1994; Jamieson et al., 2010; Eustace et al., 2013). In a trench environment, the sharp angle of the trench slope influences the sedimentation process resulting in organic matter (i.e., POM and carrion falls) accumulating at the deepest point of the trench, the axis. This produces a pattern of increasing detritus quantity with depth (Sokolova, 1994; Jamieson et al., 2010; Glud et al., 2013). The accumulation of organic matter at the axis of a trench could also be supplemented by independent seismic activity causing mass movement of organic matter down the slope of a trench (Itou et al., 2000; Itou et al., 2011). Such displacement of organic sediment has been reported in various trenches in the northwestern pacific trenches (Itou et al., 2000; Itou et al., 2011; Eustace et al., 2013).

Sedimentation of organic matter to the trench axis may be depriving the trench slopes of organic matter (Jamieson et al., 2010), and if this is the case we expect to observe fewer sediment-dependent detritivores on the slopes of trenches. Hirondellea dubia rely more heavily on detritus at the trench axis (Blankenship and Levin, 2007), and data from the 
present study show that the abundance of amphipods was much higher at the axis of the trench compared to the outer slope. Stable isotope analysis showed that juvenile $H$. dubia rely heavily on detritus on the upper slopes of trenches (Blankenship and Levin, 2007), and as they mature and migrate to the intermediate depths, the reliance on detritus decreases. However, in mature $H$. dubia at the trench axis this reliance on detritus seems to increase again (Blankenship and Levin, 2007). Therefore the middle of the trench slope may represent a POM deprived habitat while the shallower depths of the trench are still able to support detritivores due to the higher quality of POM at these depths (Honjo et al., 2008; Romankevich, 2009). Mature H. dubia may occupy greater depths to benefit from the increase in detritus quantity, while juveniles may dominate shallower depths to benefit from higher quality POM.

While the number and proportion of juveniles was much greater at $6,250 \mathrm{~m}$, the difference in juvenile size between depths was significantly greater than in other lifestages. Juveniles at 6,250 $\mathrm{m}$ were smaller than expected based on the decreases observed in other lifestages with depth. The rate of growth should be higher for juveniles in the shallower $6,250 \mathrm{~m}$ depth because the POM is higher in quality and their metabolic rate is faster (Blankenship et.al, 2006; Romankevich, 2009). Therefore juveniles at the $\sim 6,250 \mathrm{~m}$ depth may be younger than those recorded at the $\sim 10,800 \mathrm{~m}$ depth. This suggests that ontogenetically distributed $H$. dubia migrate to greater depths with age (Eustace et al., 2013).

In Blankenship et al.'s (2006) study in the Tonga Trench, H. dubia male to female sex ratios were $1: 1$ between the depths of 7,349 and 10,787 $\mathrm{m}$, while at 9,000-10,000 $\mathrm{m}$, the proportion of females increased. However, beyond $10,000 \mathrm{~m}$ the ratio of males to females returned to 1:1 (Blankenship et al., 2006). The present study indicates that trend of increasing proportion of females continues to the deepest extent of $H$. dubia's known range $(10,800 \mathrm{~m})$. The change in sex ratio between the depths of $9,000-10,000 \mathrm{~m}$ needs to be further examined, although it is likely that the change in this ratio at these depths is associated with reproduction (Thurston et al., 2002; Ingram and Hessler, 1987). Data from 
the present study suggest that the ideal mating depths may cover the deepest part of $H$. dubia's vertical range.

The mechanism by which juveniles are ontogenetically distributed to the shallower depths of their range is still uncertain (Blankenship et al., 2006). Either the ovigerous females migrate to shallower waters to disperse broods of juveniles (Eustace et al., 2013), or after dispersing the brood at the greater depths, the juveniles migrate to shallower waters unaided. For juvenile amphipods to make this migration, a large amount of lipids would need to be consumed in an environment where the quality of POM is low (Sokolova, 1994; Honjo et al., 2008). The alternative theory requires mature females to consume enough carrion to make the migration themselves; this seems more likely given that under greater hydrostatic pressure, maturing females will experience a slowed metabolism, facilitating behavior to wait between nutrient-rich carrion falls (Blankenship et al., 2006). The gathering of these food reserves are of particular importance because brooding $H$. dubia do not attend bait and therefore may not be feeding during the oviparous period (Blankenship et al., 2006). However because no brooding $H$. dubia or any Hirondellea spp. have been captured to date (Blankenship et al., 2006; Eustace et al., 2013; Fujii et al., 2013; Horton and Thurston, 2013), it is difficult to determine these processes with confidence.

Interspecific interactions may be partially responsible for vertical stratification of hadal scavenging species (Ingram and Hessler, 1983; Iken et al., 2001; Blankenship and Levin, 2007), and this may also be influencing vertical stratification between lifestages of $H$. dubia. The species is the only bait attending fauna at depths exceeding 9,000 $\mathrm{m}$, allowing them to exclusively exploit large carrion falls that reach this depth (Blankenship et al., 2006). However, the quality of POM is lower at these depths, and juveniles lack the fatty reserves of mature $H$. dubia to sustain themselves between the nutrient rich carrion events (Blankenship and Levin, 2007; Christina and Passow, 2007). Large predators such as decapods and fish have been observed in shallower hadal depths (Jamieson et al., 2009a; Jamieson et al., 2009b; Jamieson et al., 2011), but these predators may 
preferentially target larger prey items that provide greater energy return (Eustace et al., 2013). In this way, small H. dubia juveniles may avoid predation and take advantage of the higher quality POM at shallower depth, migrating to greater depths as they grow to avoid these predators. Thus, interspecific interactions may provide a driver for ontogenetic stratification in H. dubia.

Traps set at the sea floor $(0 \mathrm{~m})$ captured at least three times the number of $H$. dubia than those set at 1.5 or $1.8 \mathrm{~m}$, and the average amphipod size was significantly larger at these 0 $\mathrm{m}$ traps. One explanation for this pattern may be the partitioning of foraging strategies, where larger (older) individuals outcompete smaller individuals at carrion falls on the sea floor. Another hadal amphipod Eurythenes gryllus (Lichtenstein, 1822) displays partitioned vertical distribution, with individuals moving upwards in the water column with increases in body size, thereby transitioning to a more pelagic lifestyle (Ingram and Hessler, 1987; Christiansen et al., 1990; Jamieson et al., 2011). The mechanisms that attract high numbers of amphipods to bait appears to be highly specific, as amphipods may swarm particular pieces of baits while almost ignoring adjacent baits (Hessler et al., 1978). Future studies would benefit from analyzing how these mechanisms contribute to this stratification of amphipods sizes in differing trap heights. If a trend of increasing size with proximity to sea floor is expected, amphipods collected from the $1.5 \mathrm{~m}$ trap heights should be larger and more abundant that those collected in $1.8 \mathrm{~m}$ traps, however the opposite was the case in the present study, although the differences were very small (1-2 $\mathrm{mm}$ ). One explanation for this may lie in the methodology employed during sampling. Although all $1.8 \mathrm{~m}$ traps were deployed independently, traps of heights 0 and $1.5 \mathrm{~m}$ were always deployed together, this may have provided a choice for the amphipods attending the bait at these traps. The choice between the two trap heights probably exaggerated any difference in sizes and abundances. Previous samplings have been taken at a single trap height off the sea floor, or combined data across a variety of trap heights to represent a single sample (Ingram and Hessler, 1987; Fujii et al., 2013), and may have overlooked the influence of trap height. 


\subsubsection{Proxy analysis}

Curvature has long been an issue in accurately measuring total amphipod length (Skadsheim, 1982; Beuchel and Lønne, 2002; Thurston et al., 2002; Chapelle and Peck 2004; Arndt and Beuchel, 2006). Curvature describes the articulation of segments along an amphipod's dorsal aspect, and the resulting telescoping of these segments influences the perceived length, thereby making true body length of amphipods difficult to define with certainty (Skadsheim 1982, Chapelle, 1995). In the past, solutions to the issue of curvature included labour intensive methods such as measuring an individual's full length three times to get an average (Thurston et al., 2002), or extracting eyes to be used as a proxy (Von Westernhagen, 1976). An effective proxy should be representative of total length and display similar patterns in population size structure when analyzed, and it is therefore important to use a segment that is not sexually dimorphic. A good proxy should also require little prior experience or skill, and be easy to see and measure, even in lower resolution images or in individuals that have been damaged.

Despite being the measurements with the highest correlation to total length, pereonite 27 and the pleosome are considered poor proxies to use in future research. In both these measurements, the variability of segment length due to curvature was substantial, at 20 and $5 \%$ for pereonite $2-7$ and the pleosome respectively. These sections contain many overlapping segments so it is not surprising to observe such a large effect, and the high correlation of these segments is probably exaggerated due to total length not being adjusted for curvature. Pereonite 2-7 yielded some substantially different results in the simulated size structure analysis, the major difference being that the size of pereonite 2-7 did not vary significantly with depth. This inaccuracy can be attributed partially to the larger variance caused by the larger influence of curvature but also to the variation between sexes observed. A larger pereon has been recorded for females in the past, and this difference is likely associated with reproduction as the pereon must be large enough to provide protection and support for brooding (Hessler et al., 1978; Arndt and Beuchel, 2006). The pleosome also yielded variable results from the simulated size structure analysis, and these differences may also have been driven by variations between sexes. 
Males had significantly larger pleosomes than females and juveniles, and this dimorphism may be necessary to support the male gonads on this section (Hessler et al., 1978; Arndt and Beuchel, 2006). Both the pereonites 2-7 and pleosome measurements displayed a level of sexual dimorphism that makes them inappropriate as proxies.

The head and urosome were not further analyzed as proxies in the present study, although these segments have been used in estimates of total length in the past (Bourdillon, 1960; Von Westernhagen 1976; Chapelle, 1995). In the present study the correlation found between total length and the head/urosome segments was low in both cases. When examining the proportional length of these segments between lifestages, the proportion length of the head decreased with maturity, while the urosome showed the opposite trend. These patterns of growth are not specific to sex, however they do still make these segments unreliable as proxies.

When pereonite 1 was used in the simulated size structure analysis the interaction between depth and lifestage approached significance, and the general trends were the same as for the total length analysis. This segment has been used as a proxy in the past (Skadsheim, 1982; Beuchel and Lønne, 2002; Thurston et al., 2002; Chapelle and Peck 2004; Temperoni et al., 2004; Arndt and Beuchel, 2006), where the preonite 1 segment often had a very high correlation with total length (e.g. Thurston et al., 2002). Thurston et al. (2002) recorded an $\mathrm{R}^{2}=0.95$, whereas the correlation in the present study was much lower $\left(R^{2}=0.72\right)$, and this is likely due to the higher resolution at which the data were gathered in the present study; measurements were from 393 individuals in Thurston et al. (2002) compared to 1,177 for pereonite 1 in the present study. Amphipod length is sometimes used to define lifestages and to detect instars (Stebbing and Thomas, 1919; Hessler et al., 1978; Chapel, 1995), therefore disproportionately large juveniles may compromise the resolution of these distinctions. However the pereonite 1 proxy requires only a single measurement (from anterior to posterior dorsal margins), and studies that use a proxy composing of one segment have typically had more success in accurately detecting instars in a species (Chapelle, 1995). 
The diagonal length of the $4^{\text {th }}$ coxa is another commonly used proxy in size structure analyses (Blankenship et al., 2006 Eustace et al., 2013; Fujii et al., 2013). Chapelle (1995) argues that the $4^{\text {th }}$ coxa is more conspicuous and easier to measure than the first pereonite, however the $4^{\text {th }}$ coxa is quite a distinct feature of the Waldeckia obese (Chervreux, 1905) used to test these proxies Chapelle (1995). In many amphipods, pereonite 1 is more conspicuous and is less likely to be hidden or damaged during collection.

\subsubsection{Conclusions}

The ontogenetic vertical structuring of $\mathrm{H}$. dubia in the Tonga Trench is confirmed by new data from the present study, and this distribution is likely driven by the distribution of food sources throughout the trench. There are strong incentives for juveniles to be distributed to shallower depths despite the presence of competing scavengers. The shallower depth provides a higher quality of POM and allows for a faster metabolic rate. The discovery that juveniles at the $\sim 6,250 \mathrm{~m}$ depth were substantially smaller than at 10,800 m depth supports the theory that juveniles migrate down the trench slope with

increasing age. It seems likely that juveniles are distributed to a shallower depth by brooding females but there is still uncertainty as no brooding females have been captured. Intraspecific competition for food is likely, and the results of the trap height analysis may be demonstrating intraspecific exclusion, however more research is needed in this area.

Pereonite 1 fulfills the criteria for a good proxy. It bypasses curvature, is conspicuous and easy to measure, and is a single segment and is therefore stronger in detecting different lifestages (Chapelle, 1995). The use of an effective proxy such as peronite 1 allows for a greater proportion of samples to be measured thereby creating a higher resolution and more representative dataset from which to analyse size structure relationships. This in turn will help to elucidate the patterns and drivers behind the ontogenetic distribution observed in $\mathrm{H}$. dubia from the Tonga Trench, and elsewhere. 


\section{Chapter 4: Overview and Conclusions}

\subsection{Outline of research findings}

Hadal depths lack sufficient sampling and the communities within are not well understood. Scavenging amphipods have been examined in the past, however, often these samples are derived from a single depth and thus these studies were not able to analyse the trench habitat comprehensively. The YOK 13-10 voyage presented an opportunity to examine the scavenging community in the Tonga Trench. The voyage sampled depths of $\sim 6,250 \mathrm{~m}$ and $\sim 10,800 \mathrm{~m}$ from October 6 - October 21 in 2013. The present study has utilised the samples collected during this voyage, to address the four research questions proposed in Chapter 1 and summarised below.

4.1.1 Identify scavenging amphipod species in the hadal environment of the Tonga Trench

Six species of amphipods were identified from depths of $\sim 6,250 \mathrm{~m}$ and $\sim 10,800 \mathrm{~m}$ in the Tonga Trench. At $\sim 6,250 \mathrm{~m}$, Alicella gigantea, Eurythenes gryllus, Hirondellea dubia, Bathycallisoma schellenbergi, an alicellid species, and a gammarid species were recovered. In contrast, $H$. dubia was the only species recovered from $\sim 10,800 \mathrm{~m}$. The abundance of amphipods was higher at the $\sim 10,800 \mathrm{~m}$ site resulting in a general trend of increasing abundance and decreasing diversity with depth.

\subsubsection{Compare the scavenging amphipod assemblage structure of the Tonga} Trench with others of the South Pacific Ocean

The assemblage of scavenging amphipods in the Tonga Trench was similar to the results from past sampling efforts in the same trench. There were also similarities to the assemblages in the adjacent Kermadec Trench supporting the classification of these trenches as a single biogeographic province. The similarity of the assemblages in the 
Tonga Trench to the Peru-Chile Trench in the south eastern Pacific, was far lower. The present study provides new records of the vertical ranges of A. gigantea, E. gryllus, and $H$. dubia in the Tonga Trench. It also extends the maximum known range of $H$. dubia to 10,807 m depth. In addition, this is the second study to record A. gigantea in the southern Pacific, and the second to record the species in hadal depths. The present study also provides the first recorded instance of $A$. gigantea in the Tonga Trench.

\subsubsection{Examine the population structure of Hirondellea dubia in the Tonga} Trench

An analysis of $H$. dubia population structure revealed ontogenetic vertical structuring in the Tonga Trench. Juveniles were substantially smaller at $\sim 6,250 \mathrm{~m}$ compared to $\sim 10,800$ $\mathrm{m}$, and this suggests that juveniles migrate down the trench slope with increasing age. The most likely mechanism for distributing juveniles to the shallower depths is the ascending migration of brooding females. However there is still uncertainty as no brooding females have been captured. The proportion of females at $\sim 10,800 \mathrm{~m}$ was greater than males, however this relationship could not be examined further in the scope of this thesis. Intraspecific competition for food is likely and the results of the trap height analysis may be demonstrating intraspecific exclusion, however more research is needed in this area. The shallower depth provides a higher quality of POM and the reduced hydrostatic pressure allows for a faster metabolic rate, and there are therefore strong incentives for juveniles to be distributed to shallower depths despite the presence of competing scavengers. Thus, this distribution is likely driven by the distribution of food sources throughout the trench in combination with hydrostatic pressure.

\subsubsection{Identify a total length proxy for Hirondellea dubia}

The dimensions of pereonite 1 , peronite $2-7$, and the pleosome were all evaluated as potential proxies for total length of $\mathrm{H}$. dubia. Pereonite 2-7 had the strongest correlation to total length, however it was highly influenced by dorsal curvature. Both the pereonite 2-7 and the pleosome showed a significant degree of sexual dimorphism making them inappropriate to use as proxies. Pereonite 1 was disproportionately larger in juveniles, 
which could lower the resolution of length-based size classes in future analyses. Overall pereonite 1 was considered the strongest candidate for a proxy, because it was not affected by curvature and was a conspicuous segment that was easy to measure.

\subsection{Synthesis of findings}

Examining hadal fauna helps us to understand the age of these communities and how species were originally distributed to these environments (Beliaev and Brueggeman, 1989). In the deep sea, environmental variables underwent significant changes during the Eocene-Oligocene boundary $\sim 55$ million years ago, when the deep sea cooled by $\sim 15^{\circ}$, which likely resulted in extinction of many hadal species. Therefore, many of the present deep sea fauna are thought to have invaded from shallower habitats since this extinction event (Beliaev and Brueggeman, 1989; Rogers, 2000). These trench communities have since become isolated over time, and this might explain similarities observed between adjacent trenches. The Hirondellea genus dominates the deepest sections of trenches worldwide, and each species inhabit particular fragments of the Pacific, with H. dubia populating the Southwest Pacific Trenches (Kermadec, Tonga, New Hebrides; Blankenship et. al., 2006; Kilgallen, 2015; Ritchie et al., 2015). The limited distribution of $H$. dubia is an example that illustrates how trenches have become progressively isolated over time.

Scavenging communities of hadal trenches are distinct from those of the abyssal zone (4,000-6,000 m; Vinogradova, 1959; Jamieson et al., 2010; Jamieson et al., 2011, Fuji et al. 2013, Kitahashi et al., 2013, Gallo et al., 2015; Leduc et al., in press). The change in community structure between the two habitats was initially thought to be an ecocline, a gradual transition of fauna across a large area or depth (Wolff 1970; van der Maarel, 1990;). However analysis of scavenging amphipod data from the Kermadec Trench region suggested the presence of an ecotone, or sharp transition of fauna across a small area, at the boundary of the abyssal and hadal zones (6,000-7,000 m; Jamieson et al., 2011). Samples collected at $\sim 6,250 \mathrm{~m}$ in the present study are therefore instructive in this debate. The assemblage of scavenging amphipods collected at this depth contained a 
combination of typical abyssal fauna, such as A. gigantea and E. gryllus, and typical hadal fauna, such as $H$. dubia and B. schellenbergi. By comparing results from the present study to that of Blankenship et al., (2006), there is a change from the hadal-abyssal fauna in our 6,250 $\mathrm{m}$ samples to the exclusively hadal species recorded from 6,834 $\mathrm{m}$ in Blankenship et al. (2006). Together, these data provides strong evidence for an ecotone in the Tonga Trench somewhere between these two depths.

This thesis also provides a new Tonga Trench shallow record of $6253 \mathrm{~m}$ for $\mathrm{H}$. dubia. The species has been detected at 6,000 $\mathrm{m}$ in the Kermadec Trench (Jamieson et al., 2011), and has even been detected in depths as shallow as 5,469 m near the Mariana Trench (Ritchie et al., 2015). The detection of $H$. dubia at this shallow depth in the Tonga Trench provides new evidence that the populations of the Tonga and Kermadec trenches are likely connected. The main barrier to populations between the two trenches is the Capricorn Guyot, a sill of $\sim 6,000 \mathrm{~m}$ depth separating the two hadal habitats (Jamieson et al., 2011). Deep sea amphipods can withstand changes in pressure greater than $100 \mathrm{~atm}$, and $H$. dubia in particular have a depth range of over 450 atm (Bristein and Vinogradov, 1970; Yayanos, 1981; Jamison et al., 2011). High tolerance to pressure changes and the detection of both mature and juvenile lifestages of $H$. dubia at $\sim 6,000-6,250 \mathrm{~m}$ in both trenches (Jamieson et al., 2011), suggest that the species is capable of migrating over the Capricorn Guyot.

The finding of juveniles at both depths in the present study is in contrast to past analyses of $H$. dubia population structure in the Tonga Trench, which found that juvenile were excluded from greater depths (Blankenship et al., 2006). Blankenship et al. (2006) used estimates of length to define size classes, while the present study used a combination of length measurements and life stage assignment based on secondary sexual characteristics. The difference in methodology may have caused juveniles at the deeper sites and adults at the shallower sites to be overlooked by Blankenship et al. (2006). Mature life stages of $H$. dubia have also been detected at shallower depths in the Kermadec Trench (Jamieson et al., 2011), supporting the distribution observed in the 
present study. A change in approach to population analysis can further our understanding of this vertical structuring, and the detection of juveniles across both depths is a strong indicator that pressure alone does not drive ontogenetic structuring, and instead a combination of pressure and food availability is more likely (Eustace et al., 2013).

Within deep sea scavengers, there is intense competition for food resources (Blankenship et al., 2006; Iken et al., 2001). This competition is partially relieved by the partitioning of vertical range among scavenger species, however where amphipod ranges overlap, partitioning of feeding strategies can also be observed, with some species relying more on detrivory than on carrion falls (Blankenship and Levin, 2007). A shift in feeding strategies of juvenile $H$. dubia may be connected to interspecific interactions at shallower trench depths where scavenging amphipod ranges overlap (Blankenship and Levin, 2007). An analysis of population structure in Hirondellea gigas considered reduced predation pressure as one of the driving forces of ontogenetic structuring (Eustace et al., 2013) Their reduced size may make the juveniles a less appealing target to larger predators (Eustace et al., 2013), however this is unlikely in the case for $H$. dubia. In the Tonga Trench the range of $H$. dubia overlaps with another ontogenetically distributed scavenger $B$. schellenbergi. These two species have distinct vertical ranges, yet are similar in size where their ranges overlap and are therefore likely to be targeted by the same predators (Blankenship et al., 2006). Therefore reduced predation is unlikely to be a strong driver of ontogenetic distribution or distribution in general.

Identifying pereonite 1 as a good proxy for $H$. dubia length will allow a more efficient methodology in size structure studies. The proxy is easier to measure, and requires much less time and skill then taking a total length measurement along the dorsal aspect (Skadsheim 1982, Chapelle, 1995). The identification of this proxy will allow for more amphipods to be measured, revealing the size structure patterns to a much higher degree of accuracy and resolution. In addition, the proxy may allow for more size structure studies to be conducted overall (Chapelle, 1995). Many deep-sea lysianassoids are structurally similar (Havermans et al., 2010), and pereonite 1 might therefore provide a 
strong proxy for other lysianassoids. Larger data sets and more studies in general are necessary to uncover the population structures of scavenging amphipods, and a consistent methodology would also allow cross comparisons of size structure to a greater degree.

Although there appeared to be a trend of increasing abundance with depth, it is difficult to make accurate abundance estimates in hadal scavenging communities. Sampling methods can be highly selective and techniques such as baited traps and cameras attract mobile scavengers from the surrounding areas. Defining amphipod abundance is therefore difficult as the numbers at the bait may depend on the ability of each species to detect and locate the food source during deployment. In addition, none of the traps used had closure mechanisms, and so some trapped amphipods could escape and others could enter the traps during the descent and ascent of the landers/submersible. Escape of amphipods was considered likely, given the size and arrangement of trap openings and the wash experienced by the traps at the sea surface during recovery of the landers/submersible. Interspecific interactions at these bait events may also influence the composition and abundance perceived during sampling. These interactions include competitive exclusion, predation, and possibly a kind of succession of species attending bait (Jones et al., 1998).

In the present study, traps were baited with pieces of raw fish placed in fine mesh bags attached to an inside wall of the traps, thus the carrion itself may have been inaccessible to some scavengers due to the fine mesh of the baited bags. Hessler et al. (1978) found that amphipods did not settle randomly on bait but appeared to cluster in one spot, and this was attributed to the release of dissolved substances from the broken skin, or feeding waste products such as ammonia, both of which would have been impaired by the mesh bags used in the present study. Therefore, the use of mesh bags may have distorted the composition and abundance of scavengers in the baited traps and any other study in the past using similar trap design. 
The patterns recorded here were based on samples collected from two sites in the Tonga Trench, one of the trench edge of the oceanic slope $(\sim 6,250 \mathrm{~m})$ and one at the trench axis ( 10,800 m). The oceanic slope of the trench is typically low-angled compared to the continental side of the trench, which can have a much steeper slope (Ichino et al., 2015). POM at the seafloor is not exclusively dependent on the overlying water productivity, and sedimentation varies with topography (Ichino et al., 2015). When analysing and comparing scavenging communities within trenches, it is important to consider the distinct topographies that characterise each slope of the trench (Leduc et al., in press). Further investigations may detect different trends within hadal communities when taking the bathymetry of differing sides of a trench into account (Ichino et al., 2015).

The behaviour and distribution of mobile scavengers influence the wider hadal communities. For example, amphipods feeding on detritus stir up sediment. Nematodes are one of the most characteristic fauna of the meiobenthos in the hadal zone, and they have been frequently detected in sediment samples across the deep sea (Wolff, 1960; Jamieson, 2015). The higher abundance of scavenging amphipods at the Tonga trench axis relative to the trench slope is likely to increase vertical mixing of sediments thus facilitating deeper penetration of organisms into the sediment at the trench axis (Leduc et al., in press).

Analysis of sediment samples from the YOK 13-10 voyage have shown there is pollen in the detritus at the axis of the Tonga Trench (Leduc, unpublished). Pollen may be ingested by marine protists (Leduc, unpublished), and $H$. dubia may also consume them. Hirondellea gigas may possess cellulase, an enzyme capable of digesting wood matter (Kobayashi et al, 2012). Hirondellea dubia may also possess this enzyme, and if proven, this finding would provide a direct link from terrestrial systems to the deepest parts of the oceans. 


\subsection{Future Directions}

The results of this thesis begin to fill the gaps in the knowledge of hadal and trench biology. However, repeated sampling in trenches is important to consolidate and extend our understanding of how scavenging communities change over temporal and spatial scales. The deepest spots in the ocean provide a unique and charismatic research site, and understanding these systems helps uncover the processes acting in the wider trench environment (Jamieson, 2015). For example, although A. gigantea was recovered from both samples at $\sim 6,250 \mathrm{~m}$, the species was not captured previously at similar depths (Blankenship et al., 2006). This inconsistency suggests that $A$. gigantea has a scattered distribution (Jamieson et al., 2013). The present study also detected $H$. dubia at a shallower depth than Blankenship et al. (2006). However very little is still known on how these communities vary seasonally or annually. Future studies would benefit from replication of samples over a temporal scale, and the revisiting of previously sampled sites and depths.

Further classification of the allicelid species and the gammarid species recovered from 6,250 $\mathrm{m}$ would provide a clearer understanding of the amphipod assemblage composition at this depth, and allow more comparisons among trenches and across the abyssal-hadal transition. Morphological characteristics and genetic sequencing might allow for the identification of these individuals. The alicellid and the gammarid could also be compared to specimens collected by past sampling in the Tonga and Kermadec trenches (Blankenship et al., 2006; Jamieson et al., 2011) to confirm their identification as Paracella sp. and Uristes chastaini respectively.

The present study found that females made up a larger proportion of the assemblage at $\sim 10,800 \mathrm{~m}$. A change in sex ratio is likely associated with reproductive behaviour, however the nature of this behaviour is still unknown (Thurston et al., 2002; Ingram and Hessler, 1987). There are still many gaps in knowledge surrounding reproduction in hadal amphipods. For example, brooding Hirondellea females have not been recovered in any samples known to date (Blankenship et al., 2006; Eustace et al., 2013), and it is not yet 
understood if they migrate to shallower waters to disperse their brood. More quantitative sampling and improvements in observational technology are needed to yield information of hadal amphipod reproduction.

Hadal amphipods may be hosts to parasitic nematodes (Leduc and Wilson, 2016). The nematodes were detected in the body cavity of $H$. dubia between depths of 7,018 and 10,005 $\mathrm{m}$ in the Kermadec Trench (Leduc and Wilson, 2016). Although less than $1 \%$ of the H. dubia were host to the parasite, the ecological significance of this interaction remains unexplored (Leduc and Wilson, 2016). The low percentage of infected individuals coupled with the transition to a more opaque exoskeleton in fixed amphipods, may have influenced the lack of parasite detection in the past (Leduc and Wilson, 2016). Lysianassoid necrophagous amphipods exhibit some $\mathrm{K}$ selection traits, and it is possible that parasites limiting the amount of food the amphipod is receiving could delay maturity and reproduction in the host species (Ingram and Hessler, 1983; Blankenship et al., 2006; Leduc and Wilson, 2016).

Although it could not be examined in the course of the present study, the $4^{\text {th }}$ coxa has been used as a proxy in multiple hadal size structure analyses (Chapelle, 1995; Blankenship et al., 2006, Jamieson et al., 2011; Fujii et al., 2013; Eustace et al., 2013). Chapelle (1995) conducted an assessment of proxies for the Antarctic necrophagous amphipod Waldeckia obese (Chevreux, 1905). In this assessment, the $4^{\text {th }}$ coxa was considered superior to pereonite 1 in terms of correlation to total length and variability between individuals. However, the correlation coefficients between the two segments were almost indistinguishable $\left(R^{2}=0.98\right.$ for $4^{\text {th }}$ coxa, and $R^{2}=0.97$ for pereonite 1 in Chapelle, 1995). Furthermore, the numbers of individuals included in the assessment of correlation were small (25 individuals). In addition, the $4^{\text {th }}$ coxa is particularly prominent in $W$. obese, but this is not the case in all lysianassoid amphipods. Examining these proxies across a larger data set across multiple species will likely uncover the proxy that is the most appropriate for use in future analysis. 
One of the main objectives of the YOK 13-10 voyage was to examine the genetic connectivity of amphipod populations among other hadal environments in the South Pacific, and connections to the Kermadec Trench in particular. This objective was not included in the scope of the present study, however a COI sequence was successfully extracted from a single $H$. dubia from the $\sim 10,800 \mathrm{~m}$ site during the course of this thesis. Samples processed during the course of this thesis would be suitable for more extensive genetic sequencing, for comparison to $H$. dubia sequences reported by Ritchie et al. (2015) from various Southwest Pacific trenches. In this way, a more complete understanding of the connectivity between the Kermadec and Tonga trenches would emerge. Furthermore, this type of analysis also has scope for examining the isolation of trenches over geological time.

The Tonga and Kermadec trenches have been described as a single biological province with a similar hadal community (Vinogradova, 1979), however the extent of this connection is still unknown. The Capricorn Guyot ( 6,000 $\mathrm{m})$ represents a shallow barrier between the trenches (Jamieson et al., 2011), and should be the target of future sampling efforts. Baited traps and cameras at this sill may reveal those species that are capable of migrating over the barrier between trenches. Currently, $H$. dubia has a vertical range that suggests they are physiologically capable of crossing the Capricorn Guyot (Bristein and Vinogradov, 1970; Yayanos, 1981; Jamieson et al., 2011, present study), but there is a lack of empirical evidence.

In the present study, traps placed at different heights above the sea floor at $\sim 10,800 \mathrm{~m}$ collected different subsets of the $H$. dubia benthic population. This observation has not been recorded before and was quite unexpected, as it is hard to imagine that species with such impressive chemosensory capabilities could be confounded by such small variations in height. The influence of trap height could not be compared at the shallower depths because only one trap height was deployed to this depth $(1.8 \mathrm{~m})$, however comparison between trap heights at these depths will likely reveal interesting ecological behaviour in the future. There were multiple species at the $\sim 6,250 \mathrm{~m}$ site, and any trap height based 
influence between species might suggest further stratification of resources in this foodlimited environment.

Alicella gigantea is a poorly understood deep sea scavenger, and although specimens recovered in the present study reveal new details on the species distribution there are still many gaps in our understanding. The distribution of $A$. gigantea appears to be relatively widespread across abyssal depths (Jamieson et al., 2013), and the recent discovery of the species in hadal depths (Jamieson et al., 2013; present study) confirms how little we know about the extent of its distribution. It is likely that as sampling effort and technological capabilities advance, recovery of $A$. gigantea will become more frequent, and understanding of this species' distribution will improve.

Most organic matter in trenches is derived from surface waters, and the hadal zone may therefore be intrinsically linked to the fluctuations in production at the ocean surface (Stockton and DeLaca, 1982; Sokolova, 1994). Both of the studies that have analysed population structure of $\mathrm{H}$. dubia in the Tonga Trench took place in October (Blankenship et al., 2006; present study). This provides a good basis for comparison, however, it does demonstrate the gaps in sampling effort hadal research currently experiences. In a habitat that is so strongly influenced by the distribution of organic matter a fluctuation in POM input at different times of the year may have substantial impacts on the biological processes operating within trenches.

Although sampling efforts have increased over recent years, the hadal environment still remains one of the most understudied habitats in the marine environment. More quantitative sampling is needed to better understand the diversity, abundance, and community structure in the hadal zone, and how environmental variables shape these communities (Jamieson, 2015). 


\subsection{Conclusions}

This thesis provides insights into the composition and structure of the scavenging amphipod communities in the Tonga Trench. Overall I found a trend of decreasing diversity and increasing abundance with depth, a trend that is consistent with past hadal community analysis. This thesis expands our current knowledge of A. gigantea, here we report the first instance of this large amphipod in the Tonga Trench, and the second known instance of the species at hadal depths. The present study provides new Tongan Trench records of $A$. gigantea, E. gryllus, and $H$. dubia vertical ranges. Examination of $H$. dubia lifestages revealed that the population were ontogenetically structured with depth in the Tonga Trench. Juveniles dominated the composition in the shallow end of the $H$. dubia vertical range, while very few juveniles were found at the deepest site. The shallower depth provides a higher quality of POM and the reduced hydrostatic pressure allows for a faster metabolic rate. There are therefore strong incentives for juveniles to be distributed to shallower depths despite the presence of competing scavengers. After consideration of multiple established proxies, the pereonite 1 segment was considered the strongest candidate for a $H$. dubia body length proxy. The segment provided a conspicuous single segment making it appropriate for distinguishing size classes and it provided the strongest resilience to curvature based variation. Since the discovery of life in the hadal zone in 1951, understanding of the fauna that inhabits the deep oceanic trenches has come a long way, however there is still much to examine in these complex and extreme habitats. 


\section{Bibliography}

Abramoff, M.D., Magalhaes, P.J., Ram, S.J. (2004) "Image Processing with ImageJ". Biophotonics International, volume 11, issue 7, pp. 36-42.

Arndt, C. E., \& Beuchel, F. (2006). Life history and population dynamics of the Arctic sympagic amphipods Onisimus nanseni Sars and O. glacialis Sars (Gammaridea: Lysianassidae). Polar Biology, 29(3), 239-248.

Barnard, J. L., \& Barnard, J. L. (1969). The families and genera of marine gammaridean Amphipoda. Washington, DC: Smithsonian Institution Press.

Barnard, J. L., \& Shulenberger, E. (1976). Clarification of the abyssal amphipod, Paralicella tenuipes Chevreux. Crustaceana, 31(3), 267-274.

Barnard, J. L., \& Ingram, C. L. (1986). The supergiant amphipod Alicella gigantea Chevreux from the North Pacific gyre. Journal of Crustacean Biology, 825-839.

Barnes, M., Ansell, A. D., \& Gibson, R. N. (1992). The biology of hydrothermal vent animals: physiology, biochemistry, and autotrophic symbioses. Oceanography Marine Biology Annual Review, 30, 337-441.

Beliaev, G. M., \& Brueggeman, P. L. (1989). Deep sea ocean trenches and their fauna. Scripps Institution of Oceanography.

Beuchel, F., \& Lønne, O. J. (2002). Population dynamics of the sympagic amphipods Gammarus wilkitzkii and Apherusa glacialis in sea ice north of Svalbard. Polar Biology, 25(4), 241-250.

Birstein, J. A., \& Vinogradov, M. E. (1955). Pelagicheskie gammaridy (AmphipodaGammaridea) Kurilo-Kamchatskoi Vpadiny. Trudy Inst. Okeanol. Akad. Nauk SSSR, 12, 210-287. 
Blankenship, L. E., Yayanos, A. A., Cadien, D. B., \& Levin, L. A. (2006). Vertical zonation patterns of scavenging amphipods from the hadal zone of the Tonga and Kermadec Trenches. Deep Sea Research Part I: Oceanographic Research Papers, 53(1), 48-61.

Blankenship, L. E., \& Levin, L. A. (2007). Extreme food webs: Foraging strategies and diets of scavenging amphipods from the ocean's deepest 5 kilometers. Limnology and Oceanography, 52(4), 1685-1697.

Blankenship-Williams, L. E., \& Levin, L. A. (2009). Living Deep: a synopsis of hadal trench ecology. Marine Technology Society Journal, 43(5), 137-143.

Bourdillon, A. (1958). Biologie des crustacés marins xylophages. Centre Régional de Documentation Pédagogique, 31(19), 1-173

Britton, J. C., \& Morton, B. (1994). Marine carrion and scavengers. Oceanography and Marine Biology: an annual review, 32, 369-434

Brusca, R. C., \& Brusca, G. J. (1990). Invertebrates (Vol. 2). Sunderland, Massachusetts: Sinauer Associates.

Bruun, A. F. (1956). Animal life of the deep-sea bottom. The Galathea Deep Sea Expedition 1950-1952, 149-195.

Bryden, H. L. (1973). New polynomials for thermal expansion, adiabatic temperature gradient and potential temperature of sea water. In: Deep Sea Research and Oceanographic Abstracts (Vol. 20, No. 4, pp. 401-408). Elsevier.

Buesseler, K. O., \& Boyd, P. W. (2009). Shedding light on processes that control particle export and flux attenuation in the twilight zone of the open ocean. Limnology and Oceanography, 54(4), 1210.

Chapelle, G. (1995). Estimating size of amphipods in life cycle studies: what to measure and what for? Polskie Archiwum Hydrobiologii, 42(4), 295-302. 
Chapelle, G., \& Peck, L. S. (2004). Amphipod crustacean size spectra: new insights in the relationship between size and oxygen. Oikos, 106(1), 167-175.

Charniaux-Cotton, H. (1957). Croissance, régénération et déterminisme endocrinien des caractères sexuels secondaires d'Orchestia gammarella (Pallas) crustacé amphipode (Vol. 11). Masson.

Christiansen, B., Pfannkuche, O., \& Thiel, H. (1990). Vertical distribution and population structure of the necrophagous amphipod Eurythenes gryllus in the West European Basin. Marine Ecology Progress Series, 66(1-2).

Christina, L., \& Passow, U. (2007). Factors influencing the sinking of POC and the efficiency of the biological carbon pump. Deep Sea Research Part II: Topical Studies in Oceanography, 54(5), 639-658.

Chevreux, E. (1899). Sur deux espèeces gèantes d'amphipodes provenant des campagnes du yacht Princesse Alice. Bulletin de la Société zoologique de France. 24, 152-158.

Cohen, J. (2013). Statistical power analysis for the behavioural sciences. Academic press.

Dahl, E. (1959). From depths exceeding 6000 meters. Galathea Report: Scientific Results of the Danish Deep-Sea Expedition Round the World 1950-1952, 1, 211.

Dahl, E. (1979). Deep-sea carrion feeding amphipods: evolutionary patterns in niche adaptation. Oikos, 167-175.

Dana J.D. (1849). Synopsis of the genera of Gammaridea. The American Journal of Science and Arts, (ser. 2) 8, 22, 135-140.

Daneri, G., Dellarossa, V., Quinones, R., Jacob, B., Montero, P., \& Ulloa, O. (2000). Primary production and community respiration in the Humboldt Current System off Chile and associated oceanic areas. Marine Ecology-Progress Series, 197, 41-49.

Danovaro, R., Dell'Anno, A., \& Pusceddu, A. (2004). Biodiversity response to climate change in a warm deep sea. Ecology Letters, 7(9), 821-828. 
Danovaro, R., Gambi, C., Dell'Anno, A., Corinaldesi, C., Fraschetti, S., Vanreusel, A., Vincx, M., Gooday, A. J. (2008). Exponential decline of deep-sea ecosystem functioning linked to benthic biodiversity loss. Current Biology,18(1), 1-8.

De Broyer, C., \& Thurston, M. (1987). New Atlantic material and redescription of the type specimens of the giant abyssal amphipod Alicella gigantea Chevreux (Crustacea). Zoologica Scripta, 16(4), 335-350.

De Broyer, C., Nyssen, F., \& Dauby, P. (2004). The crustacean scavenger guild in Antarctic shelf, bathyal and abyssal communities. Deep Sea Research Part II: Topical Studies in Oceanography, 51(14), 1733-1752.

Eustace, R. M., Kilgallen, N. M., Lacey, N. C., \& Jamieson, A. J. (2013). Population structure of the hadal amphipod Hirondellea gigas (Amphipoda: Lysianassoidea) from the IzuBonin Trench. Journal of Crustacean Biology,33(6), 793-801.

Fabiano, M., Pusceddu, A., Dell'Anno, A., Armeni, M., Vanucci, S., Lampitt, R. S., Wolff, G., \& Danovaro, R. (2001). Fluxes of phytopigments and labile organic matter to the deep ocean in the NE Atlantic Ocean. Progress in Oceanography, 50(1), 89-104.

France, S. C. (1993). Geographic variation among three isolated populations of the hadal amphipod Hirondellea gigas (Crustacea: Amphipoda: Lysianassoidea). Marine EcologyProgress Series, 92, 277-277.

France, S. C., \& Kocher, T. D. (1996). Geographic and bathymetric patterns of mitochondrial 16S rRNA sequence divergence among deep-sea amphipods, Eurythenes gryllus. Marine Biology, 126(4), 633-643.

Fujii, T., Jamieson, A. J., Solan, M., Bagley, P. M., \& Priede, I. G. (2010). A large aggregation of liparids at 7703 meters and a reappraisal of the abundance and diversity of hadal fish. BioScience, 60(7), 506-515. 
Fujii, T., Kilgallen, N. M., Rowden, A. A., \& Jamieson, A. J. (2013). Deep-sea amphipod community structure across abyssal to hadal depths in the Peru-Chile and Kermadec trenches. Marine Ecology-Progress Series, 492, 125-138.

Fujikura, K., Kojima, S., Tamaki, K., Maki, Y., Hunt, J., \& Okutani, T. (1999). The deepest chemosynthesis-based community yet discovered from the hadal zone, $7326 \mathrm{~m}$ deep, in the Japan Trench. Marine Ecology-Progress Series, 190, 17-26.

Gage, J. D., \& Tyler, P. A. (1991). Deep-sea biology: a natural history of organisms at the deep-sea floor. Cambridge University Press.

Gallo, N. D., Cameron, J., Hardy, K., Fryer, P., Bartlett, D. H., \& Levin, L. A. (2015). Submersible-and lander-observed community patterns in the Mariana and New Britain trenches: Influence of productivity and depth on epibenthic and scavenging communities. Deep Sea Research Part I: Oceanographic Research Papers, 99, 119133.

Gibson, R. N., Atkinson, R. J. A., \& Gordon, J. D. M. (2005). Zonation of deep biota on continental margins. Oceanography and Marine Biology: An Annual Review, 43, 211278.

Glud, R. N., Wenzhöfer, F., Middelboe, M., Oguri, K., Turnewitsch, R., Canfield, D. E., \& Kitazato, H. (2013). High rates of microbial carbon turnover in sediments in the deepest oceanic trench on Earth. Nature Geoscience, 6(4), 284-288.

Harrison, C. S., Hida, T. S., \& Seki, M. P. (1983). Hawaiian seabird feeding ecology. Wildlife Monographs. 85, 3-71.

Hasegawa, M., Kurohiji, Y., Takayanagi, S., Sawadaishi, S., \& Yao, M. (1986). Collection of fish and Amphipoda from abyssal sea-floor at $30^{\circ} \mathrm{N}-147^{\circ} \mathrm{E}$ using traps tied to $10.000 \mathrm{~m}$ wire of research vessel. Bulletin of the Tokai Regional Fisheries Research Laboratory, No. $119,65-75$

Havermans, C., Nagy, Z. T., Sonet, G., De Broyer, C., \& Martin, P. (2010). Incongruence between molecular phylogeny and morphological classification in amphipod 
crustaceans: a case study of Antarctic lysianassoids. Molecular Phylogenetics and Evolution, 55(1), 202-209.

Herring, P. (2002). The biology of the deep ocean. Oxford University Press.

Hessler, R. R., \& Sanders, H. L. (1967). Faunal diversity in the deep-sea. In: Deep Sea Research and Oceanographic Abstracts (Vol. 14, No. 1, pp. 65-78). Elsevier.

Hessler, R. R., Ingram, C. L., Yayanos, A. A., \& Burnett, B. R. (1978). Scavenging amphipods from the floor of the Philippine Trench. Deep Sea Research, 25(11), 1029-1047.

Honjo, S., Manganini, S. J., Krishfield, R. A., \& Francois, R. (2008). Particulate organic carbon fluxes to the ocean interior and factors controlling the biological pump: A synthesis of global sediment trap programs since 1983. Progress in Oceanography, 76(3), 217-285.

Horton, T., \& Thurston, M. (2013). Hirondellea namarensis (Crustacea: Amphipoda: Lysianassoidea: Hirondelleidae), a new deep-water scavenger species from the MidAtlantic Ridge. Marine Biology Research, 9(5-6), 554-562.

Ichino, M. C., Clark, M. R., Drazen, J. C., Jamieson, A., Jones, D. O., Martin, A. P., Rowden, A., Shank, T,. Yancey, P., \& Ruhl, H. A. (2015). The distribution of benthic biomass in hadal trenches: A modelling approach to investigate the effect of vertical and lateral organic matter transport to the seafloor. Deep Sea Research Part I: Oceanographic Research Papers, 100, 21-33.

Iken, K., Brey, T., Wand, U., Voigt, J., \& Junghans, P. (2001). Food web structure of the benthic community at the Porcupine Abyssal Plain (NE Atlantic): a stable isotope analysis. Progress in Oceanography, 50(1), 383-405.

Ingram, C. L., \& Hessler, R. R. (1983). Distribution and behaviour of scavenging amphipods from the central North Pacific. Deep Sea Research Part A. Oceanographic Research Papers, 30(7), 683-706. 
Ingram, C. L., \& Hessler, R. R. (1987). Population biology of the deep-sea amphipod Eurythenes gryllus: inferences from instar analyses. Deep Sea Research Part A. Oceanographic Research Papers, 34(12), 1889-1910.

Itou, M., Matsumura, I., \& Noriki, S. (2000). A large flux of particulate matter in the deep Japan Trench observed just after the 1994 Sanriku-Oki earthquake. Deep Sea Research Part I: Oceanographic Research Papers, 47(10), 1987-1998.

Itoh, M., Kawamura, K., Kitahashi, T., Kojima, S., Katagiri, H., \& Shimanaga, M. (2011). Bathymetric patterns of meiofaunal abundance and biomass associated with the Kuril and Ryukyu trenches, western North Pacific Ocean.Deep Sea Research Part I: Oceanographic Research Papers, 58(1), 86-97.

Jamieson, A. J., Fujii, T., Solan, M., Matsumoto, A. K., Bagley, P. M., \& Priede, I. G. (2009a). First findings of decapod Crustacea in the hadal zone. Deep Sea Research Part I: Oceanographic Research Papers, 56(4), 641-647.

Jamieson, A. J., Solan, M., \& Fujii, T. (2009b). Imaging deep-sea life beyond the abyssal zone. Sea Technology, 50(3), $41 \mathrm{pp}$

Jamieson, A. J., Fujii, T., Mayor, D. J., Solan, M., \& Priede, I. G. (2010). Hadal trenches: the ecology of the deepest places on Earth. Trends in Ecology \& Evolution, 25(3), 190-197.

Jamieson, A. J., N. M. Kilgallen, A. A. Rowden, T. Fujii, T. Horton, A-N. Lörz, K. Kitazawa, \& I. G. Priede (2011). Bait-attending fauna of the Kermadec Trench, SW Pacific Ocean: Evidence for an ecotone across the abyssal-hadal transition zone. Deep Sea Research Part I: Oceanographic Research Papers. 58(1), 49-62.

Jamieson, A. J., Lacey, N. C., Lörz, A. N., Rowden, A. A., \& Piertney, S. B. (2013). The supergiant amphipod Alicella gigantea (Crustacea: Alicellidae) from hadal depths in the Kermadec Trench, SW Pacific Ocean. Deep Sea Research Part II: Topical Studies in Oceanography, 92, 107-113. 
Jamieson, A. (2015). The Hadal Zone: Life in the Deepest Oceans. Cambridge University Press.

Johnson, G. C. (1998). Deep water properties, velocities, and dynamics over ocean trenches. Journal of Marine Research, 56(2), 329-347.

Jones, E. G., Collins, M. A., Bagley, P. M., Addison, S., \& Priede, I. G. (1998). The fate of cetacean carcasses in the deep sea: observations on consumption rates and succession of scavenging species in the abyssal north-east Atlantic Ocean. Proceedings of the Royal Society of London B: Biological Sciences,265(1401), 1119-1127.

Kilgallen, N. M. (2015). Three new species of Hirondellea (Crustacea, Amphipoda, Hirondelleidae) from hadal depths of the Peru-Chile Trench. Marine Biology Research, 11(1), 34-48.

Kilgallen, N. M., \& Lowry, J. K. (2015). A review of the scopelocheirid amphipods (Crustacea, Amphipoda, Lysianassoidea), with the description of new taxa from Australian waters. Zoosystematics and Evolution, 91(1), 1-43.

Kitahashi, T., Kawamura, K., Kojima, S., \& Shimanaga, M. (2013). Assemblages gradually change from bathyal to hadal depth: a case study on harpacticoid copepods around the Kuril Trench (north-west Pacific Ocean). Deep Sea Research Part I: Oceanographic Research Papers, 74, 39-47.

Kobayashi, H., Hatada, Y., Tsubouchi, T., Nagahama, T., \& Takami, H. (2012). The hadal amphipod Hirondellea gigas possessing a unique cellulase for digesting wooden debris buried in the deepest seafloor. PloS one, 7(8), e42727-e42727.

Kullenberg, B. (1956). The technique of trawling. The Galathea Deep Sea Expedition. George Allen and Unwin, 112-118.

Lebrato, M., \& Jones, D. O. B. (2009). Mass deposition event of Pyrosoma atlanticum carcasses off Ivory Coast (West Africa). Limnology and Oceanography, 54(4), 11971209. 
Leduc, D., Rowden, A. A., Glud, R. N., Wenzhöfer, F., Kitazato, H., \& Clark, M. R. (2015). Comparison between infaunal communities of the deep floor and edge of the Tonga Trench: Possible effects of differences in organic matter supply. Deep Sea Research Part I: Oceanographic Research Papers.

Leduc, D., \& Wilson, J. (2016). Benthimermithid nematode parasites of the amphipod Hirondellea dubia in the Kermadec Trench. Parasitology research, 1-8.

Legeżyńska, J., Węsławski, J. M., \& Presler, P. (2000). Benthic scavengers collected by baited traps in the high Arctic. Polar Biology, 23(8), 539-544.

Longhurst, A., Sathyendranath, S., Platt, T., \& Caverhill, C. (1995). An estimate of global primary production in the ocean from satellite radiometer data. Journal of Plankton Research, 17(6), 1245-1271.

Menzies, R. J. (1965). Conditions for the existence of life on the abyssal sea floor. Oceanography and marine biology: an annual review, 3, 195-210.

Mora, C., Wei, C. L., Rollo, A., Amaro, T., Baco, A. R., Billett, D et al. (2013). Biotic and human vulnerability to projected changes in ocean biogeochemistry over the 21st century. PLoS Biol, 11(10), e1001682.

Murashima, T., Nakajoh, H., Takami, H., Yamauchi, N., Miura, A., \& Ishizuka, T. (2009, May). 11,000 m class free fall mooring system. In: OCEANS 2009-EUROPE (pp. 1-5). IEEE.

Nybelin, O., \& Pettersson, H. (1951). Introduction and station list. Göteborgs Kungl. Vetenskap-och Vitterhets-Samhälle.

Ohara, Y., Stern, R. J., Martinez, F., Michibayashi, K., Reagan, M. K., Fujikura, K et al. (2012, December). Geological characteristics of the Shinkai Seep Field, a serpentinite-hosted ecosystem in the Southern Mariana Forearc. In AGU Fall Meeting Abstracts (Vol. 1, p. 05).

Parry, G. (1960). Excretion. The physiology of Crustacea, 1, 341-366. 
Paterson, G. L., Glover, A. G., Froján, C. R. B., Whitaker, A., Budaeva, N., Chimonides, J., \& Doner, S. (2009). A census of abyssal polychaetes. Deep Sea Research Part II: Topical Studies in Oceanography, 56(19), 1739-1746.

Perrone, F. M., Dell'Anno, A., Danovaro, R., Croce, N. D., \& Thurston, M. H. (2002). Population biology of Hirondellea sp. nov. (Amphipoda: Gammaridea: Lysianassoidea) from the Atacama Trench (south-east Pacific Ocean). Journal of the Marine Biological Association of the UK, 82(03), 419-425.

Ramirez-Llodra, E., Brandt, A., Danovaro, R., De Mol, B., Escobar, E., German, C. R, et al. \& Vecchione, M. (2010). Deep, diverse and definitely different: unique attributes of the world's largest ecosystem. Biogeosciences, 7(9), 2851-2899

Rathburn, A. E., Levin, L. A., Tryon, M., Gieskes, J. M., Martin, J. B., Pérez, M, et al. (2009). Geological and biological heterogeneity of the Aleutian margin (19654822m). Progress in Oceanography, 80(1), 22-50.

Ritchie, H., Jamieson, A. J., \& Piertney, S. B. (2015). Phylogenetic relationships among hadal amphipods of the superfamily Lysianassoidea: Implications for taxonomy and biogeography. Deep Sea Research Part I: Oceanographic Research Papers, 105, 119131.

Rogers, A. D. (2000). The role of the oceanic oxygen minima in generating biodiversity in the deep sea. Deep Sea Research Part II: Topical Studies in Oceanography, 47(1), 119148.

Romankevich, E. A., Vetrov, A. A., \& Peresypkin, V. I. (2009). Organic matter of the World Ocean. Russian Geology and Geophysics, 50(4), 299-307.

Sainte-Marie, B. (1992). Foraging of scavenging deep-sea lysianassoid amphipods. In: Deepsea food chains and the global carbon cycle, 360, 105-124.

Seibel, B. A., \& Drazen, J. C. (2007). The rate of metabolism in marine animals: environmental constraints, ecological demands and energetic opportunities. 
Philosophical Transactions of the Royal Society B: Biological Sciences,362(1487), 20612078.

Shulenberger, E., \& Hessler, R. R. (1974). Scavenging abyssal benthic amphipods trapped under oligotrophic central North Pacific Gyre waters. Marine Biology, 28(3), 185-187.

Siedler, G., Holfort, J., Zenk, W., Müller, T. J., \& Csernok, T. (2004). Deep-Water Flow in the Mariana and Caroline Basins. Journal of Physical Oceanography, 34(3), 566-581.

Skadsheim, A. (1982). The ecology of intertidal amphipods in the Oslofjord. The life cycles of Chaetogammarus marinus and C. stoerensis. Marine Ecology, 3(3), 213-22

Sokolova, M. N. (1994). Euphausiid "dead body rain" as a source of food for abyssal benthos. Deep Sea Research Part I: Oceanographic Research Papers,41(4), 741-746.

Somero, G. N. (1992). Adaptations to high hydrostatic pressure. Annual Review of Physiology, 54(1), 557-577.

Stebbing, R., \& Thomas, R. R. (1919, December). Crustacea from the Falkland Islands collected by Mr. Rupert Vallentin, FLS-Part III. In Proceedings of the Zoological Society of London (Vol. 89, No. 3-4, pp. 327-340). Blackwell Publishing Ltd.

Stern, R. J. (2002). Subduction zones. Reviews of Geophysics, 40(4), 3-1.

Stockton, W. L., \& DeLaca, T. E. (1982). Food falls in the deep sea: occurrence, quality, and significance. Deep Sea Research Part A. Oceanographic Research Papers, 29(2), 157169.

Tamburri, M. N., \& Barry, J. P. (1999). Adaptations for scavenging by three diverse bathyal species, Eptatretus stouti, Neptunea amianta and Orchomene obtusus. Deep Sea Research Part I: Oceanographic Research Papers, 46(12), 2079-2093.

Thurber, A. R., Sweetman, A. K., Narayanaswamy, B. E., Jones, D. O. B., Ingels, J., \& Hansman, R. L. (2013). Ecosystem function and services provided by the deep sea. Biogeosciences. 10(14), 3941-3963. 
Thurston, M. H. (1979). Scavenging abyssal amphipods from the north-east Atlantic Ocean. Marine Biology, 51(1), 55-68.

Thurston, M.H., Petrillo, M., Della Croce, N., 2002. Population structure of the necrophagous amphipod Eurythenes gryllus (Amphipoda: Gammaridea) from the Atacama Trench (south-east Pacific Ocean). Journal of the Marine Biological Association of the United Kingdom. 82(2), 205-211.

Tyler, P. A. (1995). Conditions for the existence of life at the deep-sea floor: an update. Oceanography and Marine Biology: An Annual Review. Oceanography and Marine Biology. 33, 221-244

Tyler, P. A. (2003). Epilogue: exploration, observation and experimentation. Ecosystems of the World. 28, 473-476.

van der Maarel, E. (1990). Ecotones and ecoclines are different. Journal of Vegetation Science, 1(1), 135-138.

Vinogradova, N. G. (1959). The zoogeographical distribution of the deep-water bottom fauna in the abyssal zone of the ocean. Deep Sea Research. 5(2), 205-208.

Von Westernhagen, H. (1976). Some aspects of the biology of the hyperiid amphipod Hyperoche medusarum. Helgoländer wissenschaftliche Meeresuntersuchungen, 28(1), 43-50.

Warren, B. A., \& Owens, W. B. (1988). Deep currents in the central subarctic Pacific Ocean. Journal of Physical Oceanography, 18(4), 529-551.

Wolff, T. (1960). The hadal community, an introduction. Deep Sea Research (1953), 6, 95124.

Wright, D. J., Bloomer, S. H., MacLeod, C. J., Taylor, B., \& Goodlife, A. M. (2000). Bathymetry of the Tonga Trench and Forearc: a map series. Marine Geophysical Researches, 21(5), 489-512. 
Yayanos, A. A. (1981). Reversible inactivation of deep-sea amphipods (Paralicella capresca) by a decompression from 601 bars to atmospheric pressure. Comparative Biochemistry and Physiology Part A: Physiology, 69(3), 563-565. 